\title{
Pensamiento computacional, innovación y perspectivas interdisciplinarias en ámbitos educativos
}

Tesista: Gómez Noelia Soledad

Director: Lic. Javier Díaz

Co-director: Prof. Magali Catino

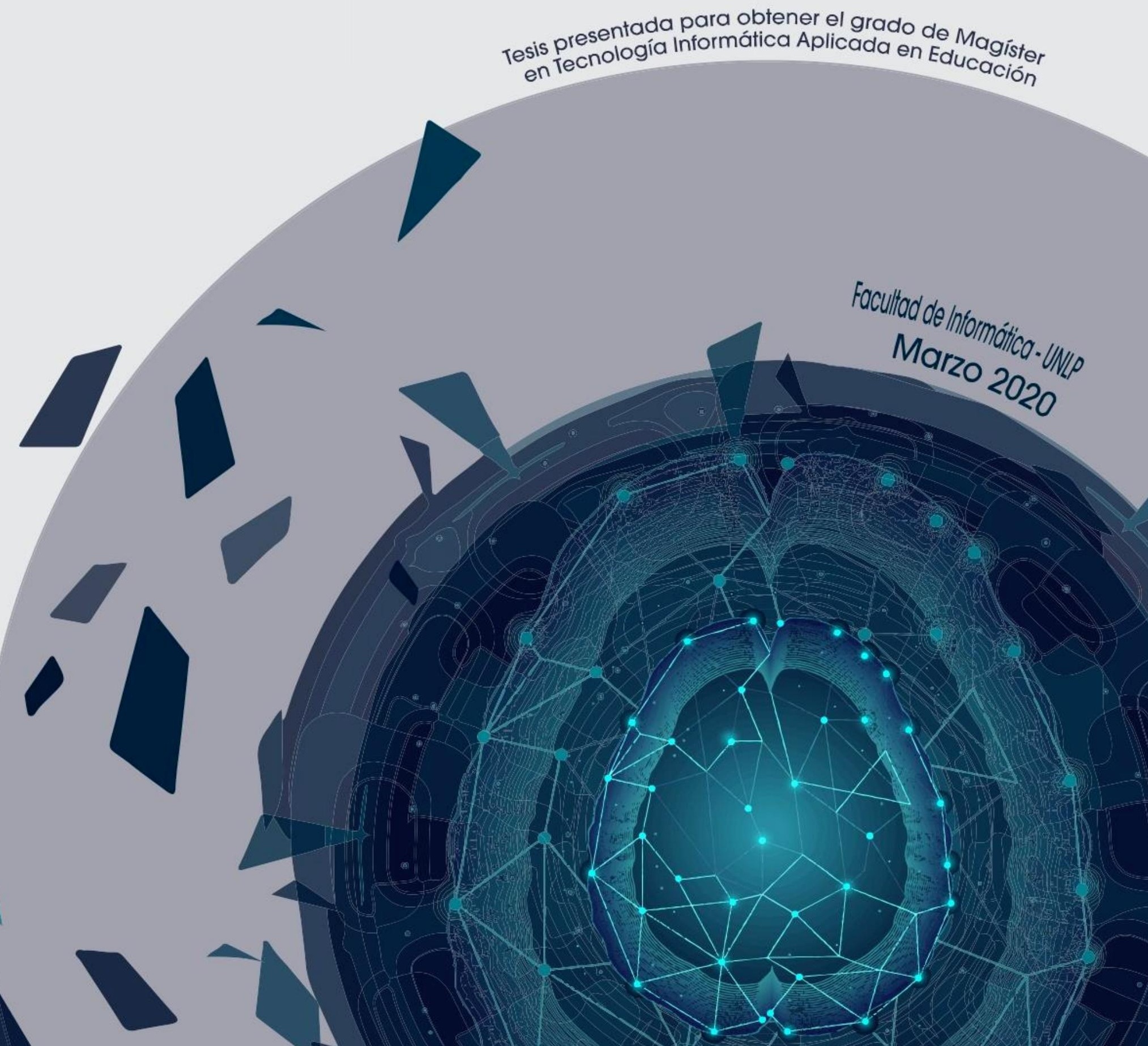




\section{Dedicatoria}

Para Amanda y Pedro, el amor y la fortaleza que necesité para escribir esta tesis. A Ezequiel, mi gran compañero de aventuras, por ser incondicional siempre. A mis viejos y mi hermano, pilares indestructibles de todo. 
Agradecimientos

A mis directores Javier y Magali por su confianza, cariño y paciencia. Por el aliento incansable y las palabras precisas para cada idea, capítulo y más.

A mis compañeras del Laboratorio de Investigación en Nuevas Tecnologías Informáticas (LINTI), por acogerme, guiarme y permitirme ser parte de hermosas experiencias de educación y tecnologías.

A mis amigos de la cátedra de Teoría de la Educación de la Facultad de Periodismo y Comunicación Social, por la amistad y el apoyo de siempre.

A mis amigas de la vida Olga, Ana, Marina, Susana y Paula que acompañaron en todo el proceso, que cuidaron de todo lo que podían mientras se escribía esta tesis.

A mis hijos, Amanda y Pedro, por su amor y fortaleza, porque su inocencia hace que cualquier sueño sea real y que todo esfuerzo valga la pena.

A Ezequiel, por su paz, por acompañarme y cuidarnos siempre.

A mis padres, que hicieron todo y más para que esto sea una realidad, para que pudiera escribir y decir, pero sobretodo soñar y disfrutar.

A mí querido hermano Daniel, por nunca dudar, por su determinación y su confianza. 
Índice

Capítulo 1: Marco Introductorio 14

1.1. Preliminares 14

1.2. Temas de esta investigación 14

1.2.1. Características del pensamiento computacional 15

1.2.2. Relación entre pensamiento computacional, competencias y nuevas 15

profesiones

1.2.3. Pensamiento computacional y la formación de sujetos dentro ám bitos 16 educativos.

1.2.4. Políticas educativas que adoptan el enfoque del pensamiento computacional. 16

$\begin{array}{ll}1.3 \text { Metodología } & 16\end{array}$

Capítulo 2:Pensamiento Computacional 19

2.1. Orígenes del término 19

2.2. Autores americanos, enfoques y perspectivas 27

2.3. Autores europeos, enfoques y perspectivas 40

$\begin{array}{ll}\text { 2.4. Conclusiones } & 45\end{array}$

Capítulo 3: Alfabetización digital $\quad 47$

$\begin{array}{ll}3.1 \text { Introducción } 39 & 47\end{array}$

3.1.2. Perspectivas pedagógicas. $\quad 52$

3.1.3. Aportes desde el campo de la comunicación, cultura y educación. 53

3.2. Los aportes desde el pensamiento pedagógico 56

3.2.1. Enfoques no críticos.

3.2.2. Pedagogías críticas para la era digital.

3.2.3. Enseñar a pensar computacionalmente. $\quad 61$

3.3. La enseñanza en el campo de las Ciencias de la Computación 64

3.3.1. Tensión entre la enseñanza de la programación y la alfabetización digital. $\quad 65$

$\begin{array}{ll}\text { 3.4. Conclusiones } & 67\end{array}$ 
Capítulo 4: Pensamiento Computacional, competencias y nuevas profesiones 69

$\begin{array}{ll}\text { 4.1. Competencias } & 69\end{array}$

4.2. Competencias en educación

4.3. Competencias digitales y nuevas profesiones 77

$\begin{array}{ll}\text { 4.4. Conclusiones } & 81\end{array}$

Capítulo 5: Políticas educativas europeas que recuperan el enfoque del

Pensamiento Computacional $\quad 82$

5.1 Introducción $\quad 82$

5.2. Análisis de documentos de la Unión Europea 83

5.2.1. Marco de referencia de competencias para el aprendizaje permanente. 86

5.2.2. Agenda de habilidades para Europa.

5.2.3. Europa 2020. 91

5.2.4. Agenda digital para Europa.

5.2.5. Plan de Acción de Educación Digital.

5.2.6. DigComp. 100

$\begin{array}{ll}\text { 5.2.7. CompuThin. } & 103\end{array}$

5.2.8. Marco europeo de competencias digitales para docentes. 104

5.2.9. Marco de cooperación para la educación y la formación. 106

$\begin{array}{ll}\text { 5.2.10. Erasmust. } & 108\end{array}$

$\begin{array}{ll}\text { 5.3. Estudio de casos } & 108\end{array}$

5.3.1. Reino Unido 108

5.3.1.1. Documentos Marco para el Currículum Nacional. 110

$\begin{array}{ll}\text { 5.3.2. España } & 118\end{array}$

5.3.2.1. Documentos de enseñanzas mínimas y currículo básico 123

5.3.2.2. Matemática orientada a las enseñanzas aplicadas y Matemática orientada a las enseñanzas académicas. 127

5.3.2.3. Primera Lengua Extranjera. 128

5.3.2.4. Tecnologías de la Información y la Comunicación. 128

5.3.2.5. Tecnología. $\quad 129$

$\begin{array}{ll}\text { 5.4. Conclusiones } & 130\end{array}$ 
Capítulo 6: Dimensiones transversales y problemáticas sobre el pensamiento computacional y la formación

6.1. Introducción: definición de las dimensiones de análisis

6.1.1. Curricularización de los contenidos

6.1.2. Enseñanza de las ciencias de la computación ¿Una didáctica específica?

6.1.3. Programación y robótica educativa como estrategia didáctica

\subsubsection{Transversalidad}

6.2. Conclusiones

Capítulo 7: Conclusiones

7.1. Líneas de trabajo o de investigación a futuro 


\section{Índice de cuadros}

Cuadro 1. Referencias centrales de Wing sobre el PC 24

Cuadro 2. Ordenamiento y sistematización de autores que recuperan el pensamiento computacional como una serie de conceptos, aplicaciones, herramientas y conjuntos de habilidades

Cuadro 3. Ordenamiento y sistematización de autores que recuperan el pensamiento computacional como lenguaje

Cuadro 4. Ordenamiento y sistematización de autores que recuperan el pensamiento computacional como proceso de abstracción

Cuadro 5. Ordenamiento y sistematización de autores que recuperan el pensamiento computacional como herramienta cognitiva

Cuadro 6. Ordenamiento y sistematización de autores que recuperan el pensamiento computacional desconectado

Cuadro 7. Primera prioridad del Plan de Acción de Educación Digital

Cuadro 8. Segunda prioridad del Plan de Acción de Educación Digital

Cuadro 9. Tercera prioridad del Plan de Acción de Educación Digital

Cuadro 10. Sistema educativo de UK

Cuadro 11. Estructura del Plan de estudios de UK

Cuadro 12. Asignatura obligatoria: Informática en Primaria

Cuadro 13. Asignatura obligatoria: Informática en Secundaria

Cuadro 15. Tramo de la ESO 


\section{Índice de Figuras}

Figura 1. Esquema de David Perkins (1990) sobre la resolución de problemas 37

Figura 2. Habilidades del PC 73

Figura 3. Áreas de desarrollo y competencias digitales 102

Figura 4. Visión general del Marco DigCompEdu 105

$\begin{array}{ll}\text { Figura 5. Visión conceptual } & 106\end{array}$ 


\section{Resumen}

El abordaje de la relación entre tecnologías, educación y comunicación, pretende generar un análisis interdisciplinario sobre pensamiento computacional en los sistemas educativos y su tratamiento en el desarrollo de políticas públicas. Se analizan los documentos marco de políticas educativas de la Unión Europea, entendidos como base de las políticas de sus países miembros. Se identifica su impacto en dos casos puntuales: Reino Unido y España. El criterio de selección de estos casos tiene que ver con su relevancia y temporalidad. En el primer caso, se reconoce al Reino Unido como país pionero en la implementación y curricularización de contenidos relacionados al pensamiento computacional en su sistema educativo. En el caso de España, además de ser uno de los países de habla hispana dentro de la Unión Europea, constituye un caso reciente de incorporación de contenidos de Ciencias de la Computación en escuelas públicas.

Esta investigación realiza una sistematización rigurosa sobre pensamiento computacional, así como el desarrollo de un trabajo interdisciplinario de articulación entre los campos disciplinares de comunicación, pedagogía e informática que contribuya al análisis del pensamiento computacional como competencia compleja ${ }^{1}$ para pensar, no solo las formas de su enseñanza, sino el impacto y su incidencia dentro de los procesos educativos.

\footnotetext{
${ }^{1}$ Pensada desde un enfoque holístico, reflexivo y contextualizado, según Pérez Gómez, 2007; Hipkins, 2006 y
} Marina, 2002. 


\section{Motivación}

Mi formación académica y profesional, me ubica en la pregunta sobre los sentidos que se construyen y se legitiman socialmente, en este caso, para acuñar al pensamiento computacional como objeto de estudio en el marco de las políticas educativas. Mi experiencia como parte de los proyectos de extensión de la Facultad de Informática sobre educación y programación promovieron mi interés por las problemáticas de enseñanza de un campo disciplinar que no es el propio. Las preguntas devenidas de acciones concretas como el diseño de plan de estudios de la Especialización en Didáctica de las Ciencias de la Computación², me permitieron desplegar nuevas zonas de interés respecto de la integración de tecnologías en ámbitos educativos, entre ellas ¿cómo enseñar a pensar computacionalmente?

El desafío de trabajar de manera interdisciplinaria promueve el desarrollo de aportes para dos campos disciplinares que abordan el tema de las tecnologías de la información y la comunicación (TIC) y su impacto en ámbito social, pero que no dialogan entre sí: las Ciencias de la Computación y las Ciencias de la Comunicación. Actualmente desde ambos campos se encuentran desarrollos e investigaciones sobre las TIC, pero la articulación entre estos dos mundos disciplinares no es frecuente. En este sentido el aporte que pueda resultar de este estudio, pretende contribuir a esta articulación, al uso de categorías de la comunicación para el análisis de procesos informáticos en ámbitos educativos. Como consecuencia de esta integración el campo de la comunicación/educación facilitará la integración de las categorías pedagógicas que en esta tesis fortalezcan el análisis sobre prácticas educativas y que sirva de antecedente para la identificación de problemáticas entre las Ciencias de la Computación y la Educación.

El auge de los contenidos en asignaturas propias de la Informática, el escenario de transformaciones culturales y el debate sobre una educación digital, hacen posible la

\footnotetext{
${ }^{2}$ Diseño e implementación de la Especialización docente en didáctica de las Ciencias de la Computación: El desarrollo del diseño curricular se realizó durante el año 2017 y la implementación comenzó en septiembre de 2018 y continúa. Tomado de: https://uanormall-bue.infd.edu.ar/sitio/especializacion-docente-de-nivel-superior-en-didactica-de-lasciencias-de-la-computacion/
} 
configuración de este tema y su abordaje desde la interdisciplinariedad. Este trabajo me permitirá, no sólo fortalecerme en la temática, sino que será insumo de los aportes que, como colaboradora, puedo realizar en mis espacios de trabajo. Mi participación como becaria de investigación en el Laboratorio de Investigación en Nuevas Tecnologías Informáticas (LINTI) y en el proyecto de investigación Internet del Futuro: Ciudades Digitales Inclusivas, Innovadoras y Sustentables, IoT, Ciberseguridad, Espacios de Aprendizaje del Futuro, así como las actividades de docencia en la materia Teoría de la Educación y mi participación en la Dirección de Tecnología Educativa de la Provincia de Buenos Aires, hacen que mi interés por el tema sea una realidad cotidiana. 


\section{Objetivos}

- General

○ Describir y sistematizar la configuración del pensamiento computacional, su incidencia y vigencia en el campo educativo a partir del análisis de políticas públicas, desde un enfoque interdisciplinario.

\section{- Específicos}

○ Investigar las implicancias y sentidos de uso del pensamiento computacional en los marcos normativos de la Unión Europea.

- Indagar en la relación que se establece entre pensamiento computacional, competencias y las denominadas "nuevas profesiones".

- Analizar los sentidos y usos del pensamiento computacional en el discurso de la Unión Europea a partir del abordaje de dos casos: Reino Unido y España.

- Identificar prácticas y experiencias educativas pensadas para el desarrollo del pensamiento computacional en ámbitos educativos. 


\section{Capítulo 1: Marco Introductorio}

\subsection{Preliminares}

El pensamiento computacional nace en el campo de las Ciencias de la Computación (CC) y se constituye como tema de interés, resultado del desarrollo de vastas experiencias y políticas públicas que intentan integrar contenidos de $\mathrm{CC}$ en procesos educativos formales. No obstante, a pesar de la cantidad de referentes y del auge de su uso, no se ha llegado a un acuerdo sobre una definición única, pues cada uno de estos aportes ha sido generado desde la perspectiva del área en la cual los expertos se desenvuelven. En este trabajo se analizarán las definiciones más relevantes sobre pensamiento computacional para su desarrollo, desde una perspectiva pedagógica y comunicacional que permita una reflexión desde los procesos educativos. La sistematización que aquí se realice permitirá un recorrido, no solo conceptual, sino de análisis con otras categorías propias del campo educativo, como la competencia, la criticidad y la formación.

Se busca estudiar el componente tecnológico en las propuestas educativas a través de una sistematización del concepto pensamiento computacional (PC) en los documentos oficiales de la Unión Europea (UE). Interesa revisar el tratamiento del PC entendido como competencia dentro de las políticas públicas en el área de educación, para lo cual se revisarán dos casos: Reino Unido y España. El interés por el abordaje del pensamiento computacional deviene de las actuales tendencias educativas que pasaron de pensar las incorporaciones de tecnologías y su impacto en los ámbitos educativos, a preguntarse por los procesos de pensamiento asociados. El desafío de enseñar a pensar computacionalmente es uno de los motivos centrales de este trabajo: ¿qué implica pensar computacionalmente? ¿Para qué es necesario pensar computacionalmente? Y ¿por qué es vital para algunos autores que los niños

y jóvenes lo hagan? Estas son las preguntas del campo pedagógico que posibilitan pensar en las diversas significaciones para revisión de los enfoques y sus características.

\subsection{Temas de esta investigación}


La presente investigación abordará las definiciones de pensamiento computacional, su incidencia y vigencia en el campo educativo a partir del análisis de políticas públicas en el marco de la Unión Europea. Para ello se seleccionan dos países miembros: Reino Unido y España. En su desarrollo se articulan los siguientes temas.

\subsubsection{Características del pensamiento computacional}

Se realizará una investigación exhaustiva sobre el estado de la cuestión en la actualidad con el fin de obtener diferentes estudios que investiguen el desarrollo del pensamiento computacional en ámbitos educativos $\mathrm{y}$, de esta manera, reconstruir el proceso de transformación del término desde el 2006, año de su aparición. En este sentido, se considera necesario para la realización de este trabajo, un estudio descriptivo sobre el término, focalizar la búsqueda bibliográfica en los trabajos que recuperen el enfoque humanístico y social que contribuya a la articulación con los temas que a continuación se desarrollan.

\subsubsection{Relación entre pensamiento computacional, competencias y nuevas profesiones}

Se analizarán documentos y trabajos que aporten insumos en la argumentación del pensamiento computacional en línea de considerarlo como competencia compleja, dado que abarca varias competencias que le permiten a cada ser humano tener la capacidad para resolver un problema desde el principio y hasta el final. Las competencias complejas conforman una sinergia de muchas competencias para que podamos tener el entendimiento y razón de comprobar los problemas y poder encontrar la mejor solución. Además, aglutinan competencias críticas, competencias creativas y competencias comprensivas. En este análisis se partirá de la relación entre competencias y PC que gira entorno a las denominadas “competencias digitales", un tema complejo y no exento de espacios de confrontación. Este

recorte está centrado en el marco de la competencia digital de los ciudadanos de la UE, DigComp 2.1 (Carretero, Vuorikari y Punie, 2017) y será trabajado en articulación con las propuestas pedagógicas que sostienen que:

El enfoque educativo por Competencias conlleva a una movilización de los conocimientos, a una integración de los mismos de manera holística y un ligamen con 
el contexto, asumiendo que la gente aprende mejor si tiene una visión global del problema que requiere enfrentar (Feito, 2008).

La articulación con las nuevas profesiones deviene de la demanda actual de profesionales cualificados en las industrias tecnológicas, pero también de la relación educación-trabajo. Esta problemática a nivel global, plantea la pregunta por la formación, que es la pregunta que acciona la potencialidad educativa y da sentido a la reflexión sobre el PC como competencia dentro de un nuevo sistema de alfabetización digital (Zapata Ros, 2015).

\subsubsection{Pensamiento computacional y la formación de sujetos dentro ámbitos educativos}

A partir de este eje se vincularán las categorías pedagógicas de formación e intervención para el análisis de las propuestas educativas de la UE y los casos seleccionados. Interesa revisar el enfoque de formación y la relación con el pensamiento computacional. La indagación estará centrada en la revisión de los interrogantes sobre para qué y por qué incorporar el pensamiento computacional en la educación.

\subsubsection{Políticas educativas que adoptan el enfoque del pensamiento computacional}

Identificar y analizar los sentidos con los cuales el pensamiento computacional es incorporado dentro de los documentos normativos de la UE posibilita pensar las bases de su presencia en los sistemas educativos europeos. Más allá de las formas y los formatos, interesa recuperar los lineamientos generales para luego estudiar dos casos puntuales: Reino Unido y España. El análisis de documentos, normativas y legislación disponible en cada uno de estos países permitirá el estudio del pensamiento computacional y las posibles estrategias de gestión institucional para la bajada al aula.

\subsection{Metodología}

Para el desarrollo de esta tesis se realizó una revisión bibliográfica del término pensamiento computacional con el objetivo de recuperar la mayor cantidad de aportes a su definición y el 
recorrido sobre las transformaciones que confluyeron desde su aparición en 2006. Para el desarrollo de la sistematización sobre los enfoques de PC, así como también la recuperación de artículos y tesis relacionadas con la temática, se priorizaron las perspectivas que recuperan la enseñanza del PC.

La búsqueda e indagación de tesis realizadas sobre esta temática y los antecedentes desarrollados en el marco de esta carrera, como las tesis de la Mg. Maira Sarmiento ${ }^{3}$ fueron consideradas para evaluar el desarrollo del tema en el campo y la producción académica actual. A su vez, el aporte del material bibliográfico especializado de las tres disciplinas trabajadas (Ciencias de la Computación, Comunicación y Educación) fue sistematizado en relación con los temas:

- Pensamiento Computacional en Educación

- CC en Educación para la formación

- Tecnologías y Educación

- Comunicación /Educación

La restricción de la búsqueda y selección fue acotada al campo educativo, lo que permitió revisar una cantidad de materiales que se fueron ajustando teniendo en cuenta las fuentes y las referencias, priorizando en todos los casos la producción científica académica.

Para el análisis de documentos se estableció una primera selección de materiales y sitios web de la UE. En lo concerniente al abordaje de políticas de la UE, se trabajó en todos los casos con sitios y publicaciones oficiales y se realizaron traducciones propias de los documentos en inglés.

Para la selección de los marcos normativos de los casos analizados se profundizó en aquellos con carácter regulatorio a nivel nacional o general y cuya regulación se encontraba en vigencia. Dicha selección permitió un ordenamiento cronológico a través del cual, por orden de aparición (publicación), se recorre un periodo que va desde el 2006 al 2020.

\footnotetext{
${ }^{3}$ Los trabajos de la Mg. Maira Sarmiento fueron clave en esta investigación, constituyen un antecedente de sistematización y revisión del término pensamiento computacional resultados del proceso de las carreras Magister y Especialización en Tecnología Informática Aplicada a Educación de la Facultad de Informática de la Universidad Nacional de La Plata.
} 
Es importante destacar que durante el proceso de realización de esta tesis se firmó el acuerdo que permite la salida de la UE al Reino Unido de Gran Bretaña e Irlanda del Norte (Brexit ${ }^{4}$ ). Las razones esgrimidas para mantener su análisis están estrechamente relacionadas con la importancia de esta unión de países como pionera en el desarrollo de propuestas curriculares sobre PC; por otro lado, su separación de la UE no modifica lo que establece su currículum nacional, documento central del análisis de caso y, por último, a la fecha de entrega de esta investigación, el Reino Unido (UK) se encuentra en la etapa de transición respecto de su salida de la UE, lo que prevé un lapso de al menos once meses para que ambas partes negocien su nuevo estatus como país no miembro.

${ }^{4}$ Brexit es una abreviatura de las palabras inglesas Britain (Gran Bretaña) y exit (salida), y es el término acuñado para referirse a la salida de Reino Unido de la Unión Europea (UE). 


\section{Capítulo 2: Pensamiento computacional}

\subsection{Orígenes del término}

La falta de consenso sobre una definición que describa y ayude a comprender a qué nos referimos cuando hablamos de pensamiento computacional ${ }^{5}$ da cuenta de uno de los problemas más álgidos que involucra la integración de este saber en los ámbitos educativos. La complejidad que implica la ausencia de una conceptualización impacta en la delimitación de un campo de referencia que contribuya al desarrollo de las propuestas curriculares y recursos en intervenciones educativas concretas en dicho ámbito. Sin embargo, estas prácticas existen y son cada vez más requeridas en el marco de las políticas públicas que promueven la integración de una alfabetización digital de la mano del pensamiento computacional.

Son varias las investigaciones que abordan el problema al que hacemos alusión, por ejemplo, en una publicación reciente (Adell et al., 2018), los investigadores sostienen que:

(...) la falta de acuerdo entre los expertos sobre la definición, estructura y componentes del PC hace muy complicados aspectos como su enseñanza y evaluación válida y fiable, la inclusión de su didáctica en la formación inicial y permanente del profesorado, el establecimiento de criterios para su integración en el currículo, bien como asignatura (optativa u obligatoria) en secundaria, bien integrado en los contenidos de las áreas STEM o STEAM en primaria o como actividad extracurricular. (p.2)

Ante esta situación, se vuelve necesario revisar las principales ideas y escritos que, sobre el PC, han dado origen a la discusión sobre su importancia, necesidad de integración y enseñanza en ámbitos educativos formales. La comunidad científica y académica ${ }^{6}$ sostiene $^{2}$ que Jeanette Wing fue quien introdujo por primera vez el término pensamiento computacional en una columna de opinión publicada en Comunicaciones, la publicación

\footnotetext{
${ }^{5}$ Abreviatura del término por sus iniciales: PC.

${ }^{6}$ Específicamente aquella referida al campo de las Ciencias de la Computación.
} 
mensual de la Associationfor Computing Machinery (ACM, por sus siglas en inglés) en marzo de 2006. En esta publicación, la informática de la Universidad de Columbia define:

El pensamiento computacional implica resolver problemas, diseñar sistemas y comprender el comportamiento humano, basándose en los conceptos fundamentales de la ciencia de la computación. El pensamiento computacional incluye una amplia variedad de herramientas mentales que reflejan la amplitud del campo de la Computación ${ }^{7}$. (p. 33)

Wing afirma, en el mismo documento, que el pensamiento computacional: " representa una actitud y unas habilidades universales que todos los individuos, no sólo los científicos computacionales, deberían aprender y usar." (p.33)

Este artículo ha despertado el interés de la comunidad científica, no solo del campo de la informática, sino que ha estimulado el debate a nivel internacional sobre la naturaleza del PC y su valor para la educación. La autora parte de la necesidad concreta de fomentar el interés por la disciplina informática como campo que va más allá del desarrollo del software y la programación. Para ello describe cómo el pensamiento computacional constituye una nueva forma de resolver problemas. A su vez advierte:

No es solo el software y artefactos de hardware que producimos los que estarán físicamente presentes en todas partes y tocar todas nuestras vidas a lo largo del tiempo; serán los conceptos computacionales que utilizamos para abordar y resolver problemas, gestionar nuestra vida cotidiana y comunicarnos e interactuar con otras personas; para todos, en todas partes. El pensamiento computacional será una realidad cuando sea tan integral para el ser humano que dejará de verse como una filosofía explícita. (p. 35)

Se destaca el trabajo Wing (2006) porque deja explícita una preocupación que aún preexiste dentro del campo de la informática y de su enseñanza. En varios momentos, la autora expone sobre la necesidad de dar a conocer el hacer informático más allá de la programación, siendo este uno de los puntos de debate en el marco de la curricularización de elementos que se

\footnotetext{
${ }^{7}$ Traducción nuestra. Todas las citas del presente documento son traducciones nuestras, a menos que se indique lo contrario.
} 
relacionan con el PC. También hace énfasis en la interdisciplinariedad que alienta al estudio de la informática sin que sea restrictivo para la articulación con otros campos. Así, afirma: "Uno puede especializarse en Informática y hacer cualquier cosa". (p.35). Así se hacen visibles en esta investigación categorías de gran resonancia dentro del campo de la pedagogía, como la creatividad y la curiosidad.

El Consejo Nacional de Investigación (NRC, por sus siglas en inglés) de los Estados Unidos, organizó dos talleres de trabajo sobre el tema, uno de ellos sobre el alcance y la naturaleza del pensamiento computacional en 2010 y un segundo, en 2011, sobre las dimensiones cognitivas y educativas del PC. En el informe publicado sobre el primero de estos talleres, Marcia Linn (2010) explica en el prólogo que existen tres enfoques de gran relevancia y vigencia que vinculan el desarrollo del PC con: 1) el uso de herramientas informáticas; 2) con la enseñanza de la programación; y 3) con juegos, robots y simulaciones. Sin embargo, también aclara que ninguno de ellos debería confundirse con aprender a pensar computacionalmente, en tanto afirma que el PC “es una habilidad analítica que todos pueden usar para la resolución de problemas, diseñar sistemas y entender el comportamiento humano" (p.7). A raíz de estos eventos, se abre una dimensión más interdisciplinaria sobre el término, gracias a la participación de los expertos del campo de las ciencias de la computación, educación y ciencias biológicas, entre otros. Todos acuerdan sobre la importancia de enseñar a los jóvenes a pensar computacionalmente, recuperando una dimensión más inclusiva. En este sentido, Allan Collins (2010) expresa:

A medida que entró el cálculo, comenzó a producirse todo tipo de nuevas formas de representación, tanto formas estructurales como formas de proceso, particularmente las formas de proceso dinámico... aspectos como reglas de producción y marcos, así como las redes semánticas y los sistemas de satisfacción de restricciones eran todas nuevas formas de pensar sobre la representación del conocimiento... Y entonces mi reclamo es que una de las cosas que debería preocuparnos es cómo conseguir este tipo de competencia representacional. Tenemos que empezar a pensar más en serio sobre cómo podemos transmitir algo de ese poder. (p. 25)

Cinco años después de la primera publicación sobre el término, Jeanette Wing (2011) rescata el concepto y asegura que, "el pensamiento computacional se refiere a los procesos de 
pensamiento implicados en la formulación de problemas y sus soluciones para que estas últimas estén representadas y puedan llevarse a cabo, de manera efectiva, por un procesador de información" (p. 1).

A raíz de esta nueva definición que ordena y caracteriza una idea más ajustada sobre el PC, se identifican dos aspectos significativos para la educación, según se expresó en el Informe CompuThink, realizado en 2016 por el Instituto Nacional de Tecnologías Educativas y de Formación del Profesorado (INTEF) de España, el cual se menciona a lo largo de esta investigación por explicar, claramente, su relación e incidencia en los procesos educativos.

La primera cuestión reconoce que asociar el PC a los artefactos tecnológicos implica un reduccionismo, en tanto afirma: "El Pensamiento Computacional es un proceso de pensamiento, por lo tanto, independiente de la tecnología" (p.6). En este sentido, resulta necesario abordar el problema de la enseñanza y el aprendizaje desde un enfoque que analice la producción de conocimiento y el desarrollo del pensamiento crítico y creativo, reconociendo la complejidad de la articulación entre los campos disciplinares de las ciencias de la computación y la educación.

El segundo rasgo característico que se desprende del informe citado se centra en la necesidad de entender la especificidad del término. Sin caer en el reduccionismo que mencionamos anteriormente, se expresa que "el Pensamiento Computacional es un tipo específico de resolución de problemas que implica capacidades distintas, por ejemplo, ser capaz de diseñar soluciones para ser ejecutadas por un ordenador, un humano, o una combinación de ambos" (p.6).

Lo que aquí se observa es la precisión respecto de los procesos implicados en el desarrollo del PC. La palabra capacidades y la sentencia que afirma que los sujetos con pensamiento computacional deben ser capaces de pensar soluciones a problemas del mundo real, da lugar a la pregunta por la formación de los sujetos y las implicancias de ello en los ámbitos formales de educación.

La distancia entre estas dos características, que hasta 2011 no aparecían con tanta claridad, es que en la primera se vislumbra un enfoque de posible intervención educativa, en tanto aparece la aseveración de procesos de pensamiento, desprendidos del componente 
instrumental tecnológico. En la segunda, lo que hay es una descripción de esos procesos que, sin la primera sentencia, no deja claridad sobre un enfoque de intervención posible.

Adicional a estos aportes conceptuales sobre el PC, hay una idea de Wing (2011) que deja entrever su complejidad al aclarar:

Mi interpretación de las palabras "problema" y "solución" es amplia. Me refiero, no solo a problemas matemáticamente bien definidos cuyas soluciones son completamente analizables, por ejemplo, una prueba, un algoritmo o un programa, sino también a problemas del mundo real cuyas soluciones pueden circunscribirse a sistemas de software grandes y complejos.

Estos problemas de la vida real son los que motivan la idea de Wing (2011) sobre la incorporación del PC en prácticas cotidianas, complejizando el problema de su enseñanza, tal como aparece en los talleres realizados por la NCR en 2010 y 2011, en los que se dieron a conocer trabajos sobre enfoques pedagógicos y experiencias de trabajo en las aulas. A partir de esta idea, la autora realizó una nueva clasificación a través de la cual distingue las posibilidades del PC para todos y para científicos y profesionales. Así, hay un primer reconocimiento de que el PC puede ser abordado desde todas las disciplinas y ámbitos de la vida cotidiana, pero con un distinto desarrollo de acciones, tal como puede apreciarse en el cuadro 1. 


\section{Cuadro 1 \\ Referencias centrales del aporte de JeannetteWing (2011) sobre el PC}

\author{
Aplicar el pensamiento computacional \\ para todos significa ser capaz de:
}

\section{El pensamiento computacional para científicos, ingenieros y otros profesionales significa además poder:}

- Comprender qué aspectos de un problema son susceptibles de cálculo

- Aplicar nuevos métodos computacionales a sus problemas

- Reformular problemas para que sean susceptibles a estrategias computacionales

- Descubrir una nueva ciencia a través del análisis de grandes datos.

- Hacer nuevas preguntas que no se pensaron o se atrevieron a hacer, debido a la escala, pero que se abordan fácilmente de manera computacional.

- Explicar problemas y soluciones en términos computacionales.

- Reconocer la oportunidad de usar la computación de una manera nueva, aplicando estrategias computacionales como dividir $\mathrm{y}$ calcular.

En el cuadro 1 pueden observarse las características distintivas del PC en relación a los perfiles de los sujetos de la educación. En este sentido, los científicos podrán desarrollar más acciones, en tanto puedan desarrollar el PC en términos de competencias; sin embargo, lo que es novedoso es la idea de recuperar un enfoque de PC para todos, más allá de las barreras disciplinares. Este componente inclusivo se observa en varios artículos (Resnick, 2012; Zapata Ros, 2014, 2015; CSTA, 2011, 2016) tanto, que en la actualidad los programas de educación digital han logrado imponer con fuerza esta característica, a pesar de no haber sucedido lo mismo con el eje de los contenidos.

En el segundo taller organizado por NCR sobre Aspectos Pedagógicos del Pensamiento Computacional durante 2011 y en su respectivo informe, se retoma y se hace mención al 
problema de la definición del término; en este sentido, Joyce Malyn-Smith del Education Development Center, Inc., declara:

Es necesario adoptar una definición coherente de pensamiento computacional porque las personas lo ven solo subjetivamente, desestimando los esfuerzos por concebir el $\mathrm{PC}$ en el plan de estudios que no será creíble en ausencia de un consenso sobre su estructura y contenido. (p. 3)

En esta afirmación, se observa la multiplicidad de enfoques y definiciones, además de la complejidad sobre su enseñanza. Al Aho, de la Universidad de Columbia, reconoció al respecto que "el verdadero desafío para toda la comunidad es definir el pensamiento computacional y también mantenerlo actualizado” (p.3). Así, emerge la necesidad de la comunidad científica de tener una definición común de PC, manifestándose en el informe lo siguiente: "Cualquier definición estática del pensamiento computacional probablemente sería obsoleta dentro de 10 o 20 años.” (p.3). Esto da cuenta de la rapidez con la que avanza y se transforma el mundo tecnológico en el cual el PC se aplica.

Como rasgo distintivo, este segundo evento estuvo atravesado por la problemática sobre la enseñanza, las limitaciones y el estudio respecto del aprendizaje del PC. En su presentación, Wing (2011) menciona la falta de investigaciones que aporten mayor claridad sobre los procesos de aprendizaje implicados y que contribuyan a la elaboración de propuestas de enseñanzas medibles y confiables.

De igual manera, Mitchel Resnick (2011) aseguró en este evento que la capacidad de usar medios computacionales para crear, construir e inventar soluciones a los problemas es fundamental para el pensamiento computacional. Los pensadores computacionales pueden expresarse a sí mismos y a sus ideas en términos computacionales.

A su vez, explicó que para que esto suceda, los estudiantes deben ser capaces de desarrollar conceptos y habilidades, por ejemplo, optimizar las capacidades de diseño y cooperación social, las cuales rara vez se enseñan en la escuela y que el PC considera esencial.

La cooperación social y el carácter colaborativo emergen en las definiciones de algunos de los expertos presentes, destacando habilidades que hasta el momento no eran nombradas con 
énfasis dentro de los elementos del PC. En el informe del segundo taller, aparece la cuestión de la transversalidad que el término ofrece para el desarrollo de habilidades y posibilidades. A partir de la potencialidad que presentaría el PC, se afirma que el poder del pensamiento computacional se observa mejor en algún contenido específico de dominio; por ejemplo, para comprender de forma más integral el genoma humano, los individuos necesitan combinar elementos del pensamiento computacional en cuanto a la descomposición de partes de un problema, con conceptos de la genética. De algún modo, bajo esta premisa, se tomaba en cuenta la magnitud de lo que luego serían las experiencias educativas y la diversidad de contextos posibles en los que el PC puede ser aplicado.

Sin duda que la aparición del término, aunque sin definir con precisión, permitió que asociaciones de renombre científico como la Computer Science Teachers Association (CSTA, por sus siglas en inglés) y la International Society for Technology in Education (ISTE, por sus siglas en inglés) contribuyeron en el desarrollo de una definición operativa. En esta definición del PC se listan y se resumen las operaciones y procesos que constituyen al PC, pero que no lo limitan, tales como:

- Formular problemas de una manera que nos permita usar un ordenador y otras herramientas para ayudar a resolverlos

- Organizar y analizar datos de una manera lógica

- Representar datos a través de abstracciones, tales como modelos y simulaciones

- Automatizar soluciones mediante el pensamiento algorítmico (una serie de pasos ordenados)

- Identificar, analizar e implementar posibles soluciones con el objetivo de conseguir la combinación más eficaz de pasos y recursos

- Generalizar y transferir este proceso de resolución de problemas a una amplia variedad de problemas (p.13)

En Europa, organizaciones científicas como Royal Society (2012) también comenzaron a trabajar en una definición sobre el PC, manifestando "la importancia de reconocer aspectos de la computación en el mundo que nos rodea, y de aplicar las herramientas y las técnicas de esta para entender y razonar los sistemas naturales y artificiales, así como sus procesos." (p.29) 
Años más tarde, en 2016, la Asociación de Profesores de Informática (CSTA) publicó los Estándares de Ciencias de la Computaciónen educación primaria y secundaria, como una actualización de los ya existentes que hacían referencia a las definiciones de pensamiento computacional de Wing (2011), y en los que se enfatizaban los aspectos relativos a la resolución de problemas, así como a la abstracción, automatización y análisis como elementos distintivos del PC. Se destaca de ese documento, lo siguiente:

Creemos que el pensamiento computacional es una metodología de resolución de problemas que amplía el campo de la computación a todas las disciplinas, proporcionando un medio distinto de analizar y desarrollar soluciones a problemas que pueden ser resueltos computacionalmente. Centrado en la abstracción, la automatización y el análisis, el pensamiento computacional es un elemento esencial de la disciplina de la computación (CSTA, 2016, p. 6).

\subsection{Autores americanos, enfoques y perspectivas}

Múltiples fueron los debates y nuevos intentos de definir el PC que afloraron en la comunidad científica, luego de que Wing (2006) diera a conocer el término. En este apartado se analizarán algunos de los enfoques más relevantes que surgieron en el mismo proceso de definición. Cabe destacar que sobre los mismos se fundamentan los diversos programas de intervención en ámbitos educativos.

Se establecerá una única clasificación y orden, que luego devendrá en el análisis de las aproximaciones conceptuales y que tiene que ver con el lugar de procedencia de los autores e instituciones que legitiman dichas aproximaciones. Se intenta diferenciar, desde este primer momento, una perspectiva americana de una perspectiva europea, no porque no existan puntos en común entre las mismas, sino porque se reconoce la configuración de escenarios y contextos distintos que, en los ámbitos educativos, condicionarán las intervenciones que se recuperan de la totalidad de los documentos que se citan y desglosan.

Para el análisis de los enfoques americanos, se parte del documento Report of a Workshop on the Scope and Nature of Computational Thinking (2010), pues se reconoce que recoge las 
discusiones nodales del evento realizado durante ese año, siendo pionero en la temática. De este informe se desprenden las principales citas y reseñas que aparecen en los documentos académicos sobre PC como definiciones fundacionales y primera aparición de clasificación de diversos enfoques sobre un mismo término. El evento que da origen al informe contó con un comité de expertos, compuesto por Jannete Wing, Mitchel Resnick, Alfred Aho, Uri Wilensky, Yasmin Kafai, Marcia Linn, Larry Snyder, Janet Kolodner y Brian Blake. Para este trabajo se citarán estos y otros autores por sus aportes al desarrollo y análisis de las perspectivas americanas sobre el PC.

La siguiente clasificación, tomada del documento Report of a Workshop on the Scope and Nature of Computational Thinking (2010) es recuperado en tanto contribuye a la identificación de una multiplicidad de posiciones sobre el término. A partir de los enfoques que se proponen, se ordenan las principales definiciones e ideas de los autores participantes, dando cuenta de los puntos en común y la complejidad de procesos socioeducativos implicados. Se reconocen 5 enfoques para definir al pensamiento computacional, tales como:

a. Una serie de conceptos, aplicaciones, herramientas y conjuntos de habilidades

b. Un lenguaje

c. Un proceso de abstracción

d. Una herramienta cognitiva

e. Posible de abordarse con o sin computadoras, "en modo desconectado"

Es necesario destacar que esta clasificación no es determinante para los expertos que participaron del evento, ya que varios de ellos comparten más de una de estas posiciones. La recuperación de esta clasificación, radica en que los enfoques propuestos nuclean y articulan las definiciones y las principales discusiones sobre el término.

Para un mejor ordenamiento e identificación de estas ideas, se diseñaron y confeccionaron cuadros de sistematización. Cada cuadro que se expone representa un enfoque desde el cual es comprendido y definido el PC, según se explicita en el Report of a Workshop on the Scope and Nature of Computational Thinking (2010). La presencia de cuadros de síntesis, hallados 
en trabajos de relevancia académica (Sarmiento, 2016; Adell, Llopis, Esteve y Valdeolivas, 2019) resultaron de gran utilidad en la realización de esta tesis, dado que han facilitado la manera en que se abordan los enfoques que se trabajan. Los cuadros presentados en este capítulo fueron armados para destacar las ideas y autores en relación a los diversos enfoques sobre el término. Lo que se pretende es lograr un ordenamiento conceptual, que lejos de determinar el aporte de los autores, contribuya a una identificación y comprensión de las ideas. Como información complementaria y, a manera de síntesis, se comparten cuadros y figuras que permiten visualizar gráficamente el abordaje del PC en EE.UU., según sus autores y evolución del término (Anexo 1).

La primera propuesta considera al pensamiento computacional como una serie de conceptos, herramientas y conjuntos de habilidades. La mayoría de los expertos adhieren a esta posición de carácter más general, reconociendo la potencialidad del término y los procesos implicados. Este enfoque es muy cercano a la definición elaborada por Cuny, Snyder y Wing (2010) donde se considera al PC "un proceso mental utilizado para formular problemas y sus soluciones de forma que estas puedan ser llevadas a cabo por un agente de proceso de información. "En este sentido, el PC se constituye sobre las siguientes premisas, que reconocen procesos y habilidades como:

1. Un elemento central a partir del cual se especifica su importancia y preponderancia en la necesidad de comprender las nuevas formas de representación y percepción en un mundo digital.

2. El ejercicio de pensar computacionalmente se reconoce desde el desarrollo de procesos complejos, ligados al campo de las ciencias de la computación para su aplicación en múltiples áreas.

3. Se reconocen los procesos de abstracción, representación, depuración, prueba y manipulación de datos como constitutivos del PC.

4. La incidencia de un pensamiento lógico matemático es relevante en este enfoque de carácter más general. Todos los aportes que aquí se realizan, se apoyan en el proceso de resolución de problemas. 
En el Cuadro 2 se ordenan los principales autores que aportaron ideas en relación a esta perspectiva generalista sobre el PC. Se observa que los autores citados parten de una noción procesual para intentar ordenar una definición más clara sobre el término. Sin embargo, se abre la discusión hacia conceptos muy amplios que hacen que este enfoque funcione como articulador de las demás propuestas.

\section{Cuadro 2}

a. Ordenamiento y sistematización de autores que recuperan el pensamiento computacional como "una serie de conceptos, aplicaciones, herramientas y conjuntos de habilidades"

Autores

Ideas preliminares

David Moursund (2007, 2010)

Recupera la noción de pensamiento procesal para explicar el PC, destacando el rol de los procesos:

-procedimientos de representación, prueba y depuración;

- conjunto de instrucciones.

Peter Lee (2011) / Andrew Mc Getrick 2010)

Bill Wulf (2010) / Peter Denning (2009)

Dar Abrahamson (2010)
Ambos autores reconocen la potencialidad del PC, en tanto aseguran que permite ampliar las capacidades mentales a través de herramientas abstractas que ayudan a administrar la complejidad y permitir la automatización de tareas.

Ambos autores acuerdan que el PC se centra en los procesos de abstracción para la resolución de problemas. Recuperan, además, la importancia sobre el desarrollo del pensamiento lógico matemático.

Establece una relación directa e indisociable del pensamiento computacional como el uso de la computación. 
Gerald Sussman (2011) / JanneteWing (2006, 2010, 2011)

Edward Fox (2010)

Brian Blace (2010)

Uri Wilensky (2013)

Janet Koladner (2010)

Robert Constable (2010)
Coinciden en entender al pensamiento computacional como una forma de formular métodos precisos para hacer las cosas. Por tanto, sugieren que el pensamiento computacional podría ser visto como un puente entre la ciencia y la ingeniería, una metaciencia sobre estudiar formas o métodos de pensamiento que sean aplicables enlas diferentes disciplinas.

Se apoya en la base del modelo de resolución de problemas poniendo el énfasis en dominio y uso de abstracciones.

Recupera los procesos de representaciones, visualizaciones, modelado o metamodelo, como constitutivos del PC.

A partir de un enfoque que recupera la importancia del PC y el poder histórico de los cambios representacionales, establece $\mathrm{y}$ asegura que las representaciones computacionales permitirían un mayor modelado y mayor acceso a modelos científicos.

Apoya esta perspectiva en tanto considera que el pensamiento computacional juega un papel en la manipulación del en apoyo de la resolución de problemas.

Explica el pensamiento computacional como una lista abierta y creciente de conceptos que refleja la dinámica de la tecnología y el aprendizaje humano.

El segundo enfoque es aquel que entiende al PC como lenguaje, se reconoce por su relación intrínseca con la programación. Sobre esta línea, los expertos en la enseñanza de la programación Karen Brennan y Mirtchel Resnick (2012) explican: 
Estamos interesados en la forma en que las actividades de aprendizaje basadas en diseño, particularmente, la programación de medios interactivos, apoya el desarrollo del pensamiento computacional en los jóvenes. Ese interés lo estimula, en parte, la creciente disponibilidad de herramientas que permiten a los jóvenes diseñar sus propios medios interactivos. (p.3)

Este enfoque de desarrollo del PC a partir de la programación es uno de los más relevantes a nivel internacional. Más adelante se analizará en profundidad las particularidades de este enfoque y su implicancia en el marco de las políticas educativas. Algunas de sus características establecen una relación directa entre el PC como lenguaje, lo que implica un proceso de alfabetización, estableciendo una comparación con las habilidades de lectoescritura. En esta perspectiva, se compara al PC con otras habilidades cognitivas, principalmente se lo entiende como lenguaje, en tanto:

1. Se lo considera, como capacidad o como sistemas de signos, entender así al PC, implica una forma de expresión y descubrimiento.

2. La programación, constituye una acción clave en este enfoque, ya que entiende y analiza en relación a los lenguajes de programación y abonando una idea inicial sobre los procesos de alfabetización en relación al PC.

3. Aparece la problemática de los nuevos empleos y las habilidades digitales que son necesarias como la programación, y se sostiene la preocupación sobre la enseñanza de los lenguajes necesarios para poder programar.

4. Se recupera el enfoque de programar para aprender, pregonado por el equipo de expertos del Massachusetts Institute of Technology (MIT) en relación a los procesos de enseñanza realizados con Scratch. $^{8}$

Desde esta perspectiva, hay un planteo clave que realza el rol de la programación como promotora del PC, en tanto se asuma su enseñanza vinculada a los procesos creativos y de

\footnotetext{
${ }^{8}$ Scratch es una herramienta de programación basada en un lenguaje visual, creado por el Massachusetts Institute of Technology (MIT, por sus siglas en inglés), que utiliza bloques. Esta herramienta ha sido ampliamente difundida para el desarrollo de actividades de programación en el aula en los niveles iniciales.
} 
colaboración, lo que define también un enfoque sobre una idea de programación: ¿para qué programar? ¿Por qué hacerlo?

En el Cuadro 3 se ordenan las ideas de los autores que sostienen que el PC como lenguaje es establece una necesidad directa con procesos de alfabetización digital que lo promueva y contribuya a su óptimo desarrollo.

\section{Cuadro 3}

b. Ordenamiento y sistematización de autores que recuperan el pensamiento computacional como lenguaje

Autores Ideas preliminares

Roy Pea (2013)

Ursula Wolz / Mitchel Resnick (2009)

Eric Roberts (2005)

Explica que la programación ha estado presente de manera implícita en el origen de una definición sobre PC, pues reconoce que los procesos implícitos en la programación son constitutivos del pensamiento computacional.

Destacan el concepto de habilidad y coinciden en comprender al PC, como una habilidad esencial como leer y escribir. Estos autores establecen una relación entre la adquisición de los contenidos necesarios para el proceso de lectoescritura y lo equiparan con el desarrollo del PC. Sostienen que el pensamiento computacional es más que la programación, pero solo de la misma manera que la alfabetización lingüística es más que escribir. En esta declaración se establece un enfoque respecto de la programación que supera el reduccionismo tecnológico.

Advierte sobre la necesidad de reflexionar en torno a la enseñanza de la programación; propone despertar su interés y sostiene la idea de Linn y Resniick acerca de la enseñanza de la 
programación como proceso de expresión y creación.

Andrea DiSessa (2010) / Owen Astrachan (2010)

Gerald Sussman (2010)

Alan Kay (2010)

Edward Fox (2010)
Incorporan el concepto de alfabetización como una construcción social; en ese marco plantea el problema de enseñar a todos a pensar computacionalmente. Entienden que el proceso de alfabetización digital permitirá a la civilización pensar y hacer cosas nuevas.

A partir del ejemplo de la poesía como algoritmo, el autor comprende al pensamiento computacional como lenguaje básico.

Basado en la idea de que los humanos poseen una capacidad innata para el lenguaje verbal, sugiere que el pensamiento computacional como cualquier lenguaje, es condicionado por las formas de su enseñanza en las distintas sociedades.

Pone en valor el desarrollo del PC, estableciendo una relación histórica. Explica que el pensamiento computacional es innato en la especie humana, ya que nuestros antepasados modelaron $y$ representaron la realidad y se lo transmitieron a otras personas, enriqueciendo esos modelos para llevar a cabo la exploración, el descubrimiento y el mantenimiento de la vida.

El tercer enfoque que se aborda entiende al PC como un proceso de abstracción para lo cual son necesarios el análisis y la síntesis. El pensamiento abstracto es reconocido como constitutivo del pensamiento computacional y también como punto de partida en los procesos de programación, y en general, para todas las operaciones ligadas al campo de las ciencias de la computación. Desnaturalizar el proceso de abstracción a partir de propuestas pedagógicas que ayuden a potenciarlo es uno de los desafíos que asume el PC. 
En este sentido, Kosík en Ruiz Limón (2006) afirma que:

Para llevar a cabo este proceso de abstracción es necesario pensar en forma dialéctica, ya que el pensamiento debe aprehender un mundo en continuo movimiento en el que la contradicción es el motor que impulsa el desarrollo de los procesos y objetos de la naturaleza y la sociedad. La esencia, la estructura de las cosas no se revela en forma directa e inmediata; la cosa misma no se manifiesta directamente al hombre. Para captarla se requiere no sólo hacer un esfuerzo, sino también dar un rodeo. (p.108)

Las características principales reconocidas en esta perspectiva son:

1. Se centra en la relevancia del pensamiento abstracto como acción principal para la realización de procesos de automatización

2. Aparece fuertemente mencionado en varios aportes, la gestión de la complejidad como fundamento de la abstracción.

3. Se recuperan los videojuegos como ejemplos de escenarios virtuales que recuperan situaciones reales de forma concreta. Porque se los comprende como prácticas educativas, en tanto los jóvenes interactúan y resuelven situaciones dentro de entornos y simulaciones.

En el Cuadro 4 se ordenan las ideas de los autores que sostienen que el PC como proceso de abstracción, donde se destacan ideas como la de automatización y resolución de problemas vinculadas al desarrollo del PC.

\section{Cuadro 4}

c. Ordenamiento y sistematización de autores que recuperan el pensamiento computacional como proceso de abstracción

\begin{tabular}{cl}
\hline \multicolumn{1}{c}{ Autores } & \multicolumn{1}{c}{ Ideas preliminares } \\
\hline Robert Constable (2010) & $\begin{array}{l}\text { Destaca que desde este enfoque, el } \\
\text { pensamiento computacional es una } \\
\text { herramienta para explicar y representar } \\
\text { complejidad a través de la automatización. }\end{array}$
\end{tabular}


Peter Lee (2011)

Andrea DiSessa / Owen Astrachan (2010)

Ken Kahn / Uri Wilensky (2013)
Atribuye al proceso de pensar computacionalmente la virtual de magnificar la inteligencia de las personas a través de automatización y resolución de problemas, así como la gestión de la complejidad.

Coinciden en la recuperación del componente social, pensando en la resolución de problemas del mundo real. Aseguran que la abstracción tiene que conectarse con las preocupaciones de los sujetos.

Recuperan los procesos de abstracción como punto de partida para que, a través del PC, se dé visibilidad a las problemáticas y sus soluciones. Entienden que el pensamiento computacional proporciona la creación de algo concreto y tangible de temas que generalmente están dominados por conceptos abstractos.

El cuarto enfoque propone abordar el pensamiento computacional como como herramienta cognitiva. Aquí se fortalece el rol de las herramientas computacionales y de la tecnología en general como potenciadores de los procesos de pensamiento. Al respecto, Moursund (2010) expone:

Si les das a todos, una calculadora, las matemáticas no desaparecen. Pensar y hacer son necesarios para representar y ayudar a resolver problemas. Si tienes mejores herramientas, puedes hacerlo mejor. Lo que la computadora está haciendo es darte mejores herramientas, lidiando con problemas más difíciles. (p.19)

El siguiente enfoque está basado fundamentalmente en el concepto de David Perkins (1988) sobre "Persona Plus" en el que se desarrollan tres dimensiones (herramientas para extender capacidades mentales, herramientas para extender capacidades físicas y capacidades físicas para usar de manera eficaz [mental y físicamente] las herramientas) que contribuyen a aumentar la resolución de problemas en equipo (Ver figura 1). 


\section{Figura 1}

Esquema de David Perkins (1990) sobre la resolución de problemas

Tools to extend mental capabilities

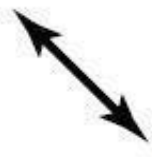

\section{Tools to extend} physical capabilities

ProblemSolving Team

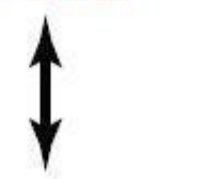

Education, training, and experience to build one's mental and physical capabilities to effectively use mental and physical tools individually and as a team member

Nota. Adaptado de David Moursund para National Research Council, 2010, Report of a Workshop on the Scope and Nature of Computational Thinking. Washington, DC: The National Academies Press.

Los autores parten del análisis de las herramientas para visualizar los procesos cognoscitivos que estas posibilitan. Dentro de este enfoque se analizan los avances tecnológicos en el campo de la comunicación como ejemplo de las transformaciones en las formas de circulación del conocimiento, tomando como caso de base la invención de la imprenta.

En el Cuadro 5 se reconoce que las herramientas computacionales posibilitan el desarrollo del pensamiento computacional, a partir de sus usos, complejizando este proceso con los múltiples usos que las personas hacen de cada uno de esos recursos. 


\section{Cuadro 5}

d. Ordenamiento y sistematización de autores que recuperan el pensamiento computacional como herramienta cognitiva

\begin{tabular}{|c|c|}
\hline Autores & Ideas preliminares \\
\hline David Moursund (2007) & $\begin{array}{l}\text { Desarrolla una teoría para pensar el PC, } \\
\text { inspirada en los aportes de Donald } \\
\text { Norman y David Perkins. } \\
\text { Retoma el concepto de herramientas para } \\
\text { la resolución de problemas, ampliando la } \\
\text { mirada y conceptualizando las } \\
\text { herramientas físicas y las herramientas } \\
\text { mentales. } \\
\text { Para este autor, el pensamiento } \\
\text { computacional y las computadoras } \\
\text { encajan en ambas categorías [de } \\
\text { herramientas físicas y mentales]. }\end{array}$ \\
\hline Roy Pea (2013) & $\begin{array}{l}\text { En parte su argumento se sostiene en el } \\
\text { desarrollo de habilidades que permiten a } \\
\text { las personas, aprender del uso de las } \\
\text { herramientas de manera autodidacta. } \\
\text { Sostiene que si se observa lo que la gente } \\
\text { hace cuando están haciendo pensamiento } \\
\text { computacional, éstas están inmersas con } \\
\text { un conjunto completo de herramientas, } \\
\text { pensando en que todo tiene propiedades } \\
\text { particulares, susceptibles de ser } \\
\text { organizadas a partir de ciertas } \\
\text { herramientas. }\end{array}$ \\
\hline
\end{tabular}

El último de los enfoques propuestos por los autores americanos reconoce al pensamiento computacional "desconectado", es decir, sin necesidad de utilizar computadoras en fomento de su desarrollo. A partir de la exposición y análisis de experiencias de trabajo áulico en las que emergen los procesos de diversas áreas sin necesidad del uso de tecnologías, se establecen ideas que contribuyen a la recuperación, descomposición, clasificación, ordenamiento, abstracción, secuencias y otros procesos asociados al PC. Las características centrales que definen este enfoque están asociadas con: 
1. La necesidad de trabajar el PC más allá de las herramientas, poniendo el énfasis en los procesos involucrados.

2. Reconocerse como una didáctica posible y efectiva para la enseñanza de estos contenidos, sin necesidad de equipamiento o conectividad.

3. A nivel mundial, son reconocidas las experiencias como el cuadernillo de actividades gratuito Computer Science Unplugged. Este enfoque sostiene la importancia de promover las actividades mentales necesarias para el desarrollo del PC, debido a la ubicuidad y al aumento de la omnipresencia de herramientas computacionales a lo largo de la vida moderna.

En el Cuadro 6 se destacan las ideas de los autores que consideran esta forma de pensar, a partir de las implicancias del uso de métodos de la informática, tales como la depuración, algoritmos de búsqueda y casos de prueba para abordar problemas cotidianos, involucrando recursos tecnológicos.

\section{Cuadro 6}

e. Ordenamiento y sistematización de autores que recuperan el pensamiento computacional desconectado

Autores

Marcia Linn (2010)

\section{Ideas preliminares}

A partir del desarrollo de ejemplos de la vida cotidiana, la autora propone el reconocimiento de las posibilidades que ofrece la tecnología de la información moderna, en tanto que requiere habilidades de razonamiento específicas (depuración, casos de prueba y habilidades lógicas para resolver problemas cotidianos).

Estos autores presentan experiencias de estudiantes que participan en la construcción del concepto de pensamiento computacional sin usar computadoras. Sostienen y apoyan la 
UrsulaWolz (2010)

Tim Bell (2010)

Allan Calling (2010) necesidad de difundir y trabajar sobre este método.

En su aporte, recupera la transversalidad en la enseñanza del PC como una posibilidad. A partir de la descripción de un proyecto de articulación con el periodismo, enuncia procesos involucrados en el trabajo con computadoras, especialmente programación (investigar, recolectar y seleccionar datos, ordenar, diseñar, colaborar, etc).

A partir de la descripción del proyecto Computer Science Unplugged realiza una caracterización de las didácticas desconectadas que se utilizan para promover el pensamiento computacional.

Reconoce que una característica clave del pensamiento computacional es la competencia representacional, la cual describe como la aplicación efectiva de medios computacionales de representación del conocimiento.

\subsection{Autores europeos, enfoques y perspectivas}

Los autores europeos no desarrollan definiciones sobre PC diferentes de las realizadas por los autores norteamericanos. Retoman la bibliografía americana para explicar el proceso de aparición del término y las definiciones sobre PC de Wing, ISTE, CTSA y NRC, entre los más citados. A partir de ellas, se realizan aportes de tipo analítico sobre intervenciones concretas en ámbitos educativos y se rescatan las políticas educativas para la enseñanza del PC en la región.

Asimismo, hay dos contribuciones que se sistematizan a modo de conceptualización y que son nodales para el desarrollo de esta tesis: 
a. Pensamiento computacional como alfabetización digital.

b. Pensamiento computacional como competencia.

Para el desarrollo del primer enfoque, se consideran los procesos y contenidos del PC para el desarrollo de su enseñanza. En este sentido, uno de los primeros artículos en los que se plantea esto es en Pensamiento computacional y precoding, escrito por Miguel Zapata-Ros (2014). Este autor desarrolla toda una línea de trabajos (Zapata Ros, 2009a, 2010b, 2014c, 2015d, 2018e, 2019f, 2020f) que valora ese enfoque, considerando los procesos de pensamiento involucrados en el desarrollo del PC, la necesidad de curricularizar su enseñanza y comprenderlo más allá de la programación. En este sentido el autor sostiene que:

La idea que algunos tenemos es la de que no hay que esperar a la universidad ni tan siquiera a la educación secundaria para iniciar el aprendizaje de habilidades de programación, y que al igual a como sucede en otras habilidades instrumentales (cálculo o lectura) y claves o con competencias que empiezan a desarrollarse en las primeras etapas de la vida (música, danza), las habilidades necesarias para la codificación han de ser detectadas y desarrolladas desde las primeras etapas. Es la precodificación (precoding) o el desarrollo del pensamiento computacional. (Zapata Ros, 2014).

El autor se pregunta por las implicancias que tiene la enseñanza de la programación como acción clave para el desarrollo del PC. Se preocupa por lo que, asociado a ello, ocurre en los ámbitos educativos y que tiene que ver con la enseñanza del código por el código mismo, dejando de lado elementos constitutivos del PC que resultan fundamentales. Bajo la premisa del PC como la nueva alfabetización digital, el autor esboza:

Sin embargo, tenemos referencias (Raja, 2014) de investigaciones que ponen de manifiesto que, si se empieza por el pensamiento computacional en vez de por la elaboración de códigos, desvinculando la iniciación a ser diestros con el ordenador, tal como se entiende habitualmente, se evita el principio de discriminación que hace que algún tipo de niños y de niñas se inhiban. Supone pues, un principio de democratización del aprendizaje. Esto supone además que los que en un futuro 
pueden ser bibliotecarios, médicos o artistas pueden ser también buenos programadores. Y por ende podría ampliar la base de conocimiento que se vuelca al mundo de la computación, lo que constituye el motor y el combustible de la Sociedad del Conocimiento. (Zapata Ros, 2015, p 7)

Otros autores comparten esta idea de alfabetización digital complementaria a la enseñanza de la programación, no solo como referente del campo de las ciencias de la computación, sino como formación de sujetos en el campo. Al respecto, Gros y Contreras (2006) señalan:

La sociedad digital ha creado nuevas formas de alfabetización que no podemos dejar de lado si pensamos que la formación ciudadana también implica ser competente en el mundo digital. El acceso a la información globalizada, los sistemas de participación en la red, la comunicación a través de los medios electrónicos, son elementos de importancia para el desarrollo de competencias ciudadanas. (p. 107)

A su vez otros autores como: Cassany (2002), Gutiérrez (2003), Majo y Marqués (2001) Millán (2000) y Rodríguez (2004) consideran la “participación activa” de la ciudadanía como la clave para cualquier proceso de entendimiento y construcción de la sociedad de la información, y coinciden en que el desarrollo requiere de un proceso de alfabetización digital.

Sin embargo, el autor más reconocido por los aportes realizados al concepto de alfabetización digital es Gilster (1997), quien sugiere la existencia de cuatro competencias centrales en la alfabetización digital con independencia de los cambios tecnológicos: 1) construcción de conocimiento; 2) búsqueda en Internet; 3) navegación por hipertexto; y 4) evaluación del contenido (Gutiérrez Martín, 2003).

La obra de Gilster (1997) realiza un aporte sustancial a la idea de una nueva alfabetización que contribuya a la comprensión de los cambios tecnológicos, más allá de las tecnologías en sí mismas, pero con sujetos con competencias para su pleno desarrollo en el mundo digital. Esta obra de la década del 90 es resistida por quienes aseguran que el autor establece una reducción del término de alfabetización digital al compararla con la alfabetización en internet. En el trabajo de Bawden (2001) se reconoce el aporte realizado por Gilster (1997) 
y se comprende la relevancia que el autor le da a internet, por el contexto en que escribe y publica su obra.

Los trabajos de Gilster (1997) y Bawden (2008) son recuperados por Miguel Zapata Ros (2015) al trabajar los procesos cognitivos presentes en el pensamiento computacional y hablar de una "nueva alfabetización digital". De esta manera, el autor desarrolla una línea de trabajo en la que afirma:

(...) la construcción de una idea del pensamiento computacional a partir de elementos o de formas específicas de pensamiento para resolver problemas, tiene que ver con la Alfabetización Digital en que éste está constituido por competencias clave que sirven para aprender y comprender ideas, procesos y fenómenos no sólo en el ámbito de la programación de ordenadores o incluso del mundo de la computación, de Internet o de la nueva sociedad del conocimiento, sino que es sobre todo útil para emprender operaciones cognitivas y elaboración compleja que de otra forma sería más complejo, o imposible, realizar. (p.11)

Las referencias académicas que definen de forma clara al PC como alfabetización digital son escasas en comparación con la gran cantidad de artículos y publicaciones que abordan PC y alfabetización digital por separado. Sin embargo, el abordaje del concepto de alfabetización digital en la bibliografía consultada presenta los elementos constitutivos del PC, según las definiciones que sobre este término se analizaron anteriormente. Adell Segura (2019) revive este tema y refiere:

La relación entre el PC y la competencia digital es un tema complejo y no exento de espacios de confrontación. Todavía hay escasas publicaciones en las que se explore dicha relación en profundidad, quizá porque el concepto de competencia digital es netamente europeo y en el mundo anglosajón se utiliza habitualmente el concepto de alfabetización digital, similar solo en parte. (p. 175)

Sobre la conclusión realizada por Eshet (2002) y Zapata-Ros (2015), reconoce y sostiene que la alfabetización digital debe ser considerada como la capacidad de utilizar fuentes digitales de forma eficaz, tratándose de un tipo especial de mentalidad o pensamiento, poniendo el 
foco en la resolución de problemas y no en las formas en que se procesa la información. Sobre esta recuperación Zapata Ros $(2015$, p.9) aclara que "el pensamiento computacional es más una resolución de problemas."

El segundo enfoque, que entiende al pensamiento computacional como una competencia digital, está relacionado con las denominadas "competencias clave" que la Unión Europea define y desarrolla la comunicación oficial, bajo el nombre Recomendación del Parlamento Europeo y del Consejo, del 18 de diciembre de 2006, sobre las competencias clave para el aprendizaje permanente. Lo que se establece en dicho documento son ocho competencias sobre las cuales se sugiere se desarrollen los procesos educativos, bajo una mirada integral que va desde el establecimiento de metas y estándares de evaluación hasta estrategias metodológicas y actividades. Este documento instala en la cuarta competencia clave la competencia digital, que se describe como:

La competencia digital entraña el uso seguro y crítico de las tecnologías de la sociedad de la información (TSI) para el trabajo, el ocio y la comunicación. Se sustenta en las competencias básicas en materia de TIC: el uso de ordenadores para obtener, evaluar, almacenar, producir, presentar e intercambiar información, y comunicarse y participar en redes de colaboración a través de Internet. (p.7)

Según esta definición, es difícil asociar al PC con esta competencia, en tanto no está enunciada esta relación en el documento de origen de uno de los dos términos involucrados, sin embargo, la producción científica que a posteriori se desarrolló aborda esta relación como posible. Trabajos como los de Bocconi S. et al, (2016), The Royal Society (2012) o Informatics Europe and ACM Europe (2013), fortalecen una idea de relación entre ambos términos para promover un enfoque posible sobre la enseñanza de contenidos de las $\mathrm{CC}$, que lo diferencia de un enfoque de uso de TIC. De esta forma, el enfoque que plantea al PC como competencia digital se caracteriza por:

- promover una línea de articulación con contenidos disciplinares específicos, e intentar establecer propuestas curriculares para definir un campo de contenidos para PC y separarse de un enfoque generalista que recupera las TIC 
- establecer estándares de evaluación para el desarrollo de la competencia digital, basado en los elementos constitutivos del PC como procesos medibles y evaluables.

- estimular el desarrollo de políticas que promueven su enseñanza para el desarrollo de una competencia digital que forme para el trabajo, promoviendo el desarrollo de profesionales y ciudadanos mejores capacitados

- establecer una articulación con el concepto de alfabetización digital, otorgándole un sentido más acotado al término, en tanto lo asocia a la adquisición de habilidades para el manejo de las TIC

Es relevante el desarrollo es esta aproximación conceptual, dado que orienta el desarrollo de las políticas EU que se analizan en este trabajo, pero además, promueven una propuesta de impacto para todos a través de los documentos DigComp para ciudadanos, organizaciones, docentes y emprendedores (Brecko et al, 2016, Carretero et al, 2017, y Redeckery Punie, 2017) orientados a mejorar las competencias digitales de los ciudadanos, consumidores y educadores de la UE. Enfocan su implementación en tres áreas: 1) formulación de políticas públicas; 2) planificación educativa, de formación y de empleo; y 3) evaluación y certificación.

\subsection{Conclusiones}

En este capítulo se realizó un recorrido por los principales enfoques que definen el PC, y que se desarrollaron desde su aparición en 2006 y continúan vigentes en la actualidad. La falta de especificidad y conceso en las definiciones del término, obligó al desarrollo de las líneas fundamentales que ayuden a comprender el cruce y la articulación sobre los términos, no sólo como síntesis sino, en reconocimiento a los sentidos que cada uno de ellos, le adjudica al término.

La realización de los cuadros síntesis permitió un ordenamiento por enfoques, en los que se recuperan ideas centrales que definen la posición sobre el término, los autores y los contextos en que se dan dichas definiciones. A partir del trabajo realizado, en este capítulo se concluye que las ideas sobre PC en América surgen entre los años 2006 y 2011. Asimismo, los aportes 
que recuperan al PC a partir de la relación con procesos educativos fundados en la necesidad de la enseñanza, se desarrollan a partir de 2009. En este punto se concluye que los trabajos europeos analizados plantean con mayor énfasis la relación entre PC, procesos educativos y enseñanza de contenidos asociados a la programación. Sin embargo, existen mixturas dentro de los enfoques, producto del avance en la discusión sobre el término, lo que permite el desarrollo de un análisis interdisciplinario e integral sobre la relación entre educación, programación y PC que fortalece los estudios que entienden al PC como un proceso de alfabetización emergente.

Se destaca que para esta tesis se toman los estudios europeos que definen al PC en relación con la competencia digital (que se constituye a partir de los aportes americanos revisados) dado que permiten el trabajo en un contexto común, la UE. El desarrollo de una articulación con el campo de la pedagogía a partir de un enfoque de enseñanza por competencias que pone en tensión la configuración de enfoques sobre los contenidos (TIC y CC) que permiten su desarrollo. Sobre esto se trabajará en los próximos apartados, en los que se asumirá un sentido amplio sobre el término la alfabetización digital que permite articular los campos de desarrollo de esta tesis (Comunicación, Educación, CC). 


\section{Capítulo 3: Alfabetización Digital}

\subsection{Introducción}

El desarrollo y configuración de una cultura digital y su impacto en las lógicas de circulación de conocimientos devuelven al centro de la escena la pregunta por la educación en esta época. Existe una necesidad de reconocer el escenario inestable y en movimiento continuo. Para considerar nuevas formas de enseñanza y pensar qué tipo de sujeto necesita esta cultura. Pérez Gómez (2012) habla de la penetración de las tecnologías en los espacios cotidianos y reconoce siete grandes rasgos respecto de cómo se produce y circula el conocimiento y su impacto en ámbitos cotidianos, como la escuela y el trabajo. Tales rasgos se evidencian en:

- La expansión de las herramientas digitales como extensión de los recursos y posibilidades de conocimiento y acción

- El carácter distribuido del conocimiento

- La externalización hacia las máquinas de tareas, funciones y actividades

- La necesidad de un aprendizaje superior que contribuya a vivir en la incertidumbre y la complejidad

- La cooperación como exigencia del conocimiento y la acción en la era de la información

- El cambio en la concepción sobre la naturaleza y funcionalidad de la información y el conocimiento

- La exigencia de los enfoques holísticos (p. 61-65)

Estos aspectos permiten analizar el desarrollo de otras formas de concebir y pensar las prácticas educativas con nuevos tipos de intervenciones, poniendo de manifiesto múltiples problemáticas que atraviesa la educación a nivel general. De estos principios se desprende el problema de la formación para el trabajo, la relación entre conocimientos y habilidades, el carácter colaborativo de las producciones, así como la interconexión de redes, entre otros.

Con respecto al cuarto de los rasgos enunciados por Pérez Gómez (2012) en lo atinente a la idea de "aprendizaje superior", el autor afirma que "la era digital requiere desarrollar hábitos 
intelectuales que preparan para un futuro en el cual casi todo es accesible, complejo, global, flexible y cambiante” (p. 63). Así, las características respecto del tipo de aprendizaje necesario son una pista para comprender un nuevo eje de preguntas y problemas, asociados con las tecnologías y su integración en los procesos educativos. En este sentido, cabe aclarar que esos procesos se dan, en tanto sean comprendidos según su constitución socio cultural y al componente tecnológico que se desarrolle; pues ambos son factores que intervienen esos procesos y condicionan su desarrollo.

El hacer hincapié en esta línea de trabajo entre tecnologías y educación involucra considerar un escenario en el que la alfabetización digital parece ser el proceso necesario y apropiado. Sin embargo, el contexto devenido de las transformaciones sociales y culturales, implica algunos retos. Así, por ejemplo, Köppel, Suchodolski, y Zappalá (2012), mencionan estos desafíos para explicar su incidencia en las escuelas. El primero de ellos se relaciona con el aumento en cantidad y diversidad de conocimientos, textos y productos que circulan en forma permanente. En segundo lugar, se reconoce una transformación sobre cómo es considerada la alfabetización, en tanto no se restrinja su concepción al acceso a la lectura y la escritura. La alfabetización ha dejado de ser conceptualizada en singular para dar cuenta de una pluralidad de saberes, en los que se incluyen los lenguajes audiovisuales, la capacidad de seleccionar y organizar cantidades importantes de información, la programación, la operación de computadoras y otros artefactos tecnológicos. El tercer reto reside en el acceso a otros medios como Internet, al generar nuevas demandas en términos de competencias. Aquí es necesario aclarar que estas competencias de la alfabetización digital no se restringen a las habilidades técnicas, sino a las que permiten utilizar las conexiones y la circulación de información e imágenes de manera significativa, crítica y creativa.

Estos desafíos configuran el escenario propicio para la pregunta por la alfabetización digital y su incorporación dentro de las escuelas; a su vez, estas transformaciones no solo han sacudido la concepción de ciertos procesos educativos, sino que han revolucionado el sector productivo, logrando que los empleos y las denominadas nuevas profesiones alienten al desarrollo de una educación digital. 
Una idea general sobre esto último es la desarrollada por Inés Dussel (2006), quien explica que la alfabetización digital debería ayudar a promover otras lecturas (y escrituras) sobre la cultura que portan las nuevas tecnologías y que le permitan a los sujetos entender los contextos, las lógicas y las instituciones de producción de esos saberes, la organización de los flujos de información, así como la procedencia y sus efectos para que se habilite la posibilidad de pensar otros recorridos y otras formas de producción y circulación. Esta autora define el proceso a partir de la importancia de producir en la cultura digital. Hay una necesidad de poder comprender, participar y desarrollar contenidos de una forma que no es la que conocíamos y esto hace de la alfabetización digital un desafío.

En la misma línea, Salomon (2000) explica que es necesario pensar de manera más productiva la relación con las tecnologías, de modo tal que se logre trascender la visión tecnocéntrica. Ello implica entender y reconocer que las tecnologías no solo ayudan a alcanzar objetivos existentes, sino que crean nuevas necesidades, nuevos propósitos y metas que jamás hubieran sido considerados antes de que dichas herramientas se incorporaran.

En este punto de la disertación, es importante destacar que la concepción de alfabetización digital es la aproximación más fuerte a una idea de pensamiento computacional en educación. El concepto remite con mayor claridad a una perspectiva que considere centrales los procesos de enseñanza y eso se debe a que la alfabetización es un proceso que debe ser enseñado, mediado y facilitado por otro. En este capítulo se hará énfasis en la idea de alfabetización digital y su relevancia para comprender la relación entre PC y ciertos procesos educativos. Lo que aquí se pretende es evidenciar los procesos presentes en la alfabetización, las implicancias analizadas desde el campo de la pedagogía y los sentidos que puede adquirir el desarrollo de su puesta en práctica.

El accionar educativo de alfabetizar, constituye el desarrollo de las competencias necesarias para leer y escribir. Esta definición base, se complejiza en los diferentes escenarios y contextos en que este proceso se desarrolla; más allá de las estrategias empleadas, las formas de lo cultural hacen de esta práctica un mundo de posibilidades. Entonces, vale la pena interrogarse: ¿qué significa alfabetizar digitalmente? Esta inquietud se instaló fuertemente, adquiriendo gran relevancia a la luz de las transformaciones sociales y culturales, 
desarrolladas de manera acelerada, por los procesos de avance tecnológico. En este sentido, el impacto de estas transformaciones promovió la revisión sobre su significado; así por ejemplo, la UNESCO (2019) incorporó elementos de la cultura digital para definir el proceso de alfabetización, destacando algunas de sus características:

La alfabetización es también una fuerza motriz del desarrollo sostenible ya que permite una mayor participación de las personas en el mercado laboral, mejora la salud y la alimentación de los niños y de la familia; reduce la pobreza y amplía las oportunidades de desarrollo durante la vida. Más allá de su concepto convencional como conjunto de competencias de lectura, escritura y cálculo, la alfabetización se entiende hoy día como un medio de identificación, comprensión, interpretación, creación y comunicación en un mundo cada vez más digitalizado, basado en textos, rico en información y en rápida mutación.

Esta conceptualización del término visibiliza el desarrollo de un enfoque que destaca el proceso de alfabetización desde una perspectiva amplia, pues reconoce otros procesos (en ámbitos no académicos) y su efecto "multiplicador". Se inscribe en el contexto de cultura digital y da lugar a una serie de elementos (trabajo, comunicación, interacción, producción y creación) que se observan en las producciones académicas y que definen, esbozan y establecen características de una nueva alfabetización: una alfabetización digital (Giroux, 2011; Mc Laren, 1992; Pérez Gómez, 2012).

La idea de una alfabetización digital se relaciona con el pensamiento computacional a partir de la obra de Miguel Zapata-Ros (2015), quien, a partir de una perspectiva amplia de la educación, identifica los procesos involucrados en el desarrollo de PC, los define y fundamenta al afirmar:

(....) se trata de una nueva alfabetización, de una alfabetización que permita a las personas en su vida real afrontar retos propios de la nueva sociedad y que vaya más allá, que permita a los individuos organizar su entorno, sus estrategias de desenvolvimiento, de resolución de problemas cotidianos, además de organizar su mundo de relaciones, en un contexto de comunicación más racional y eficiente. Todo ello con el resultado de poder organizar estrategias para conseguir objetivos 
personales. En definitiva, se trata de conseguir una mayor calidad de vida y un mayor nivel de felicidad. (p. 3)

Este autor reconoce el desarrollo de competencias dentro de sus trabajos y abona a una idea sobre el PC, pensada para el desarrollo en ámbitos educativos y en relación con las nuevas exigencias del mundo digital. En ese sentido, sostiene:

Se trata de una forma de pensar propicia para el análisis y la relación de ideas, para la organización y la representación lógica. Esas habilidades se ven favorecidas con ciertas actividades y con ciertos entornos de aprendizaje desde las primeras etapas. Se trata del desarrollo de un pensamiento específico: el pensamiento computacional. (Zapata Ros, 2015, p. 1)

En el tratamiento de sus trabajos académicos aparece una fuerte crítica a las estrategias que comparan al PC con la programación. Señala que la programación solo es vista como una parte del PC; para esto se inspira en la obra de Seymour Paper (1980) bajo el lema de que los niños deben programar la computadora en lugar de ser programados por ella. Sobre esta base, Zapata-Ros (2015) reconoce que "igual a como sucede con la música, con la danza o con la práctica de deportes, es clave que se fomente una práctica formativa del pensamiento computacional desde las primeras etapas del desarrollo" (p. 3)

Considerar al PC como una nueva alfabetización implica reconocer que la relevancia de su enseñanza exige el desarrollo de propuestas integrales que reconozcan, desde un campo legitimado por contenidos, un sentido claro en relación con el tipo de sujeto que se pretende formar. Carlos Magro (2018) coincide con la idea de que las transformaciones culturales actuales obligan a repensar el sentido sobre la incorporación de las tecnologías en la escuela al sostener:

(...) las actuales tecnologías, lejos de constituir simplemente una caja de herramientas, definen un nuevo entorno de aprendizaje que, entre otras consecuencias, está ampliando el concepto de alfabetización, modificando nuestra relación con los contenidos, demandando nuevas formas de enseñanza-aprendizaje y difuminando las fronteras entre el aula y el hogar, lo formal y lo informal. (Magro,2018) 
En este punto, el desarrollo de competencias digitales que contribuyan a generar nuevas formas de entendimiento, diseño y producción de conocimiento, constituye un desafío para los ámbitos educativos formales, superando la enseñanza exclusiva de la programación. Respecto de esta tensión presente en las propuestas de enseñanza, pero también en el ámbito académico, Zapata-Ros (2015) aclara:

Hay, por tanto, multitud de áreas del aprendizaje que conviene explorar e investigar en esta nueva frontera. Y en la planificación de los currículos tendrá que plantearse esta dicotomía: Enseñar a programar con dificultad progresiva (si se quiere incluso de forma lúdica o con juegos) o favorecer este nuevo tipo de pensamiento. Obviamente no hace falta decir que nuestra propuesta es la segunda, que además incluye a la primera. (p. 4)

\subsubsection{Perspectivas pedagógicas}

Pensar en prácticas educativas que promuevan el pensamiento computacional, nos permite articular algunas relaciones con el campo de la pedagogía. La pregunta por la educación y sus procesos es asumir el interrogante por los sentidos de esas prácticas y analizar dónde está puesto el foco. En este apartado se retomarán algunos enfoques pedagógicos que contribuyen en el análisis entre educación y tecnologías, para analizar al PC en el marco de la alfabetización digital, tal como se ha destacado en apartados anteriores. Nos interesa sistematizar algunos rasgos generales sobre la inclusión de las tecnologías en las aulas para desarmar el mito de que la innovación pedagógica viene garantizada de la mano de nuevas herramientas (software, robots, programación). Cuando una tecnología, sea cual sea, es asimilada dentro de las prácticas educativas existentes sin desafiarlas, sus posibilidades de estimular un cambio o transformación, en realidad son muy pocas. Existen experiencias áulicas con TIC en el proceso de aprendizaje que muestran cómo estas pueden estar al servicio de prácticas pedagógicas más tradicionales. Es decir, situaciones educativas en que las tecnologías no favorecen procesos de reflexión, comprensión, creatividad y análisis crítico, sino que, por lo contrario, cumplen la función de transmitir información y demandan a los estudiantes memorizar y emitir respuestas repetitivas. 
Si el aporte del campo pedagógico y didáctico sobre la incorporación de contenidos está relacionado con la pregunta ¿para qué enseñamos?, en esta investigación, lo que nos interesa recuperar es ¿para qué enseñamos a pensar computacionalmente? Así, partimos de una perspectiva crítica para comprender la enseñanza del PC como competencia y no nos centramos en las herramientas ni en los artefactos que lo promueven. Esto implica reconocer al PC como un proceso de desarrollo de habilidades específicas, admitir su articulación con otras formas de pensamiento (lógico, matemático, ingenieril) y pensar estas características a partir de una lógica que destaque los múltiples condicionamientos que lo atraviesan. No se trata de un efecto de la enseñanza con tecnologías, sino de un conjunto de habilidades que potencian un proceso de creación.

A lo largo de la historia se han sucedido distintas alfabetizaciones y todas han tenido una significación común: han supuesto una adaptación a los nuevos medios de comunicación, representación y proceso de la información entre humanos. La revolución tecnológica y de la sociedad de la información, se considera, en sentido estrictamente tecnológico, una revolución de medios de comunicación y de difusión de ideas. La Alfabetización Digital es la adaptación y la capacitación para esas funciones de comunicación, representación y proceso del conocimiento a las coordenadas de la revolución tecnológica y de la sociedad de la información. (ZapataRos, 2018)

\subsubsection{Aportes desde el campo de la comunicación, cultura y educación}

Abordar la problemática de la alfabetización digital desde la comunicación y la educación, nos permite recuperar, analizar e interpretar los distintos escenarios que configuran a los sujetos y condicionan los modos de ver e intervenir en el mundo. En ese sentido, la cultura mediática y el mercado se erigen como lugares clave de constitución de identidades y se perfilan como protagonistas de un medio. Analizar estos procesos desde la comunicación, la cultura y la educación permiten abordar el eje de las tecnicidades como elemento de transformación y de producción de nuevos sentidos sociales y culturales posibles. La educación, entendida como proceso en su historicidad e institucionalización, ha tenido como 
característica central la necesidad creciente de garantizar la conservación de la cultura y la sociedad en vistas a un tipo específico de sujeto y de proyecto. El actual escenario de cambios muestra que lo permanente es el proceso mismo de la transformación que tiene implicancias directas en las renovaciones periódicas de los currículos y en mecanismos permanentes de actualización. La presencia cada vez mayor de la tecnología digital en la vida cotidiana está borrando los límites tradicionales entre lugar/espacio; producción/consumo; actos únicos/simultáneos; tiempo síncrono/asíncrono; $\quad$ personas/instituciones; libertades/restricciones.

Entendemos que estamos ante una formación inmersa en tecnologías de descodificación, donde ya no existe la regulación de los usos tecnológicos, pues estos son parte esencial de la vida en el cotidiano. Al respecto, Van Dijck (2016), expone "la socialización se vuelva tecnológica, no solo alude a su desplazamiento al espacio on line, sino al hecho de que las estructuras codificadas alteran profundamente la naturaleza de las conexiones, creaciones e interacciones humanas" (p. 42)

En este sentido, los aportes del campo de la comunicación/educación constituyen una nueva forma de leer los modos y expectativas, los protocolos de usos y producción que los medios digitales aportan a la escena educativa (Dussel 2012; Southwell, 2013). El énfasis en estas teorías estará en el vínculo con los sujetos de la educación porque el vínculo del binomio comunicación/educación son las relaciones de los sujetos que producen sentidos a partir de prácticas educativas. $^{9}$

La relevancia de este campo en esta tesis es central, en tanto se rescata de Martín Barbero (2002) la idea de que el lugar de la cultura en la sociedad cambia cuando la mediación tecnológica de la comunicación deja de ser meramente instrumental para espesarse, densificarse y convertirse en estructural. Así, la tecnología remite hoy no solo a unos aparatos, sino a nuevos modos de percepción y de lenguaje, a nuevas sensibilidades y escrituras.

\footnotetext{
${ }^{9}$ Se definen prácticas educativas en sentido amplio según Buenfil Burgos (1992).
} 
En ese sentido es importante resaltar que las tecnicidades no son las técnicas, las tecnologías o los dispositivos técnicos, sino los saberes sociales, las prácticas culturales, los poderes en juego, los sentidos dominantes, pero también, los sentidos resistentes que se condensan, se potencian o se silencian en los dispositivos técnicos, así como los contextos que se crean en torno a ellos, son sus historias y sus presentes. No son sus usos únicamente, sino también lo atinente a la educación. De esta forma, los procesos educativos están siendo interpelados, no solo por la enorme cantidad de contenidos disponibles dislocados y diseminados, sino también por los modos en que se transmite, se legitima y se produce el conocimiento.

En ese orden de ideas, Da Porta (2018) expone que las tecnicidades implican algo más que usos, pues son una de las mediaciones constitutivas de nuestra cultura contemporánea, dado que no solo habitan, atraviesan, constituyen y desafían las prácticas comunicacionales. Así, recuperar el concepto de tecnicidades nos permite salir de la lógica dual y teleológica "medios-fines" que nos lleva a pensarlas según los efectos logrados. Si consideramos las tecnicidades como las formas culturales, políticas, sociales y rituales en que las tecnologías se hacen parte de la vida social, entonces es posible reconocer cuestiones que son centrales hoy para el campo de la comunicación/educación en el que la historia de este posicionamiento político/académico, plantea problemáticas propias de las cuales tenemos mucho que decir, investigar, denunciar y transformar.

Pensar las técnicas desde la lógica de tecnicidades nos lleva a explorar de qué modo se articulan con las subjetividades con los deseos, los temores, las aspiraciones, las expectativas sobre el futuro y las creencias personales, es decir, con los modos de ser y de estar que están permeados y constituidos por esas tecnicidades.

Consideramos que centrarnos en este enfoque, además de pensar en términos de articulación e interdisciplinariedad en esta investigación, contribuye al desarrollo de estrategias didácticas y pedagógicas que promuevan el pensamiento computacional, pues nos permite reconocer el proceso, más allá de la técnica; incluso más allá de los enfoques educativos en los que el contexto condiciona la práctica y nos obliga a pensarnos en múltiples roles, todos atravesados por la cultura y sus múltiples tecnicidades. 


\subsection{Los aportes desde el pensamiento pedagógico}

El estudio y sistematización de las teorías sobre la educación (Saviani, 1980; Libaneo, 1980; Palacios, 1995; Silber, 2007) permite relacionar educación, sociedad y cultura en un nivel de análisis teórico y contextual. Esto posibilita identificar cuestiones más específicamente didácticas, visualizando su vinculación con dimensiones sociales y pedagógicas, las cuales nos ayudan en esta tesis a profundizar en las configuraciones teóricas que enriquecen el tema de esta investigación.

A partir de la respuesta acerca de si es legítimo o no cuestionar la sociedad en la que nos ha tocado vivir, caben al menos dos grandes concepciones y propuestas, que nos permiten dar densidad analítica al PC y la alfabetización digital desde los aportes de la pedagogía:

1. La aceptación de las condiciones de la vida social como un orden natural y dado: da lugar a teorías que, a partir de la aceptación de lo socialmente establecido, realizan propuestas educativas con acento en los métodos centralmente, desde una lógica medios / fines. Es así que la solución que proponen es centrar en la educación la solución a los problemas sociales los que, por otra parte, son considerados parte normal del sistema.

2. Cuestionamiento de las condiciones establecidas, como un orden producido, histórico y desigual: da lugar al desarrollo de enfoques o teorías que sobre la base de un cuestionamiento a la sociedad y la cultura realizan propuestas educativas con un acento en la mirada compleja, situacional e integral de los procesos.

Nos resulta pertinente destacar en este punto, que en la presente investigación se plantean cuatro ejes teóricos articuladores que evidencian la relación sociedad, cultura, sujetos y contenidos, elementos estructurales para pensar los procesos educativos. Los mismos además permiten identificar las diferencias entre los dos grandes enfoques (críticos y no críticos) en educación, que, si bien no es un objetivo de este trabajo abordarlos en su totalidad, sí lo es recuperar algunos desarrollos e implicancias (muy distintas) respecto de las formas de pensar los procesos educativos para la alfabetización digital y el PC. 
De estas dos grandes clasificaciones se recuperan algunos enfoques teóricos pertinentes a las dimensiones planteadas para pensar las tecnologías y las tecnicidades.

\subsubsection{Enfoques no críticos}

Las pedagogías no críticas se enfocan en la relación educación/sociedad/cultura a partir de la identificación de problemas, pero asumen esta relación de manera armónica. En otras palabras, es la sociedad la que depende de la educación y con una mejor educación, se desarrolla una mejor sociedad. Este modelo de educación se constituye desde estas perspectivas vinculadas a la homogeneidad, a un sentido de nación, a una identidad, a una clase, lo que representa la "verdad unívoca". Asimismo, la formación es comprendida desde una lógica de transmisión vertical de saber universal y único (que describe o explica un orden de lo real dado). En cuanto a las intervenciones educativas, estas se desarrollan sobre la base de dispositivos que garanticen y legitimen dichas prácticas como la escuela. En lo pedagógico, se valora el rol del docente como un técnico ejecutor de metodologías de enseñanza que deberían generar ciertos resultados de aprendizaje, y a los contenidos, en tanto son verdades que resultan pertinentes para esto y para lo que la sociedad/mercado laboral demanda en términos de conocimientos y competencias.

Dentro de estos enfoques sobre este aspecto se reconoce que las líneas que vinculan el trabajo con educación y tecnologías recuperan algunas posturas ya desarrolladas por la pedagogía a principios del siglo XX. Uno de los representantes de ese momento fue J. Dewey, para quien la pedagogía en la educación se materializa a partir de la experiencia. Según su visión, una situación educativa es el resultado de la interacción entre las condiciones objetivas del medio social y las características internas del que aprende, haciendo énfasis en una educación que desarrolle las capacidades reflexivas y el pensamiento, el deseo de seguir aprendiendo y los ideales democráticos y humanitarios. En este mismo orden de ideas, Dewey (1995) afirma que "La unidad fundamental de la nueva pedagogía se encuentra en la idea de que existe una íntima y necesaria relación entre el proceso de la experiencia real y la educación.” (p.96) 
En consecuencia, un principio básico de este enfoque plantea que los estudiantes deben aprender en el contexto pertinente. De esta manera, y según Gros (2016), quien comparte el mismo enfoque teórico, el diseño de los contextos de aprendizaje se convierte en una de las tareas básicas para el profesor, por lo que el rol de este cambia de forma muy notable.

En cuanto a los orígenes de los enfoques de la tecnología educativa, estos pueden hallarse en la enseñanza programada con la idea de elevar la eficiencia de la dirección del proceso docente. Su creación se debe a Skinner (1954), profesor de la Universidad de Harvard. Sus trabajos se enmarcan en la corriente psicológica del Conductismo que centra el aprendizaje en la fijación de un repertorio de estímulos del medio y sus respuestas $(E-R)$. Esta mirada iguala al aprendizaje con los cambios en la conducta observable, bien sea respecto a sus formas o a su frecuencia; así, el aprendizaje se logra cuando se demuestra o se exhibe una respuesta apropiada después de la presentación de un estímulo ambiental específico. Este modelo psicológico del aprendizaje sirvió de base para la enseñanza programada, primera expresión de la tecnología educativa. El modelo pedagógico presente en esta tendencia, se puede resumir en objetivos conductuales, organización del contenido de forma lógica en secuencia de unidades; métodos basados en el autoaprendizaje para lo que se utilizan las preguntas y respuestas, y la búsqueda de la eficacia y la eficiencia de los procesos metodológicos.

En cuanto a los enfoques neotecnicistas (cuyo antecedente "moderno" lo constituye una pedagogía tecnicista que, en la década del 60, respondía a un modelo desarrollista) en los 90 se redefine dentro del modelo político neoliberal.

En esta tendencia se reconoce la influencia del administrador de empresas estadounidense Peter Drucker, quien en su texto La sociedad poscapitalista (1994) valora esencialmente el saber productivo para la creación de riqueza, criticando a los tradicionalistas que quieren volver a las humanidades y a los clásicos del siglo XIX, ya que entiende que hay que apostar al futuro y no al pasado. Sin embargo, agrega que hay que cuidar de comprender y aceptar las ideas occidentales que incluyen saberes como el dinero, las finanzas y la banca al estilo occidental. También critica a los deconstruccionistas como "una variopinta pandilla de posmarxistas, feministas, radicales y otros “anti” que no aceptan el universalismo que supone 
la persona instruida y promueven culturas e individuos separados, aislados.” (Drucker, 1994, p.177)

En común encontramos en estos enfoques que la función educativa, sigue siendo regida por el principio de formar a un sujeto para acomodarse a un mundo que se presenta naturalmente como dado, y que más allá de los acentos en las experiencias o en los métodos presuponen una fabricación de un tipo de sujeto a partir de los requerimientos del mundo.

\subsubsection{Pedagogías críticas para la era digital}

El posicionamiento crítico permite comprender la educación y sus dinámicas desde una perspectiva amplia que la reconoce como proceso cultural, valorando al sujeto como creador de cultura. Este enfoque asume la relación educación/sociedad/cultura en permanente dinámica de tensión y conflicto, haciendo hincapié en las condiciones subjetivas y discursivas, en tanto la realidad son construcciones no unívocas (estatutos del saber: episteme, doxa, praxis, techné, ciencia). Sobre esto, Ricardo Nassif (1980) explica:

En este terreno aparecen obra como la de Theodor Brameld (1961) quien, aprovechando las conclusiones de la antropología cultural, examina la cultura como el contexto de la educación y pone la problemática educativa en una vinculación muy estrecha con la teoría cultural en sus diversos niveles de análisis. En el ámbito más concreto de la praxis educativa, Paulo Freire (1970) se apoya en el concepto más antropológico de cultura. Su primera meta es hacer comprender al sujeto que también él es creador de cultura, así como la necesidad de la lectura y la escritura como medios liberadores de comunicación. (p.69)

En el desarrollo de esta cita queda en evidencia la relación entre procesos culturales/educativos/sociales/ comunicacionales como mutuamente imbricados, y que en su movimiento promueven tanto lógicas de reproducción y como de transformación cultural. Así, pues, el sujeto de la educación, a partir del movimiento entre la objetivación/subjetivación cultural, será el promotor de todos esos procesos en sus múltiples roles (educador, educando, trabajador, político, etc.). 
Es así que, desde estos enfoques, los procesos formativos son parte de esta lógica de asimilación y transformación cultural. En este sentido, la formación es permanente, subjetiva y experiencial; es la experiencia la que forma como proceso histórico y personal. Las configuraciones de las prácticas educativas y las maneras de construir la enseñanza en esta corriente ponen el acento en los sujetos de la educación, en tanto sujetos en relación, porque se reconocen sus experiencias en torno a todo aquello que los constituye: sus tiempos, lenguajes, contextos, configuraciones y discursividad. Autores como Mc Laren (1998), Ferry (1997), Cornu (1999), Meirieu (1998), Larrosa (2000), Ranciére (1991), entre otros, realizan aportes al campo pedagógico según esa concepción. Algunos rasgos que las definen, radican en el análisis de la configuración de subjetividades desde las propias experiencias que realiza el sujeto, oponiéndose a la idea de la educación como fabricación. También reconocen lo indeterminado de los procesos educativos, promueven la inclusión en ellos de las ideas de libertad y autonomía, advirtiendo sobre el no poder del educador sobre las decisiones del sujeto que aprende (Meirieu, 2011). Además, el sujeto del que se trata no es únicamente significado como sujeto escolar (Buenfil Burgos, 1992).

La configuración del campo pedagógico dentro de las pedagogías críticas media entre la noción positivista de educación como ciencia aplicada (ciencia/técnica-teoría/práctica) y la de la criticidad como praxis reflexiva o ciencia práctica. Se legitima la experiencia, y se reconocen, también, los múltiples espacios educativos. Las incorporaciones de los estudios sobre la conformación de la subjetividad han permitido a las teorías críticas posmodernas insertarse en los estudios que implican la comprensión de los procesos educativos en una sociedad con las características contemporáneas, en donde los rasgos dominantes son las transformaciones, la fluidez (Bauman, 2000), el desborde (Appadurai, 1996). Sobre esto, y circunscripto a nuestro país, Julia Silber (2011) explica que "La línea que pone énfasis en la subjetividad, ha ido creciendo en los últimos años, al punto que tal vez se esté constituyendo como la de mayor influencia en el espacio educativo argentino.” (p. 3)

En ella se retoman conceptualizaciones relativas al funcionamiento del poder y sus relaciones con el saber, al lugar del discurso y el texto en la construcción de lo social, al sentido de lo contingente y a los modos de configuración de los procesos de subjetivación. Pueden encontrarse en ella variadas influencias, entre otras, de la filosofía política desarrollada por 
Hannah Arendt (1993) del psicoanálisis lacaniano y de teorizaciones de Foucault (1995), Deleuze (1988) y Derrida (1997).

En este contexto teórico, Apple (1996) define las pedagogías críticas como expresiones posmodernas a las que nombra como "análisis personales-literarios-autobiográficos" influidos por enfoques fenomenológicos, psicoanalíticos y feministas" y en los que subyace frecuentemente una fuerza de carácter moral.” (p.16). Valoriza lo ético, estético y personal de esas posturas, pues la actividad educativa sin esos rasgos deja de ser educativa para convertirse en entrenamiento. Pero luego señala las limitaciones que suelen aparecer en sus variantes porque "queda algo, demasiado, en el fondo: un sentido penetrante de lo político, de las estructuras sociales que condenan a tantas personas de carne y hueso a una vida de lucha económica y cultural (y corporal) y a veces a la desesperación.” (Apple, 1996, 16)

En estas posiciones críticas, el análisis del contexto sociopolítico y las relaciones de poder que en el sujeto se manifiestan, a veces se dejan entrever, otras veces permanecen ocultas, otras se expresan, pero en todos los casos se posicionan desde la preocupación acerca de lo que le ocurre al sujeto, su subjetividad, sus interpretaciones o su formación. Por último, introducen y legitiman un lenguaje y un discurso diferente al de las teorías tradicionales. En algún sentido, pueden ser vinculadas con las teorías pedagógicas antipositivistas por su encuentro con la filosofía, particularmente en sus aspectos axiológicos, debido al acento otorgado a las relaciones pedagógicas, así como por inclinarse hacia planteamientos metodológicos interpretativos, aunque sus fuentes son otras y a diferencia de aquellas, no tienen una preocupación por otorgar un carácter científico a la pedagogía (Silber, 2000).

En común encontramos, en estos enfoques, que a las funciones educativas (conservación y transformación socio cultural) se le escapa indefectiblemente la formación de un sujeto (en tanto fabricación) respecto de un mundo que está así pero que podría estar de otra manera.

\subsubsection{Enseñar a pensar computacionalmente}

La necesidad de trabajar para potenciar el desarrollo del PC, constituye una situación ética/educativa, en tanto este sea entendido como posibilidad de creación y criticidad. Al 
inicio de este capítulo se enumeraron los rasgos de la producción de conocimiento según Pérez Gómez (2012), en los que queda en evidencia la velocidad y voracidad del cambio en las lógicas de producción social y cultural. Es indiscutible que las tecnologías hayan permeado el entramado cultural, de modo tal que hoy no exista proceso por fuera de las lógicas digitales, siendo ello tan veloz que cuesta desnaturalizar los procesos de automatización. Sin embargo, nuestra capacidad de creación y transformación es ilimitada, no sabemos de qué somos capaces hasta que lo hacemos realidad, lo cual deja un resquicio importante en manos de la mente humana, su capacidad creadora, interpeladora y analítica.

De esta idea se desprende la articulación entre PC y las pedagogías críticas, por la necesidad de pensar computacionalmente en pos de transformar lógicas de producción con tecnologías que impactan la vida de los sujetos. Lo que se intenta reflexionar desde esta articulación es que la potencia del PC es indiscutible, en tanto se trabaje desde un posicionamiento crítico y reflexivo para no circunscribirse al ámbito de ciencia sin trascender a la conciencia (Nassif,1980). El contexto nos coloca frente al desafío de pensar nuevas formas de educar(nos); pensar en el PC como una nueva alfabetización puede contribuir a la formación, no solo de profesionales con conciencia digital, sino sujetos con real conciencia sobre los procesos tecnológicos que nos atraviesan. Al respecto, Pérez Gómez (2012) expresa:

Esta nueva ilustración para la educación demanda de nosotros, como profesionales, herramientas conceptuales de carácter holístico que intenten abarcar la multiplicidad y complejidad de elementos que componen la personalidad de ciudadanos que nos proponemos formar, así como su naturaleza dinámica e interactiva, abierta, flexible y emergente. Términos como cualidades, capacidades, pensamiento práctico o competencias humanas, son a mi entender mucho más adecuados a nueva exigencia de "comprensión” holística de nuestra naturaleza humana. (p.142)

El contexto nos obliga, debido al surgimiento de sus nuevas formas de funcionamiento digital, a pensar nuevos contenidos para la formación de sujetos. Ahora bien, el preguntarse cuáles son los procesos y contenidos que promueven el desarrollo del $\mathrm{PC}$, el principal interrogante, que, tal como se expuso en el primer capítulo de esta tesis, no es una tarea menor, teniendo en cuenta que la definición del término aún no está consensuada. Lo que nos queda medianamente claro, es que intentaremos llegar a responder la pregunta inicial, 
asumiendo la línea de las pedagogías críticas y la intencionalidad de las prácticas educativas que tensan la función de transformación, vinculando al PC con la alfabetización digital. Al respecto, Zapata-Ros (2015) explica claramente lo siguiente:

Pero volvamos al principio, antes de empezar a escribir código de forma compulsiva, lo importante es saber cómo se representan la realidad, el mundo de objetivos y expectativas, lo que piensan en definitiva los que tienen éxito en hacer programas potentes. Lo importante no es el software que escriben sino lo que piensan. Y sobre todo la forma en que piensan. Conocer este mundo de ideas y de representaciones, cómo operan, constituye el principio básico del "pensamiento computacional, y cualquier otro conocimiento como memorizar a la perfección las reglas de toda la sintaxis y las primitivas de cualquier lenguaje de programación no le sirve de nada a los alumnos si no pueden pensar en buenas maneras de aplicarlas. (p.6)

Enseñar a pensar computacionalmente es el desafío. En esta línea, el sentido sobre la constitución del PC va más allá de su definición, se comprende como un proceso pedagógico crítico, que implica el desarrollo de un tipo de sujeto: el sujeto crítico, pues, hablar de él, es reconocer a un sujeto activo social y culturalmente, un sujeto que es consciente de los condicionamientos sociales de época y en función de ello, toma las decisiones de su accionar cotidiano. Ahora bien, el reconocimiento de estos condicionantes incluyen una formación digital en la era de la información (Castells, 1990). Al respecto Van Dijk (2016), explica:

En escasos diez años los algoritmos han logrado calificar y puntuar todos los actos sociales. Edger Rank, Page Rank, Graph Rank y sus múltiples equivalentes convierten en el mundo de la informática, comportamientos pasados en acciones futuras. Contactar a un amigo al que no se ha visto desde la escuela secundaria tal vez sea un acto completamente humano, pero si se lo realiza on line, por lo general será a través de un algoritmo de "personas que tal vez conozcas". Un adolescente al que nunca se le ocurrió "seguir" a su cantante favorito puede querer hacerlo por la transversalidad de los microsistemas que conectan los videos virales en YouTube, Twitter y Facebook. La presión tecnológica de las múltiples plataformas por elegir a la persona o idea más popular o más conectada se ve, a su vez, reforzada por la presión 
social de los pares en la vida real. Esta se convirtió en una fuerza híbrida, social y tecnológica; las conexiones entre las personas dan forma a otras automatizadas, y viceversa. (p.255)

Promover el desarrollo de un PC desde los niveles de educación inicial podría ser una solución para el desarrollo de procesos cognoscitivos que reconozcan las formas de lo digital y su impacto en el desarrollo de los procesos sociales, desde los más cotidianos a los más complejos. El manejo de datos, el cuidado de la información personal y las nuevas formas de sociabilidad a través de las redes emergen como problemáticas al interior de los espacios educativos, pero a nivel general, no se sabe cómo lidiar con ellos.

En este escenario, los Estados llegan tarde a esta discusión y la población a nivel individual carece de las herramientas para poder regular y administrar su vida digital. Es crítico comprender las limitaciones de la era actual, tomar en cuenta que la estupidez artificial (derivada de sistemas que ofrecen de manera automatizada pobre o información de mala calidad) puede ser más peligrosa que la falta de información oportuna. Hoy resulta necesario desarrollar una nueva comprensión de lo que significa alfabetismo digital crítico, una ciudadanía digital que permita comprender y actuar frente a las nuevas reglas del juego. (Cobo, 2019)

\subsection{La enseñanza en el campo de las Ciencias de la Computación}

La enseñanza del pensamiento computacional está ligada al desarrollo de los contenidos de las CC por el origen del término y los fines con los que Jeannette Wing (2006) propone su desarrollo "pensar cómo informáticos". En este sentido, el reconocimiento de un campo disciplinar específico constituyó las bases para que se problematice qué contenidos de las CC son las constituyen al PC y las formas de su enseñanza.

Este marco se vio condicionado por la inexistencia de espacios curriculares propios para el desarrollo de contenidos específicos y el auge de la integración de las TIC como forma legitimada de trabajo en escuelas. Lo que dio lugar para pensar las formas transversales de su enseñanza, situación que en la actualidad existe. En este marco las CC se encuentran frente 
al desafío de reflexionar sobre las formas en que se constituye el campo desde la transmisión de saberes legitimados como un arbitrario cultural plasmado en un currículo de contenidos específicos.

La enseñanza de la Informática y su incorporación en las currículos de la educación escolar obligatoria han sido abordadas en múltiples trabajos de investigación y reportes

gubernamentales como ACM \& CSTA (2010), Bocconi et al. (2016), The Royal Society (2012), Informatics Europe and ACM Europe (2013), Fundación Sadosky (2013), Echeveste et al. (2016), Zapata Ros M., (2015), Adell et al. (2019) y Denning (2017). En ellos se discute la necesidad de dotar a las ciudadanas y ciudadanos de los conceptos, habilidades y actitudes para desarrollar una competencia digital crítica, entendiendo que el dominio de las tecnologías digitales, actualmente se vincula con dinámicas de inclusión/exclusión social.

La enseñanza de la programación resolvió en algún sentido esta cuestión, posicionándose como contenido y como estrategia de enseñanza, a la vez. Fue así que en las primeras consideraciones se establece la comparación entre programación y PC. Sin embargo, los nuevos aportes que ya se han realizado en este capítulo sobre la enseñanza de la programación, recupera el desarrollo de alguno de los elementos constitutivos del PC como abstracción, resolución de problemas, trabajo colaborativo, entre otros; pero no son lo mismo, o para ser más precisos, no lo determina.

\subsubsection{Tensión entre la enseñanza de la programación y la alfabetización digital}

El reconocimiento de una nueva brecha digital que es la que Tim Berners-Lee (Bell, 2013) denominó segunda brecha digital separa a las personas que saben programar de aquellas cuyas habilidades informáticas se limitan, simplemente, a usar instrumentalmente las computadoras y manejar fluidamente aplicaciones. La vacancia de profesionales con competencias de programación en el sector productivo y el auge de los software de programación para niños (lenguajes de programación visuales basados en bloques) generan un escenario social donde la enseñanza de la programación se legitima y gana espacio en el desarrollo de experiencias y eventos. Ideas sobre la programación desde enfoques de la 
complejidad, explican que programar no significa simplemente codificar en un lenguaje de programación, sino saber programar abre el camino al pensamiento computacional y esto implica aprender a resolver problemas aplicando conceptos propios de la Informática como abstracción y descomposición (Wing, 2006). A su vez, las competencias que se adquieren mediante el pensamiento computacional pueden impactar positivamente en otras áreas disciplinares independientes de la informática (NRC, 2012) y convertirse en un habilitador para entender e intervenir en un mundo cada vez más tecnológico, permitiendo crear artefactos tecnológicos (Brennan K et al., 2012). Este enfoque se sostiene sobre una fuerte necesidad de curricular la enseñanza de las CC en materias basadas en programación.

A partir de esta situación, emerge la discusión sobre si el campo de las CC se representa en la enseñanza de la programación y la respuesta frente a eso es otro enfoque para el desarrollo de los contenidos de CC, más asociado a la transversalidad y que tiene que ver con el abordaje de una alfabetización digital. Esta corriente se asocia al desarrollo de competencias, fuertemente ligado al concepto de competencia digital en el que los contenidos son significativos en relación a las habilidades que promueven, la programación está integrada junto a otros contenidos considerados de relevancia como la seguridad digital, la robótica y ciudadanía digital.

Ambos puntos de vista convergen en la importancia del fortalecimiento de procesos que desarrollen el pensamiento computacional desde los niveles iniciales de la enseñanza (Resnick, 2011; Zapata-Ros, 2015; Valverde et al., 2015). Lo que implica que estas posiciones sean consideradas una lucha sobre los contenidos legitimados para un campo o una tensión entre dos perspectivas sobre su enseñanza. Las iniciativas gubernamentales proveen el marco necesario para incorporar la enseñanza de la programación en el aula de la escuela, sin embargo, el principal obstáculo que se manifiesta, es que requiere de un acompañamiento a los docentes, dado que rara vez los mismos tienen una formación en esta temática. Debido a ello se fortalecieron, en los últimos 10 años, las líneas de investigación trabajan en el diseño de enfoques de intervención en relación con la incorporación del pensamiento computacional en la escuela a través de la programación, así como en la evaluación del desempeño de los estudiantes en las dimensiones del pensamiento 
computacional. Los enfoques adoptados mayoritariamente consisten en la incorporación de actividades y herramientas didácticas cercanas al mundo de los/as niños/as y adolescentes.

Ambos enfoques coexisten en la actualidad, generando todo tipo de desarrollos desde experiencias con TIC y robótica hasta eventos que convocan centenares de estudiantes para el desarrollo de desafíos de programación. La necesidad de establecer el contrapunto o mejor dicho un escenario de tensión entre ambos es la visibilización de la disputa de un campo disciplinar (CC) por ser integrado en los diseños de la educación en todos sus niveles y que en esa búsqueda establece formas distintas a través de experiencias.

\subsection{Conclusiones}

En este capítulo se analizaron las posiciones pedagógicas que dan cuenta de un anclaje basado en la interdisciplinariedad para el desarrollo de propuestas críticas sobre los procesos educativos, más allá de los contenidos específicos. En este sentido se reconoce un aporte en la recuperación de categorías de la pedagogía y la comunicación para dar respuesta a la complejidad de un mundo digital que necesita un marco disciplinar y ético para la formación de sujetos críticos.

De las lecturas realizadas se considera a las pedagogías críticas porque permiten considerar el abordaje de las prácticas educativas desde una perspectiva que desarrolla el concepto de mediación ${ }^{10}$ entendido como los lugares donde los sujetos participan e interactúan comunicacionalmente desde una dimensión política y una perspectiva cultural, siempre de acuerdo con las exigencias de las circunstancias (Martín Barbero, 1998). Este lugar dialógico reflexivo constituye un elemento central en la articulación que en esta tesis se propone entre Comunicación, Educación y CC, pues, propone una mirada epistemológica que, sobre la base de una pedagogía crítica, aporte elementos que redefinen las prácticas educativas de un campo emergente, como lo es el PC.

\footnotetext{
10"Las mediaciones son los lugares de donde provienen las contradicciones que delimitan y configuran la materialidad social y la expresividad cultural" (Martín Barbero,1998, p. 297).
} 
Las CC se encuentran en un proceso de reivindicación de los procesos educativos, asumiendo la potencia de los contenidos que le competen a nivel disciplinar en la complejidad de los procesos educativos. Este escenario involucra la reflexión sobre las herramientas de un campo para pensar problemas que no le son propios, pero que en la dinámica de movimientos culturales y sociales le competen, por ejemplo, la formación para el desarrollo de la competencia digital de los ciudadanos o la nueva alfabetización digital. 


\section{Capítulo 4: Pensamiento computacional, competencias y nuevas profesiones}

\subsection{Competencias}

La pregunta que motiva el desarrollo de este capítulo tiene que ver con la formación por competencias y su relación con la educación y el trabajo. El análisis sobre las competencias constituye una perspectiva controversial en el campo de la pedagogía, disciplina fundamental en el desarrollo profesional que, además, guarda relación con la adquisición de saberes y con el desarrollo de habilidades.

El concepto de competencia en educación constituye una red conceptual amplia que hace referencia a una formación integral del ciudadano a partir de un enfoque que resalta el aprendizaje significativo en diversas áreas: cognoscitiva (saber), psicomotora (saber hacer, aptitudes) y afectiva (saber ser, actitudes y valores). Involucra todo un conjunto de capacidades que se desarrollan a través de procesos que conducen a la persona responsable a ser competente para realizar múltiples acciones (sociales, cognitivas, culturales, afectivas, laborales, productivas), mediante las cuales proyecta y evidencia su capacidad de resolver un problema dado en un contexto específico y cambiante (Beneitone et al., 2007, p. 36).

Las competencias se constituyen por diferentes niveles y estos se relacionan con: 1) saber: comprendido dentro de los procesos de adquisición de datos, conocimientos, conceptos, etc.; saber hacer: asociado a las habilidades, destrezas y métodos de actuación; y 3 ) saber estar: nivel que comprende las capacidades relacionadas con la comunicación interpersonal y el trabajo. A partir del reconocimiento de estos niveles, se comprende que una competencia es más que un conocimiento, se remite más a la adquisición de un saber que se pone en práctica, siendo necesario desarrollar habilidades relacionadas con las emociones humanas, lo que hace de la competencia un sistema complejo. Así, se reconoce que "las competencias son mucho más que un saber hacer en contexto, pues van más allá del plano de la actuación e implican compromiso, disposición a hacer las cosas con calidad, raciocinio, manejo de una fundamentación conceptual y comprensión.” (Tobón et al., 2016, p.100). 
Este enfoque destaca la complejidad, se reconoce la necesidad de analizar las competencias en relación con el contexto, los saberes y las relaciones humanas para su desarrollo en todos los ámbitos de la vida cotidiana. Al respecto Tejada Zabaleta (2007) aclara:

(...) la forma más acertada de enfrentar el concepto de las competencias que vaya más allá de lo cognitivo o lo laboral y que se centre en la comprensión del ser competente como una forma de vivir, de allí que parecería más conveniente el concepto de formar competencias para la vida. (p.42)

Este autor estudia dos formas de comprender las competencias: una perspectiva estructural y una perspectiva funcional. Sobre la primera, desarrolla los elementos que la componen, explica a partir de las siguientes tres dimensiones: sentir, preferir y saber, que estas son constitutivas de la identidad y de la disponibilidad para la acción:

Se pueden integrar otros elementos fundamentales, generando una estructura aún más compleja, como son el saber (conocimiento), el sentir (los afectos y emociones) y el hacer (la acción), para constituir un todo integrado que, conjuntamente con el papel y función del contexto y los procesos de interacción que posibilitan la construcción y organización del conocimiento adquirido, configuraran una estructura básica que al conjugar las diferentes dimensiones constituyen la condición de ser." (Tejada Zabaleta, 2007, p.43)

Este autor asegura que estas dimensiones interactúan y se relacionan como un todo complejo entre sí y con el contexto, el cual, a su vez, se encuentra condicionado histórica, jerárquica, situacional y físicamente. Por otro lado, esas dimensiones (sentir, preferir y saber) mantienen:

(...) relaciones biunívocas, de interinfluencias entre todos los elementos del sistema y de la estructura, que es lo que posibilita que el conocimiento se adquiera, se fortalezca, se mantenga y se autorregule a través de los principios, procesos y procedimientos del aprendizaje. (Tejada Zabaleta, 2006, p. 20)

Sobre la segunda de las perspectivas, la denominada funcional, se reconocen los procesos implicados en la formación y desarrollo de una competencia. Aquí se reconocen tres elementos principales: conocimiento, aprendizaje y competencias, y se hace hincapié en las 
múltiples interrelaciones, reconociendo diferentes niveles de desarrollo de competencias. Estas interrelaciones posibilitan el reconocimiento de diferentes niveles de aprendizaje y de desarrollo de competencias. Sobre estos procesos y las estructuras, Tejada Zabaleta (2007) sostiene:

El interjuego dialéctico y permanente entre la reflexión y la acción, podrá ser mejor entendido desde una perspectiva de la complejidad, la flexibilidad, la integración y la totalidad. Y ese interjuego debe ser definido y caracterizado en la conjugación métodos los elementos, procesos, condiciones, etc., que constituyen una competencia. (p.47)

Pensar en competencias y sus múltiples definiciones resulta una tarea compleja para la cual es necesario tomar algún criterio que ayude a la selección de materiales. En este caso se rescatan aportes en relación con los ámbitos en los cuales se promueve su desarrollo, fundamentalmente educación y trabajo. Estos ámbitos son los principales espacios desde los cuales se recupera la noción de competencias para pensar la formación de los sujetos. En su tesis doctoral, Isabel Fernández Solo (2015) explica:

Las competencias se ponen en acción en un determinado contexto, y este puede ser educativo, social, laboral o científico, entre otros; la responsabilidad se refiere a analizar antes de actuar las consecuencias de los propios actos, respondiendo por las consecuencias de ellos una vez se ha actuado, buscando corregir lo más pronto posible los errores. En las competencias, toda actuación es un ejercicio ético, en tanto siempre es necesario prever las consecuencias del desempeño, revisar cómo se ha actuado y corregir los errores de las actuaciones, lo cual incluye reparar posibles perjuicios a otras personas o a sí mismo. El principio en las competencias es entonces que no puede haber idoneidad sin responsabilidad personal y social. (p. 113)

En esta tesis se abordará el concepto de competencia desde una perspectiva compleja, en tanto nos permita sostener el enfoque pedagógico crítico abordado en el capítulo anterior, así como incluir los trabajos que analizan las competencias relacionadas con el pensamiento computacional y con la formación para el futuro. En este orden de ideas y a modo de síntesis, se toma la definición de Pérez Gómez (2012), en la que explica: 
Para mí, las competencias son sistemas complejos, personales, de comprensión y de actuación; es decir, combinaciones personales de conocimientos, habilidades, emociones para articularlas desde la complejidad, valores que orientan la interpretación, toma de decisiones y la actuación de los individuos humanos en sus interacciones con el escenario en el que habitan, tanto en la vida personal, social como profesional. Las competencias implican la capacidad y el deseo de entender, analizar, proponer, desarrollar y evaluar. (p.145)

Sobre este enfoque de competencia, se comprende el planteamiento realizado por ZapataRos respecto del PC como nueva alfabetización. A partir de esta conceptualización, el autor reconoce catorce habilidades que son constitutivas del PC: análisis ascendente, análisis descendente, heurística, pensamiento divergente, creatividad, resolución de problemas, pensamiento abstracto, recursividad, iteración, métodos por aproximaciones sucesivas (ensayo-error), métodos colaborativos, patrones, sinéctica y metacognición. Tal como se muestra en la siguiente figura: 


\section{Figura 2}

Habilidades del PC

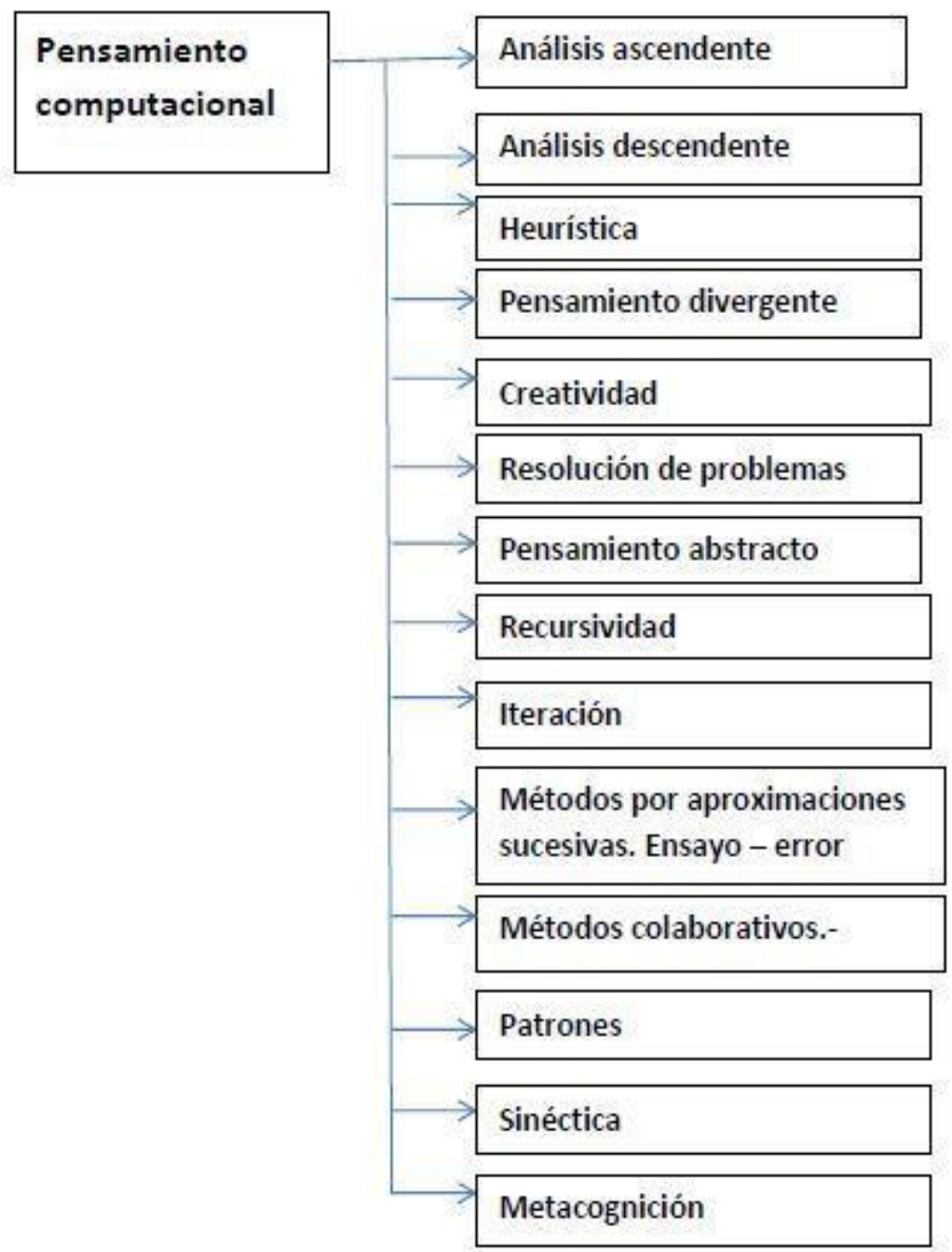

Nota. Adaptado de Pensamiento computacional: Una nueva alfabetización digital (p. 13), por Zapata-Ros, 2015, RED (Revista de Educación a Distancia).

Sobre este esquema, el autor plantea que el PC constituye una competencia clave en la nueva alfabetización digital, constituida por las competencias que permiten a los individuos desarrollar las funciones de comunicación, representación y proceso de la información en la cultura epistemológica que implica la Sociedad del Conocimiento. 


\subsection{Competencias en educación}

El tema de las competencias en los ámbitos educativos no es nuevo, muy por el contrario, se encuentran muchos trabajos sobre los diferentes enfoques y posicionamientos. La disputa por los sentidos del término dan como resultado dos grandes perspectivas: la conductista y la constructivista, que desde su aparición en los 70 se constituye como un tema debate que recupera las problemáticas del currículum y el mundo laboral. Sobre esto, Pérez Gómez (2007) afirma:

Es cierto que el término competencias es polémico y alude a un campo semántico brumoso. Se deriva de una tradición claramente escorada a la interpretación conductista del aprendizaje y comportamiento humanos, por lo que exigirá estar atentos y detectar los inevitables influjos mecanicistas que se infiltrarán en el desarrollo de esta propuesta a nivel nacional, regional y local. (p.10)

La corriente conductista en educación ve la competencia como habilidad, restringida al carácter individual y sin relación con el contexto sociocultural en el que esta se ponga en práctica. Los comportamientos aquí son observables, las conductas son concebidas aisladas, de manera independiente y son consideradas agrupables bajo el lema "todo es igual a la mera suma de las partes" (Pérez Gómez, 2012, p.144)

Esta concepción sobre la competencia es limitada a la hora de pensar su potencialidad educativa. En este sentido, el autor plantea tres elementos (Pérez Gómez, 2012, p. 142) para su consideración: el primero asociado a la fragmentación que se realiza sobre los comportamientos y la conducta; habla de micro competencias, haciendo alusión a esta separación. En segundo de los elementos se refiere a la concepción mecanicista y lineal de las relaciones entre estas micro competencias, y, por último, destaca la necesidad de sumar micro competencias para la obtención de comportamientos más complejos. Este tipo de enfoques sobre la competencia en educación se vio relacionado fundamentalmente al lema educar para el trabajo, corriente que en la década de los 70 promulgaba la necesidad de una escuela que se vincule con el sector productivo a partir de la preparación para el empleo y el desarrollo profesional como lo testimonian Díaz Barriga, Arceo y Rigo (2000). 
Los enfoques socioconstructivistas, en cambio, reconocen que la educación basada en competencias concierne a una experiencia práctica que se vincula con los conocimientos para lograr una intención. Así, la teoría y la experiencia práctica convergen con las habilidades y los valores, utilizando la teoría para aplicar el conocimiento a la construcción o desempeño de algo. Es necesario facilitar el desarrollo de las habilidades, la madurez de los hábitos mentales y de conducta que se relacionen con los valores universales. Es preciso asegurarse de que el fin y centro del aprendizaje sea el alumno, reforzando el desarrollo del pensamiento crítico del estudiante con objeto de que este cuente con herramientas que le permitan discernir, deliberar y elegir libremente, de tal forma que en un futuro próximo pueda comprometerse en la construcción de sus propias competencias.

En un nivel más general, Vigotsky (1985) define competencia como “acciones situadas que se definen en relación con determinados instrumentos mediadores" (Hernández et al.,1998, p. 14; Tobón et al., 2006). Dichas acciones se dan a partir de la mente y esta se construye en relaciones sociales, siendo fuertemente influida por la cultura. Noam Chomsky (1957) propuso el concepto de competencia lingüística y lo definió como una estructura mental implícita y genéticamente determinada que se ponía en acción mediante el desempeño comunicativo, es decir, se refería al uso efectivo de la capacidad lingüística en situaciones específicas (Omaggio, 1993).

En 1971, Hymes definió competencia comunicativa como el empleo efectivo del lenguaje en situaciones específicas, teniendo en cuenta determinantes del entorno y situando esta como base de la interacción del individuo con el medio. Según este autor, la competencia comunicativa es la capacidad de formular reglas pragmáticas en la gramática, esto es: que el individuo no tenga sólo la capacidad de construir expresiones gramaticales “correctas", sino también de usar tales expresiones adecuadamente en alguna situación comunicativa (Van Dijk, 1980). Estos desarrollos ponen en evidencia otro sentido sobre la competencia al considerarla como sistema complejo. A partir del desarrollo y definición de la competencia lingüística, se comprende la capacidad de un individuo para comunicarse en determinadas situaciones problemáticas, siendo influida, en gran medida, por la cultura y el contexto.

Sobre este enfoque de complejidad, Tobón et al. (2006, p. 1) explica: "Las competencias son un enfoque para la educación y no un modelo pedagógico”. Para este autor, estas se focalizan 
en tres aspectos específicos: 1) la integración de los conocimientos, los procesos cognitivos, las habilidades y los valores, ante los problemas; 2) el diseño de programas de formación con base en los requerimientos contextuales; y 3) la orientación de la educación por medio de estándares e indicadores de calidad en todos sus procesos. Es importante resaltar que el impacto del reconocimiento de la competencia como potenciadora de los currículos configura las formas de pensar respecto de las funciones de la escuela y los modelos didácticos tradicionales.

En consonancia con lo que se plantea en este apartado, resulta pertinente destacar el aporte del Proyecto Alfa Tuning, coordinado por universidades de distintos países, tanto latinoamericanos como europeos, y que está orientado a "identificar e intercambiar información y mejorar la colaboración entre las instituciones de educación superior para el desarrollo de la calidad, efectividad y transparencia”. Reconoce en su informe del año 2007 , que las competencias se pueden distinguir entre específicas y genéricas. Así, se reconoce plenamente la importancia de desarrollar conocimientos y habilidades específicas de cada campo como base para los currículos. Sin embargo, se hace foco en la importancia de las “competencias genéricas o habilidades transferibles", estando ligada la necesidad de desarrollo a la formación de los estudiantes para su futuro papel en la sociedad en términos de empleabilidad y ciudadanía (Beneitone et al., 2007).

El informe Tuning (2007) reconoce tres tipos de competencias genéricas, que son de carácter transversal y técnicamente deberían presentarse en cualquier graduado universitario. El primer grupo son las competencias instrumentales, dentro de las cuales se reconocen las habilidades cognitivas, las habilidades metodológicas, las habilidades tecnológicas y las habilidades lingüísticas. En el segundo grupo se destacan las competencias interpersonales, integradas por tanto por habilidades individuales como las habilidades sociales (interacción social y cooperación). Finalmente, en el tercer grupo aparecen las competencias sistémicas, entendidas como habilidades y destrezas, relacionadas con sistemas completos (combinación de comprensión, sensibilidad y conocimiento; además de requerir adquisición previa de competencias instrumentales e interpersonales).

Este proyecto además de los aportes y conclusiones a las que remite representa el avance de la comunidad educativa mundial respecto del tratamiento y el rol de las competencias en los 
planes de estudios. Si bien este proyecto analiza carreras universitarias, su impacto es legible también en otros ámbitos educativos como por ejemplo la escuela secundaria. La legitimidad del concepto de competencia resulta innegable, dado por la necesidad explícita de los países de pensar políticas educativas que atiendan el desarrollo de las mismas apostando a los nuevos condicionamientos culturales incluido el ambiente laboral.

En este sentido, Pérez Gómez (2007) plantea esta problemática y explica:

Los sistemas educativos afrontan, en las democracias actuales, dos grandes retos que están íntimamente relacionados: por un lado, consolidar una escuela comprensiva que permita el máximo desarrollo de las capacidades de cada persona, respetando la diversidad y asegurando la equidad de acceso a la educación y compensando las desigualdades; por otro, favorecer la formación de sujetos autónomos, capaces de tomar decisiones informadas sobre su propia vida y de participar de manera relativamente autónoma en la vida profesional y social. (p. 7)

Abordar las competencias en educación resulta indispensable para este trabajo en tanto se pretende comprender y aportar al desarrollo de estrategias que potencien su desarrollo en los ámbitos educativos. Comprender el sentido amplio del concepto de competencias y diferenciarlo de una mera sumatoria de acciones, nos permite reconocer y entender al PC como competencia clave y problematizar su potencia educativa y múltiples direccionalidades.

\subsection{Competencias digitales y nuevas profesiones}

El concepto de competencia digital es utilizado en la actualidad en relación a las habilidades necesarias para el S.XXI. La competencia digital aparece entendida como actitud y capacidad para utilizar adecuadamente las herramientas para identificar, acceder, integrar, gestionar o evaluar los recursos digitales. A su vez se desprende esta idea de los enfoques instrumentales, en tanto se evoca una "conciencia" sobre los procesos que permite construir nuevos conocimientos, expresarse con diferentes medios y comunicarse (Martin, 2008; Esteve y Gisbert, 2013). La competencia digital, definida en la Recomendación del Parlamento Europeo y del Consejo sobre las competencias clave para el aprendizaje permanente (2006): 
(...) entraña el uso seguro y crítico de las tecnologías de la sociedad de la información (TSI) para el trabajo, el ocio y la comunicación. Se sustenta en las competencias básicas en materia de TIC: el uso de ordenadores para obtener, evaluar, almacenar, producir, presentar e intercambiar información, y comunicarse y participar en redes de colaboración a través de Internet. (p.13)

Así también la definen Calvani et al. (2008), quienes sostienen:

Ser capaz de explorar y enfrentar las nuevas situaciones tecnológicas de una manera flexible, para analizar, seleccionar y evaluar críticamente los datos e información; para aprovechar el potencial tecnológico con el fin de representar y resolver problemas, y construir conocimiento compartido y colaborativo, mientras se fomenta la conciencia de sus propias responsabilidades personales y el recíproco respeto de los derechos y obligaciones. (p.186)

Para el desarrollo de este trabajo, se comprende la competencia digital desde la perspectiva de complejidad propuesta por Pérez Gómez (2012) y Tobón et al. (2006); el componente digital marca la especificidad de una época y una cultura. Sin embargo, la adopción del término refiere a la necesidad de entender a la alfabetización digital no solo como la adquisición de determinados saberes y habilidades, sino que remite al desarrollo de la competencia digital.

En este punto, la articulación entre PC, alfabetización digital y competencia digital no es un comparativo de sinónimos sino una articulación imprescindible de procesos cognitivos que los sujetos críticos de esta época deben desarrollar. El pensamiento computacional como competencia clave se constituye de las competencias digitales en un proceso de alfabetización digital. Esas competencias digitales no tienen que ver con el uso y destreza de los elementos tecnológicos sino con la comprensión de ciertas lógicas de producción y apropiación.

El avance de las transformaciones tecnológicas y su impacto en los modos de producir y consumir dan lugar a nuevas ocupaciones en el mercado laboral. Aunque la tecnología ha hecho que ciertas ocupaciones sean casi obsoletas, también ha creado una gran cantidad de 
nuevas carreras que ni siquiera existían hace una década. Estas nuevas profesiones son uno de los motivos que preocupan respecto de la formación en estos tiempos.

El proceso iniciado a partir de los años 80 consolidó las bases de un nuevo paradigma productivo, basado en la automatización, robotización, programación, la informatización de las finanzas, de la administración pública y privada, en la incorporación de la teleinformática y la bioingeniería en los diversos procesos productivos. La evidente centralidad de los procesos comunicativos e informativos en dichas transformaciones no es menor. Consecuencia de ello son hoy Internet, las fibras ópticas, el ciberespacio, la inteligencia artificial, la realidad virtual, etc., que van señalando nuevas competencias que implican actuar en el mundo contemporáneo en cuanto a conocimiento, reflexión y habilidades.

Desde estas lógicas es importante analizar sus diversas dimensiones, las formas en que la revolución científico tecnológica impacta en la sociedad por ende en el mundo del trabajo. Estos diagnósticos son fundamentales de considerar para cualquier diseño curricular. En tanto un currículum es considerado como una hipótesis de intervención social, mediada por la educación. Las transformaciones que inicia la era postindustrial son en realidad una totalidad. Abarcan el conjunto de los órdenes de la vida. Comprender sus consecuencias a la hora de pensar los diseños curriculares, la creación de nuevas carreras y profesiones. De aquí se desprende que sea importante reconocer cuáles son los signos de este nuevo mapa de realidad que, desde lo tecnológico, lo cultural, lo social y lo político, constituyen a los futuros trabajadores y profesionales.

Como consecuencia de la cuarta revolución industrial (Scolari, 2018) el proceso de automatización de los procesos productivos de bienes y servicios y el desarrollo de la inteligencia artificial se está generando una sustitución del empleo humano en ocupaciones que desarrollan actividades manuales y cognitivas sean estas rutinarias o no. A su vez los ciudadanos incorporan nuevas habilidades y promueven cambios en la forma de concebir a los empleos. En este sentido, la transformación en las lógicas de concepción del empleo y nuevos modos trabajar, es evidente. Ejemplo de ello son las modalidades de co-working (trabajo colaborativo), del trabajo en el hogar y la flexibilidad en su vinculación con las empresas; todas estas formas generan transformaciones que impactan en todas las generaciones y ámbitos laborales. 
Se reconocen características que deberán promover las denominadas "nuevas profesiones" como son: adaptabilidad, flexibilidad, autoaprendizaje, capacidad de reciclaje, habilidad multidisciplinar, capacidad de innovar, creatividad, habilidades de comunicación y de interrelación, capacidad para el análisis y la interpretación de datos, emprendedorismo y competencias interculturales.

Estas habilidades, requeridas por nuevas dinámicas laborales, son recuperadas para penar los procesos de formación de los profesionales. En este sentido, se ha dado la transformación del sistema educativo hacia alternativas con mayor flexibilidad y dinámica ante el cambio acelerado que imponen las nuevas tecnologías. El sistema educativo universitario por créditos es una de las alternativas cuya aceptación es bastante generalizada en cada vez más universidades del mundo y el diseño del currículum por competencias. Algunos nuevos puestos laborales como productores de contenido híbrido, gerentes de conocimiento digital y desarrolladores web multilingüe, analistas de datos, reflejan el impacto digital en la industria del marketing digital por mencionar un campo de desarrollo.

La revolución científica-tecnológica promueve configuraciones en lo laboral que necesariamente se deben atender a la hora de construir el currículum. Sin embargo, los impactos de esta revolución, no solo están relacionados entre sí, sino que además profundizan la segmentación social, ya que no es posible desconocer los circuitos diferenciados en cuanto al consumo y las reestructuraciones o tensiones que ocasiona. El currículum tiene que reflejar las transformaciones que la tecnología produce en el campo profesional, provocando nuevas instancias de conocimiento, habilidades y competencias, y además tiene que dar cuenta de la reestructuración de las percepciones, la necesaria adecuación de las competencias lingüísticas y de las competencias técnicas, la problematización y tensión entre interactividad e interacción comunicativa, las nuevas formas de consumo, en tanto uso y apropiación de las innovaciones tecnológicas.

La necesidad de nuevas habilidades relacionadas con el mundo digital para el trabajo es un aspecto a articular en esta tesis sin perder el eje en los procesos educativos. Se parte de considerar al trabajo como otro ámbito de sociabilidad y por ello su relevancia. A su vez se comprende que el enfoque de competencias para el desarrollo del pensamiento computacional abarca y contiene esta urgencia. 


\subsection{Conclusiones}

En este capítulo se consultan y analizan los trabajos académicos que contribuyen al abordaje del concepto de competencia en educación, recuperando el desarrollo de una línea de intervención que no es nueva, pero que cobra relevancia en relación al pensamiento computacional. El desarrollo de este capítulo propone el abordaje de las competencias en educación desde un enfoque complejo y humanista que reconoce la incidencia de los procesos educativos en su interrelación indisociable de los contextos que rodean al sujeto. Desde ese lugar se piensan la formación en competencias.

Asimimo, se analizan documentos que desarrollan ideas sobre las competencias en educación desde una perspectiva crítica y se reconocen las características específicas de un sistema de educación que es y ha sido particular (UE), por su desarrollo a partir de las competencias. En este sentido, y en función de los documentos analizados en este capítulo, se puede identificar que la idea de competencia digital guarda estrecha relación con la necesidad de identificación y reconocimiento del desarrollo digital en la vida de las personas. La UE define y establece una competencia específica que sea la base para el desarrollo de los procesos educativos en la región, la competencia digital.

La bibliografía consultada en este capítulo fue seleccionada en función de poder establecer relaciones que contribuyan a pensar al PC como competencia digital. Se recupera de lo estudiado una articulación de elementos que constituyen tanto al PC como a la competencia digital, atendiendo a los procesos complejos que, desde una perspectiva constructivista, abonan su desarrollo y problematizan su funcionalidad en un mundo (especialmente lo laboral) donde lo digital es un innegable vector transversal de todas las dimensiones micro y macro escala. Sobre esta base conceptual, se analizan los documentos seleccionados en el capítulo siguientes intentado reconocer al PC en ellos, a la competencia digital y los procesos de integración de ambos, en los diseños curriculares. 


\section{Capítulo 5: Políticas educativas europeas que incluyen principios del pensamiento computacional}

\subsection{Introducción}

Las políticas públicas en general, y las políticas educativas en particular, representan el conjunto de decisiones gubernamentales que buscan modificar uno o varios de los componentes de un sistema y de la relación entre ellos (salud, vivienda, desarrollo rural/urbano, educacional, etc.) con el propósito de producir cambios o nuevos equilibrios en el sistema. Estos componentes tienen que ver con insumos, procesos y resultados, así como también con actores, instituciones y sus relaciones que se producen en un contexto determinado.

Los instrumentos de políticas públicas ${ }^{11}$ a través de los cuales se pretende el desarrollo de diversas propuestas, como en el ámbito educativo, son fundamentalmente de cuatro tipos:

1. Normativo: hace referencia a la creación o supresión de leyes, normas o reglamentaciones específicas.

2. Financiero: relacionado con la asignación o supresión de recursos.

3. Institucional: creación, modificación o supresión de instituciones, programas o proyectos.

4. De consensos: entre los actores que participan en la modificación de las prácticas.

Estos instrumentos de políticas públicas no son excluyentes entre sí y no se producen en el vacío, se construyen a partir de escenarios complejos en los cuales se manifiesta y se contraponen la diversidad de intereses, motivaciones y comprensiones de distintos actores sociales y políticos implicados. Sin embargo, la definición y diseño de las políticas educacionales, constituyen un proceso diferente, pues confluyen en su realización motivos e intereses, experiencia y conocimientos de actores (sociales e individuales) de diferente procedencia.

\footnotetext{
${ }^{11} \mathrm{Si}$ bien esta clasificación es genérica, hemos tomado la expuesta por Zorrilla (2010).
} 
En tal sentido, Muñoz Izquierdo (2002) explica que:

(...) es necesario que nuestros estudios se adelanten a los cambios educativos; lo que implica rebasar en todo momento los intereses y necesidades inmediatos de los tomadores de decisión. De este modo, la investigación “iluminará” la realidad desde nuevos ángulos y permitirá descubrir nuevos problemas, así como las causas y consecuencias de los mismos. Además, debemos contribuir a preparar las plataformas que son necesarias para el cambio educativo y someter constantemente a prueba, nuestros paradigmas y propuestas de solución. (p.18)

\subsection{Análisis de documentos de la Unión Europea}

En esta tesis se trabaja sobre los marcos normativos de la Unión Europea (UE) sobre educación, tecnologías y trabajo. Se intenta relevar y sistematizar los argumentos y fundamentaciones que sobre estas áreas promueven líneas de acción concretas y que impactan en el diseño y conformación de las políticas educativas de los países miembros de la UE. Se analizan las referencias y apariciones textuales sobre PC para analizar su incorporación, desarrollo de contenidos, acciones sobre tecnologías, cultura digital, programación y robótica educativa. A su vez, se trabajan las líneas estratégicas de acción sobre educación digital en pos de su análisis y en relación con el concepto de alfabetización digital.

En los últimos 20 años, la UE, atendiendo a los nuevos retos de la sociedad de la información, ha implementado políticas tanto a nivel europeo, como nacional y regional, destinadas a la integración de las tecnologías en los sistemas educativos. Estas políticas, conscientes de que necesitan buenos sistemas educativos, con modernas herramientas tecnológicas, entre otros aspectos, han incidido en la alfabetización digital de los ciudadanos y en facilitar posibilidades de aprendizaje permanente que propician alcanzar unos niveles educativos básicos y polivalentes que permitan el progreso económico, la cohesión social y el desarrollo democrático. Las primeras referencias a la importancia que tiene la educación en la sociedad de la información, las encontramos en el informe Europa y la sociedad mundial de la información (1996) y en el Libro Blanco sobre la Educación y la formación. Enseñar y 
aprender, hacia la sociedad cognitiva (Comisión de las Comunidades Europeas, 1995). En el primero, se hace alusión a la necesidad de formar y alfabetizar informáticamente al profesorado; y en el segundo, se dice:

Lo ideal sería llegar a dotar a cada clase de los equipos necesarios para que los jóvenes accedan a la informática. Esto implica, concretamente, que Europa se dote de nuevos instrumentos pedagógicos de calidad, adaptados a sus tradiciones educativas y culturales. (Comisión de las Comunidades Europeas, 1995, p.32.)

También se reconoce el papel central del profesorado y la necesidad de modificar sus prácticas pedagógicas, de forma que los individuos sean capaces de desarrollar un sentido crítico que les permita protegerse de la manipulación e ideologías dominantes de los “profesores salvajes” como los medios de comunicación y las redes informáticas.

La Comisión Europea, órgano ejecutivo de la UE, ha insistido en el desarrollo de líneas prioritarias para que los países miembros las cumplan como políticas de Estado para el período 2019-2024. Se establecen las siguientes prioridades:

- Un acuerdo Verde Europeo

- Una economía que funcione para las personas

- Una Europa apta a la era digital

- Promoción de nuestro modo de vida europeo

- Una Europa más fuerte en el mundo

- Nuevo impulso para la democracia europea.

Estas líneas de desarrollo prioritario marcan la agenda respecto de las temáticas que delimitan un campo de acción posible. El período en el cual se prevé su desarrollo corresponde a los cinco años que van desde 2019 hasta 2024, en tal sentido, nos encontramos iniciando dicho período de ejecución, por ende, los documentos sobre estas prioridades aún son aproximaciones.

De las treinta y ocho temáticas que se trabajan en la Comisión Europea, se seleccionó Educación y Formación por ser la más pertinente para el tipo de problemática que en esta investigación se plantea. Sin embargo, cabe destacar que existen otras temáticas que abordan 
transversalmente ejes relacionados con innovación, desarrollo tecnológico y formación para el trabajo, pero que al no tratar el problema de la enseñanza directamente, no fueron analizados en la presente investigación.

Dentro del eje Educación y Formación se desarrollan políticas de acción que contienen los principales marcos, programas y planes que la UE valida en apoyo a los países miembros, funcionando de esta manera como un marco de orientaciones y posicionamientos pedagógicos, políticos, técnicos y didácticos. Las políticas dentro del eje Educación y Formación en la actualidad son cinco: Educación Superior; Aprendizaje de Adultos; Política

Educativa; Educación y Formación de Profesionales y Cooperación Internacional en Educación y Formación.

Para el análisis de las políticas educativas de la UE, se seleccionan las que se enuncian a continuación, sobre las cuales se desarrolló un proceso de identificación y sistematización que permitió la realización de un análisis, basado en la posible presencia del PC como competencia compleja para pensar una nueva la formación en un mundo digital. El criterio de ordenamiento que se establece es el cronológico:

1. Nuevo marco de referencia de competencias para el aprendizaje permanente

2. Agenda de habilidades para Europa

3. Agenda digital

4. Europa 2020

5. Plan de acción de educación digital

6. DigComp

7. CompuThink

8. Marco europeo de competencias digitales para docentes

9. Marco de cooperación para la educación y la formación

10. Erasmus + 


\subsubsection{Marco de referencia de competencias para el aprendizaje permanente}

E documento fue publicado en el año 2006 por una recomendación del Parlamento Europeo y del Consejo sobre las competencias clave para el aprendizaje. En el mismo, las competencias se definen como una combinación de conocimientos, capacidades y actitudes adecuadas al contexto. Se definen las denominadas "competencias clave" consideradas como aquellas que "todas las personas precisan para su realización y desarrollo personales, así como para la ciudadanía activa, la inclusión social y el empleo". Las competencias clave son consideradas relevante en este documento, ya que como se afirma en dicho marco, cada una de ellas puede contribuir al éxito en la sociedad del conocimiento. El marco de referencia de competencias para el aprendizaje establece ocho competencias clave que son las siguientes:

1. Comunicación en la lengua materna

2. Comunicación en lenguas extranjeras

3. Competencia matemática y competencias básicas en ciencia y tecnología

4. Competencia digital

5. Aprender a aprender

6. Competencias sociales y cívicas

7. Sentido de la iniciativa y espíritu de empresa

8. Conciencia y expresión culturales

A su vez, en este documento se desarrollan temas que se relacionan con las competencias clave: el pensamiento crítico, la creatividad, la capacidad de iniciativa, la resolución de problemas, la evaluación del riesgo, la toma de decisiones y la gestión constructiva de los sentimientos.

Este marco identifica la competencia digital y es pionero en el desarrollo de características y procesos que relacionan su incorporación en ámbitos educativos. Si bien no aparece 
relacionada al PC de forma explícita, resulta interesante poder describir y analizar lo expuesto en el desarrollo de las competencias 3 y 4, pues consideramos que son relevantes y que es pertinente un análisis en conjunto para su comparación con el PC. Respecto de la Competencia 3: matemática y competencias básicas en ciencia y tecnología, se explica:

La competencia matemática es la habilidad para desarrollar y aplicar el razonamiento matemático con el fin de resolver diversos problemas en situaciones cotidianas. Basándose en un buen dominio del cálculo, el énfasis se sitúa en el proceso y la actividad, aunque también en los conocimientos. La competencia matemática entraña —en distintos grados - la capacidad y la voluntad de utilizar modos matemáticos de pensamiento (pensamiento lógico y espacial) y representación (fórmulas, modelos, construcciones, gráficos y diagramas). (Parlamento Europeo y Consejo, 2006ª p.8)

Más adelante, en el mismo documento, se amplía:

La competencia en materia científica alude a la capacidad y la voluntad de utilizar el conjunto de los conocimientos y la metodología empleados para explicar la naturaleza, con el fin de plantear preguntas y extraer conclusiones basadas en pruebas. Por competencia, en materia de tecnología, se entiende la aplicación de dichos conocimientos y metodología en respuesta a lo que se percibe como deseos o necesidades humanos. Las competencias científica y tecnológica entrañan la comprensión de los cambios causados por la actividad humana y la responsabilidad de cada individuo como ciudadano. (p. 8)

La descripción que se da sobre esta competencia está fundada en el manejo de conocimientos relacionados con el campo de la matemática y la ciencia, dando elementos para la comparación con las habilidades enunciadas por Zapata Ros (2015) como constitutivas del PC. Sin embargo, esta definición se comprende mejor al recuperar la Competencia 4 digital que expresa lo siguiente:

La competencia digital entraña el uso seguro y crítico de las tecnologías de la sociedad de la información (TSI) para el trabajo, el ocio y la comunicación. Se sustenta en las competencias básicas en materia de TIC: el uso de ordenadores para 
obtener, evaluar, almacenar, producir, presentar e intercambiar información, así como comunicarse y participar en redes de colaboración a través de Internet. (p.9)

Tomando como referencia este marco, el PC no aparece explícitamente, pero la unión de estas competencias nos permite visibilizar el proceso complejo a partir del cual se reconocen los múltiples procesos implicados en el desarrollo del PC. La combinación de estas dos competencias permite recuperar elementos de desarrollo cognitivo más relacionados con la adquisición de saberes y al desarrollo de nuevas producciones, asemejándose más a un proceso de metacognición. Al respecto, Michael C. Corballis (2007) considera que "la facultad de pensar sobre el pensar, constituye el atributo crítico que nos distingue de todas las demás especies”. Este aporte que es el proceso de metacognición como elemento constitutivo del PC según Zapata-Ros (2015), despliega una problemática conceptual fundamental, pues la concibe como:

(...) un plan de actuación que implica habilidades y destrezas -que el individuo ha de poseer previamente- y de una serie de técnicas que se aplican en función de las tareas a desarrollar sobre las que el alumno decide y sobre las que tiene una intención de utilizar consciente. Por tanto, lo más importante de esta consideración es que para que haya intencionalidad, ha de existir conciencia de (...) la situación y los recursos (...) En todos estos puntos, decisiones y representaciones, ha de existir, en definitiva, la conciencia de los propios recursos cognitivos con que cuenta el aprendiz. Eso es lo que se ha denominado metacognición. Así pues, no es sólo una estrategia o un conjunto de estrategias. Es la condición necesaria para que pueda darse cualquier plan estratégico. Lo contrario serían simplemente algoritmos o incluso estrategias, pero donde al no haber intencionalidad, no habría la valoración que conlleva la adopción de un plan con previa deliberación de la situación y de los recursos. (p.34)

El reconocimiento de la competencia digital como competencia clave, centra las bases de lo que son sus desarrollos posteriores a la publicación de este trabajo. Es importante resaltar que, en este marco, la competencia digital, no solo se define, sino que propone un análisis en relaciona con su enseñanza. Luego de la publicación de este marco de referencia, dicha competencia está presente en cada uno de los marcos, documentos y propuestas de enseñanza de la UE. 


\subsubsection{Agenda de capacidades para Europa}

Esta política está constituida por diez iniciativas pensadas para trabajar hacia una visión común respecto de la importancia estratégica de las habilidades para mantener el empleo, el crecimiento y la competitividad en Europa. Esta agenda busca el desarrollo de un compromiso compartido para la reforma en varias áreas donde la acción de la Unión Europea aporta el mayor valor agregado. Establece tres líneas de trabajo: 1) mejorar la calidad y relevancia de la formación de habilidades; 2) hacer que las habilidades y calificaciones sean más visibles y comparables y, 3) mejorar las habilidades de inteligencia e información para mejores elecciones de carrera. Así, por ejemplo, se establece en el documento de la Comisión Europea titulado Una nueva agenda de capacidades para Europa (2016):

Europa necesita personas digitalmente inteligentes que no solo puedan usar, sino también innovar y liderar el uso de estas tecnologías. Sin ella, Europa no tendrá éxito en aceptar esta transformación digital. La adquisición de nuevas habilidades es vital para mantener el ritmo de los avances tecnológicos y la industria ya está introduciendo métodos de capacitación innovadores. Los centros de investigación e innovación también pueden ayudar a desarrollar y transferir tales habilidades, actuando como catalizadores para la inversión y para la creación de negocios y empleos. (p. 9)

Esta agenda propone diez acciones concretas -algunas de ellas ya citadas y referenciadas en este trabajo en apartados anteriores- tales son:

1. Caminos de mejora: nuevas oportunidades para adultos

2. Marco europeo de cualificaciones

3. Coalición de habilidades digitales y empleo

4. Plan para la cooperación sectorial en habilidades

5. Herramienta de perfil de habilidades de la UE para nacionales de terceros países 
6. Educación y formación profesional (FP)

7. Competencias clave

8. Europass

9. Seguimiento de graduados

10. Análisis e intercambio de mejores prácticas sobre flujos cerebrales

En esta investigación se reconocen las acciones 3 y 6 . La coalición de habilidades digitales y empleo funciona nucleando instituciones y organizaciones que estén dispuestas a comprometerse con alguna de las siguientes líneas de acción:

- Habilidades digitales para todos: desarrollar habilidades digitales para permitir que todos los ciudadanos sean activos en nuestra sociedad digital.

- Habilidades digitales para la fuerza laboral: fortalecer el desarrollo de habilidades digitales para la economía digital, por ejemplo, mejora de habilidades y actualización de trabajadores, solicitantes de empleo; acciones sobre asesoramiento y orientación profesional.

- Habilidades digitales para profesionales de las TIC: mejorar el desarrollo de habilidades digitales de alto nivel para profesionales de las TIC en todos los sectores industriales.

- Habilidades digitales en educación: transformar el aprendizaje y la enseñanza de habilidades digitales en una perspectiva de aprendizaje permanente, incluida la formación de docentes.

Como vemos a partir de las habilidades descritas, esta estrategia es amplia y reconoce las prácticas educativas como las que promueven el trabajo con las habilidades digitales en todos los ámbitos de desarrollo humano. Aquí no hay reseñas claras sobre el PC, tampoco se nombra la competencia digital, sino que se reconocen las habilidades. Por el análisis realizado, las competencias sobre las cuales se forma dicha coalición, son las denominadas 
competencias clave dentro de la cual se enuncia a la competencia digital. Aun así, no hay documentos que lo hagan de forma explícita y clara.

En cuanto a la acción 6: Educación y formación profesional (EFP), esta constituye una de las iniciativas de la UE en la que se puede observar la articulación entre procesos educativos y competencias para la formación laboral. Este enfoque está arraigado y es la base de la mayoría de las políticas educativas sobre un sistema de enseñanza basado en competencias. En este punto, lo que se intenta es desarrollar un marco de cooperación para el desarrollo de habilidades y competencias para el trabajo, lo cual involucra al mercado laboral en general, así como las necesidades específicas de cada uno de los países miembros en materia de formación y empleos.

Las acciones dentro de esta iniciativa están orientadas hacia la educación y formación profesional inicial (I-VET) y La EFP continua (C-VET). Para ambos niveles, la agenda de desarrollo propone el abordaje de los diferentes objetivos para el período 2015-2020, en los que se destaca fortalecer las competencias clave en los planes de estudio de EFP y proporcionar oportunidades más efectivas para adquirir o desarrollar esas habilidades a través de I-VET y C-VET.

Sobre esta iniciativa no se hallaron referencias que den lugar al análisis sobre las utilizaciones del término pensamiento computacional. Tampoco existen definiciones concretas sobre la relación con la competencia digital; sin embargo, existen diferentes documentos asociados a este como el Marco de Referencia Europeo de Garantía de Calidad -EQAVET-, la Recomendación del Consejo sobre un Marco Europeo para la Calidad y el Aprendizaje Eficaz y la Alianza Europea para el Aprendizaje, en los que se hace alusión a la competencia digital. Se considera que uno de los motivos que explica un leve nivel de desarrollo de estas relaciones, tiene que ver con que estas iniciativas están dirigidas y planificadas para fortalecer políticas de marco común y no para diseño de intervenciones concretas.

\subsubsection{Europa 2020}


Es la estrategia de crecimiento aprobada por la Comisión Europea para el período 2010-2020 que tiene como meta crear las condiciones propicias para un tipo de crecimiento distinto, más inteligente, sostenible e integrador. El objetivo está basado en la obtención de beneficios económicos y sociales sostenibles, que promuevan la constitución de un mercado único digital basado en un internet rápida y ultrarrápida y en unas aplicaciones interoperables. Esta agenda aborda cinco problemáticas: 1) empleo; 2) investigación y docencia; 3) cambio climático y sostenibilidad energética; 4) educación y lucha contra la pobreza y, 5) la exclusión social (Ministerio de Ciencia e Innovación, Gobierno de España, [MICINN] s.f).

La estrategia incluye siete "iniciativas emblemáticas" que constituyen un marco en el que la UE y las administraciones nacionales pueden aunar esfuerzos y reforzarse mutuamente en áreas relacionadas con las prioridades de Europa 2020, tales como la innovación, la economía digital, el empleo, la juventud, la política industrial, la pobreza y el uso eficiente de los recursos.

Las medidas educativas que se proponen en este documento tienen por objetivo disminuir la brecha, la exclusión digital y modernizar la educación y la formación, pero no tienen en cuenta la educación para la e-participación, entendida como toma de decisiones; aunque, sí se aborda el desarrollo de las tecnologías y servicios que permitan el e-gobierno, entendido como realización de gestiones administrativas (Echeverría y Unceta, 2012).

En esta estrategia no se considera el término PC en el desarrollo de ninguna de las prioridades que aquí se establecen y que sí se vinculan con el desarrollo digital en relación a diferentes áreas. Cabe destacar que aparecen líneas de acción ligadas a las competencias digitales para el mundo del trabajo, pero su tratamiento no comprende al PC como principio.

\subsubsection{Agenda digital para Europa}

Este plan constituye una de las siete iniciativas de la estrategia Europa 2020. Tiene como objetivo, definir las instancias de formación necesaria para el uso de las Tecnologías de la información y la comunicación (TIC) para que Europa pueda hacer realidad sus objetivos para el 2020. Dentro de sus marcos y objetivos, se establece garantizar un entorno digital seguro, abierto e imparcial. Entre las acciones ligadas al desarrollo y mejoramiento en 
materia de tecnologías se destaca la Estrategia para el Mercado Único Digital, que se estructura en base a tres ejes centrales: 1) mejorar el acceso de los consumidores y las empresas a los bienes y servicios digitales en Europa; 2) crear las condiciones adecuadas para el éxito de los servicios y las redes digitales, y 3) aprovechar al máximo el potencial de crecimiento de la economía digital.

Sobre esta política, se desarrollan acciones tendientes al mejoramiento de la conectividad y a la infraestructura en red. El primer objetivo clave es mejorar el acceso de los consumidores y las empresas a los bienes y servicios digitales en Europa, así como proporcionar un avanzado sistema de derechos de los usuarios y protección de los consumidores y empresas. Como segundo objetivo, se propone crear las condiciones adecuadas para el éxito de los servicios y las redes digitales dentro de la UE. En tercer lugar, pretende maximizar el potencial de crecimiento de la economía digital, fomentando las competencias digitales y la informática de alto rendimiento, digitalizando la industria y los servicios, desarrollando la inteligencia artificial y modernizando los servicios públicos.

Las temáticas y elementos que propone esta estrategia, resultan relevantes en su relación con el PC; sin embargo, el término no solo no es mencionado, sino que no se hace alusión al desarrollo de un proceso similar. En este punto, cabe destacar que la estrategia apuntó a un mejoramiento de las condiciones digitales y no a la formación en esa competencia. Se busca promover y mejorar el avance en términos de conexión, banda ancha y comercio, pero no al fortalecimiento de las estrategias para la producción de conocimiento en estos temas.

\subsubsection{Plan de Acción de Educación Digital}

La Comisión Europea ha producido el Plan de Acción de Educación Digital 2018-2020 (Comisión Europea [CE], s.f) que, a partir del desarrollo de tres objetivos prioritarios, propone once acciones para promover el uso de la tecnología y el desarrollo de las competencias digitales en la educación. Los cuadros que se presentan a continuación fueron elaborados en esta investigación para sintetizar las acciones y herramientas que se proponen en relaciona a las tres prioridades. 


\section{Cuadro 7}

Primera prioridad del Plan de Acción de Educación Digital

Prioridad 1: Hacer un mejor uso de la tecnología digital para la enseñanza y el aprendizaje
Acciones
Descripción
Herramientas

Acción 1 - Conectividad en los centros educativos.

Acción 2 - Selfie (herramienta de autoevaluación y asesoramiento para centros educativos).

Acción 3 - Títulos certificados digitalmente.
Busca mejorar los datos estadísticos respecto de la brecha digital a través de la concientización y la inversión financiera.

Promueve el uso de recursos digitales en ámbitos educativos (primaria, secundaria e institutos) a través de herramientas.

Desarrolla un enfoque técnico común para la emisión de calificaciones firmadas digitalmente. El objetivo es garantizar que los certificados de un Estado miembro puedan entenderse e interpretarse correctamente en cualquier otro.
Red de oficinas de competencia de banda ancha (BCO).

Selfie es un software educativo que funciona mediante un sistema de mentoría.

Plataforma Europass basada en estándares abiertos e integrado. Permite el almacenamiento de las calificaciones firmadas.

La primera prioridad del plan propone aminorar la tensión entre la enseñanza, los recursos y los procesos, haciendo énfasis en el desarrollo técnico. La primera acción: conectividad para una sociedad gigabit europea, adoptada por la comisión en septiembre de 2016, establece una visión de Europa donde la disponibilidad y la utilización de redes de muy alta capacidad, permiten el uso generalizado de productos, servicios y aplicaciones en el mercado único digital. Al respecto, el Consejo Europeo pidió, en junio de 2016, una conexión inalámbrica y fija de muy alta capacidad, pues la conectividad de banda ancha en toda Europa, es condición previa para la competitividad futura, junto a reformas regulatorias de 
telecomunicaciones necesarias para incentivar grandes inversiones en redes, mientras se promueve una competencia efectiva y derechos del consumidor.

La segunda de las acciones en esta línea, aborda el problema de las formas de la enseñanza en lo concerniente a apoyar el desarrollo de la integración de las prácticas de enseñanza basadas en las TIC a través de la colaboración y el aprendizaje entre pares. Es importante destacar que solo el 20-25\% de los estudiantes trabajan con maestros que confían en el uso de la tecnología. Para aumentar estos porcentajes, se creó la herramienta SELFIE a partir de la cual se basa el Marco Europeo para Organizaciones Educativas Digitalmente Competentes (DigCompOrg) (Centro Común de Investigación de la Comisión Europea [JCR], 2015). Gracias a este plan, más de 67.000 líderes escolares, maestros y estudiantes de 650 escuelas generales y vocacionales en 14 países europeos, probaron la versión beta de SELFIE en octubre de $2017^{12}$.

A su vez, dentro de esta primera prioridad analizada, aparece la necesidad de una administración compartida con Europa para fortalecer el sistema de cooperación, movilidad y egreso de todas las carreras. En 2003, tras efectuar amplias consultas con las administraciones nacionales y los agentes sociales, la Comisión Europea preparó una propuesta de Decisión del Parlamento y del Consejo Europeo sobre un Marco Único para la Transparencia de Cualificaciones y Competencias (Europass) (Comisión Europea [CE], 2004) que fue aprobado por el Parlamento y el Consejo Europeos en diciembre de 2004.

Si bien estas acciones reflejan tres áreas de intervención concretas sobre la educación digital: infraestructura, enseñanza y administración, no se logra rastrear indicios sobre el desarrollo y fomento del PC.

Con respecto a la segunda prioridad del Plan de Acción de Educación Digital, veamos el siguiente cuadro sinóptico que luego explicaremos en detalle:

${ }^{12}$ Esto datos fueron extraídos del Plan de Acción de Educación Digital (2018-2020) de la Comisión Europea (CE). Ver Referencias Bibliográficas. 


\section{Cuadro 8}

Segunda prioridad del Plan de Acción de Educación Digital

Prioridad 2: Desarrollar competencias y capacidades digitales

Acciones Descripción

Herramientas

Acción 4 - Plataforma de Educación Superior
Promueve una plataforma en línea como único punto de acceso a las plataformas en línea existentes en pos del mejoramiento de la difusión de las mejores prácticas a todas las instituciones de Educación Superior (IES).

Acción 5 - Capacidades de ciencia abierta.
Promueve el desarrollo de las habilidades de Open Science, desde la gestión de datos hasta aspectos legales, incluidas las habilidades técnicas como la administración y protección de datos, la comunicación académica y la difusión.
La plataforma contará con el apoyo del programa Erasmus. Se desarrollará una convocatoria de propuestas.
Financiación de propuestas de capacitación en el marco del programa Erasmus + (proyectos de cooperación prospectiva).
Acción 6 - Semana de la Programación de la UE en los centros educativos.
Constituye un movimiento de base dirigido por voluntarios en toda Europa. La semana promueve el pensamiento computacional, la codificación y el uso creativo y crítico de las tecnologías digitales.
Acción $7 \quad-\quad$ La ciberseguridad en la educación.
Desarrolla campañas de sensibilización en la UE sobre la cultura cibernética destinada a niños y adultos, sobre seguridad en línea,
A través de CodeWeek.eu escuelas, docentes, bibliotecas, clubes de códigos, empresas, autoridades públicas, pueden organizar una clase o evento de codificación y agregarlo al mapa.

El dispositivo principal es un curso semipresencial para docentes sobre ciberseguridad y enfoques pedagógicos para la enseñanza de la 
alfabetización mediática e "higiene cibernética". ciberseguridad en la educación primaria y secundaria.

Talleres interdisciplinarios.
Acción 8 - Formación en capacidades digitales $y$ empresariales para las chicas.
Prevé la realización de una serie de talleres sobre habilidades digitales y empresariales que se organizan en toda Europa para niñas y jóvenes en educación primaria y secundaria.

La segunda prioridad del plan está relacionada con las competencias y capacidades digitales. Dentro de esta línea se encuentran las cinco acciones más relevantes sobre el desarrollo del PC. En tal sentido se hace referencia a las acciones vinculadas con la programación, la ciberseguridad y la ciencia abierta. Aparece por primera vez la valoración del contenido específico del área de Ciencias de la Computación. Las actividades centrales que en esta prioridad están orientadas a la concientización de problemáticas a través de las lógicas de funcionamiento del mundo global. Se reconoce, además, la necesidad de articular y aunar esfuerzos entre los países miembros y se propone la creación de una plataforma de enlace único para la Educación Superior.

En el sitio web de la UE, se declara que uno de cada cinco jóvenes no tiene habilidades digitales básicas y que el 90\% de todos los trabajos, requieren de habilidades digitales básicas en la actualidad. Se sabe que la codificación fomenta el pensamiento lógico, la resolución de problemas y la creatividad. Así, la relación entre programación y educación debería estar centrada en la problemática de enseñanza y en los desafíos de las propuestas que buscan su transversalidad o curricularización; en pos de fomentar esto, las iniciativas como la Semana del Código de la UE se presentan como alternativas para el desarrollo de capacidades de creación en ambientes digitales. A su vez, se promueve la difusión de actividades en las que la programación sea más visible, mostrar a los jóvenes, adultos y ancianos cómo dan vida a las ideas sobre codificar, desmitificando los temores sobre estas habilidades y reunir a 
personas motivadas para aprender. La iniciativa fue lanzada en 2013 por Young Advisors para la Agenda Digital para Europa: Code Week.

En este sentido, la UE sobre esta política específica describe: "Promueve el pensamiento computacional y la capacidad de convertirse en creadores en lugar de usuarios pasivos de tecnologías digitales".

Dentro de la segunda prioridad del Plan de Acción de Educación Digital 2018-2020 (Comisión Europea [CE], s.f) se aborda otra temática del área de las Ciencias de la Computación relacionada con las transformaciones culturales actuales y la ciberseguridad. Esta necesidad radica en los siguientes datos: uno de cada tres usuarios de internet, dentro de la UE es niño, y la mitad de los jóvenes de entre once y dieciséis años en la UE se ha encontrado con uno o más de los riesgos de Internet. Para la UE esto constituye uno de los temas de mayor relevancia, de tal forma que existe la necesidad de aumentar la conciencia pública sobre los riesgos potenciales de estar en línea y desarrollar habilidades para actuar de manera segura y responsable.

El desarrollo de competencias y habilidades se relaciona con algunas problemáticas a nivel mundial y que no están restringidas al mundo de lo tecnológico y la técnica, como el tema de los derechos y de la brecha de género. El plan de acción busca promover la igualdad de género y los derechos de las mujeres en todo el mundo. Los datos sobre los que se sustenta este objetivo, arrojan, según el informe del plan, que el 52\% de la población europea son mujeres y que solo el 15\% de los trabajadores del sector tecnológico en la UE son mujeres. A pesar de la creciente demanda de habilidades en TIC, el porcentaje de europeos con educación relacionada con las TIC está disminuyendo. Aunque esto es común para ambos sexos, menos mujeres que hombres toman trabajos y educación relacionados con las TIC. Por cada 1000 mujeres, solo 24 se gradúan en campos relacionados con las TIC (Comisión Europea [CE], s.f).

Las habilidades que potencia el desarrollo del PC tienen incidencia en este tipo de problemáticas si el enfoque de formación en competencias va más allá del manejo de contenidos disciplinares. Sobre el PC, se relacionan y evidencian experiencias educativas que promueven la creación y la resolución de problemas en el ámbito de la programación. Es 
importante referir a manera de cierre de esta segunda prioridad, que sería significativo que se ampliara el desarrollo del PC en la resolución de situaciones problemáticas de la vida cotidiana y así ampliar su concepto y desarrollo en otras disciplinas.

\section{Cuadro 9}

Tercera prioridad del Plan de Acción de Educación Digital

Prioridad 3: Modernizar la educación mediante la previsión y un mejor análisis de los datos.

Acciones Descripción Herramientas

Acción 9 - Estudios sobre las TIC en la educación.
Acción 10 - Inteligencia artificial y análisis.
Evaluar los progresos realizados en la integración de la utilización de las TIC en la educación. Se desarrollará un marco para la utilización pedagógica de las TIC en el aprendizaje, vinculando el uso de las TIC a resultados cognitivos mensurables.

Desarrollo de proyectos piloto de inteligencia artificial. A partir de análisis, se buscará predecir habilidades futuras y ampliar competencias para el mercado laboral.
Acción 11 - Prospectiva estratégica.
Intenta establecer soluciones innovadoras a los desafíos que enfrentan las instituciones educativas de hoy.
Cuestionario sobre la utilización de las TIC que acompaña a la encuesta PISA y que se actualizará en cooperación con la OCDE.
Proyectos de análisis de datos para predecir los viajes de aprendizaje y los requisitos de formación para futuros perfiles de competencia como el Programa Marco Horizonte 2020 y la creación de un mercado único digital.

Hackathon y publicaciones en el área.

El análisis sobre el impacto de todas las políticas que se desarrollan tiene como correlato el diseño y armado de los instrumentos de evaluación. En el ámbito educativo esto no es menor, pues existen múltiples enfoques y teorías sobre los procesos de evaluación y su incidencia en 
los resultados que posibilita. En tal sentido, la UE promueve el desarrollo de una línea de evaluación en competencias, fiel al desarrollo que esta categoría tiene para pensar los procesos educativos y la necesidad respecto de la recopilación de datos sobre la digitalización en las instituciones de educación y formación, así como de las tecnologías digitales. En el aprendizaje esto es crucial para la elaboración de políticas. En ese sentido, en el Plan de Acción de Educación Digital 2018-2020 la UE declara:

Los datos comparables y completos sobre el uso de la tecnología en los sistemas educativos, y sobre el seguimiento de los avances en el uso de la tecnología, suelen ser escasos, parciales o anticuados. Hace falta una recopilación de datos más eficiente, eficaz y coordinada a nivel de la UE. (Comisión Europea [CE], s.f)

El problema de la evaluación en materia de educación digital se halla vinculado con el desarrollo de una perspectiva estratégica ${ }^{13}$ en tanto se prevé fortalecer las estrategias de planificación y liderazgo de un cambio de manera proactiva. Esto contribuye al diseño de políticas y estrategias para abordar las tendencias y necesidades futuras. A su vez, estas acciones se retroalimentan, pues lo que arrojen las evaluaciones sobre educación digital y la adquisición de competencias digitales será lo que las nuevas estrategias debieran incorporar en futuros planes de acción.

El Plan de Acción de Educación Digital no sitúa al pensamiento computacional como actor central del desarrollo de las acciones que aquí aparecen, sin embargo, el PC aparece asociado a la programación y es mencionado como fundamento de la acción que, dentro del plan, promueve la Semana del Código. Este tipo de consideraciones responde a los propuestos por Llopis, Esteve y Valdedivas (2018) al explicar que existen dos posiciones al definir el PC: 1) la que hace hincapié en aspectos informáticos y está estrechamente relacionada con la programación; y 2) la que resalta el concepto ligado a procesos cognitivos, la formulación de problemas y la búsqueda de soluciones efectivas.

\footnotetext{
${ }^{13}$ Ver acción 11 del Plan de Acción de Educación Digital.
} 


\subsubsection{DigComp 2}

El Marco de Competencia Digital para Ciudadanos (DigComp2) fue elaborado por la Unidad de Capital Humano y Empleo (Centro Común de Investigación) en nombre de la Dirección General de Empleo, Asuntos Sociales e Inclusión de la Comisión Europea. Este documento, que busca difundir y concientizar las competencias digitales que debe tener los ciudadanos, constituye uno de los materiales más representativos para el abordaje sobre PC y competencias. En su sitio web se explica: "El marco no se centra en dispositivos o software, sino que busca apoyar el uso seguro, crítico y responsable de la tecnología digital por parte de las personas."

El presente documento desarrolla cinco dimensiones para analizar la competencia digital:

1. Áreas de competencia identificadas como parte de la competencia digital

2. Descriptores de competencias y títulos pertinentes a cada área

3. Niveles de competencia para cada competencia

4. Conocimientos, habilidades y actitudes aplicables a cada competencia

5. Ejemplos de uso sobre la aplicabilidad de la competencia a diferentes propósitos

Este documento amplía la cantidad de niveles, y por ende, el desarrollo que sobre la dimensión 3 se había realizado en la versión anterior DigComp 2.0 (Vuorikari et al., 2016) en torno a los niveles de la competencia. En esta nueva versión se han definido ocho niveles para cada una de las competencias a través de resultados de aprendizaje (usando verbos de acción, siguiendo la taxonomía de Bloom) e inspirados en la estructura y el vocabulario del Marco europeo de calificación (EQF).

Las competencias que en este documento se describen y que integran el conjunto de habilidades denominadas "Competencia digital” son clasificadas según áreas:

- Área de competencia 1: alfabetización en información y datos

- Área de competencia 2: comunicación y colaboración

- Área de competencia 3: creación de contenido digital

- Área de competencia 4: seguridad

- Área de competencia 5: resolución de problemas. 
A continuación, se muestra una figura que representa las áreas de competencia referidas anteriormente:

\section{Figura 3}

Áreas de desarrollo y competencias digitales

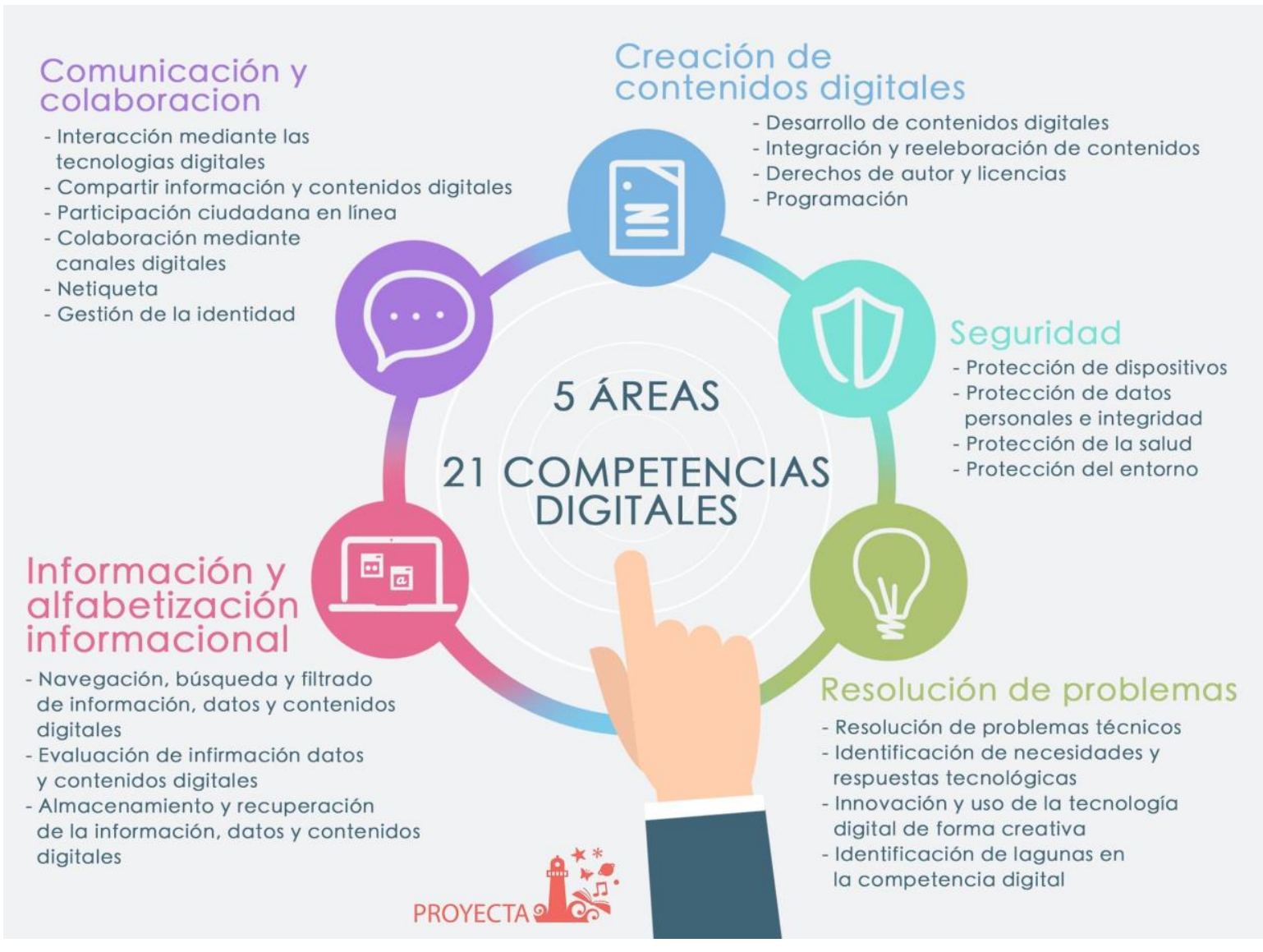

Nota. Tomado de Competencia Digital: Vital para profesores y estudiantes del siglo XXI, por

Garasa Marcos, 2018. Disponible en:

https://marcosgarasa.wordpress.com/2018/04/20/competencia-digital-vital-para-profesores-y-

$\underline{\text { estudiantes-del-siglo-xxi/ }}$

El conjunto de habilidades, así como los niveles que se describen para cada una de ellas, abona una idea de formación en competencias atravesado por el componente digital. En este caso, la relación con el PC deviene de los contenidos del campo de las Ciencias de la Computación a los que se hace alusión y por la habilidad referida a la "resolución de 
problemas". Esta concepción involucra una de las primeras definiciones sobre el PC, realizada por Wing (2006) y destacada en múltiples ocasiones. Si bien el documento no menciona el término PC, existe una relación entre los procesos asociados a las áreas de las competencias y los niveles de cognición que se plantean. Ello hace que para autores como Téllez Ramírez (2019) y Zapata Ros (2015), la competencia digital constituya una de las formas de definir, entender y problematizar al PC.

\subsubsection{CompuThink}

A raíz del desarrollo y publicación del DigComp, se desprende una investigación sobre el PC, promovida por el eje de relaciones que, entre la competencia digital y este, tuvieron lugar luego de la publicación del presente informe. El documento que resulta de dicha investigación fue publicado por la Comisión Europea en 2016 bajo el nombre Desarrollando el pensamiento computacional en educación obligatoria (Bocconi et al., 2016). Este documento resulta ser un avance destacable de la UE por desarrollar y problematizar no solo el término, sino las implicancias que el mismo tiene en procesos educativos, fundamentalmente en su enseñanza. Tal como se ha expuesto previamente en esta tesis, el desarrollo de modelos basados en competencias es central para la Unión Europea, siendo este marco el que establece la relación entre la competencia digital y el PC.

En este documento se realiza un análisis respecto de la relación entre la competencia digital (considerada en el DigComp 2.0) y las habilidades del PC. Resalta una idea que visibiliza los estudios y publicaciones sobre estas posibles relaciones, exponiendo que "de la literatura surge un fuerte consenso de que el pensamiento computacional es más que programación y la relación con la competencia digital, podría no ser capaz de capturar completamente las ideas centrales y habilidades asociadas con el pensamiento computacional.” (Bocconi et al., 2016, p.20)

Sobre la primera de estas ideas existe un gran consenso a nivel internacional que expone que la programación constituye un gran aporte al desarrollo del PC, sin embargo, no son equivalentes en términos de los procesos que implican. De esta forma, se dividen los enfoques respecto de enseñar a programar, y enseñar a pensar computacionalmente, aunque 
es importante destacar que se puede enseñar programación para fortalecer el desarrollo del PC. Aquí aparece la tensión entre trabajar a nivel curricular contenidos de las Ciencias de la Computación para abordar el PC o trabajar transversalmente.

Lo que consideran los expertos como Zapata-Ros (2015), promotores del PC como competencia y como fundamento de una nueva alfabetización digital es que el problema en relación al PC tiene que ver con:

La respuesta más frecuente y más simple, ha consistido en favorecer el aprendizaje de la programación y de sus lenguajes de forma progresiva. Esto consistiría en proponer a los niños tareas de programar desde las primeras etapas, de manera que la progresión estuviese en la dificultad de las tareas y en su carácter motivador, desde las más sencillas y más lúdicas, hasta las más complejas y aburridas. Se vincula el aprendizaje con la respuesta a un estímulo, no con las características de aprendizaje y cognitivas del niño, en la tradición más clásica del conductismo. (p.20)

Dentro de los análisis que se realizan en el CompuThink, destacan las contribuciones más significativas sobre la relación entre competencia digital y PC, en el que se explica que los desarrollos sobre ellos son el resultado de documentos de política y de discusiones sobre la implementación de PC y las Ciencias de la Computación.

\subsubsection{Marco europeo de competencias digitales para docentes}

El desarrollo de un Marco Europeo para la competencia digital del profesorado (DigComEdu) (Centro Común de Investigación de la Comisión Europea [JCR], s.f) propone áreas concretas de intervención para facilitar la inclusión de las tecnologías en los ámbitos educativos. Este marco pretende, a su vez, abordar la formación docente y la falta de competencias sobre lo digital. Propone seis áreas de trabajo: 1) compromiso profesional; 2) recursos digitales; 3) pedagogía digital; 4) evaluación y retroalimentación; 5) empoderar a los estudiantes; y 6) facilitar la competencia digital de los estudiantes, tal como se muestra en la figura 4: 


\section{Figura 4}

Visión general del Marco DigCompEdu

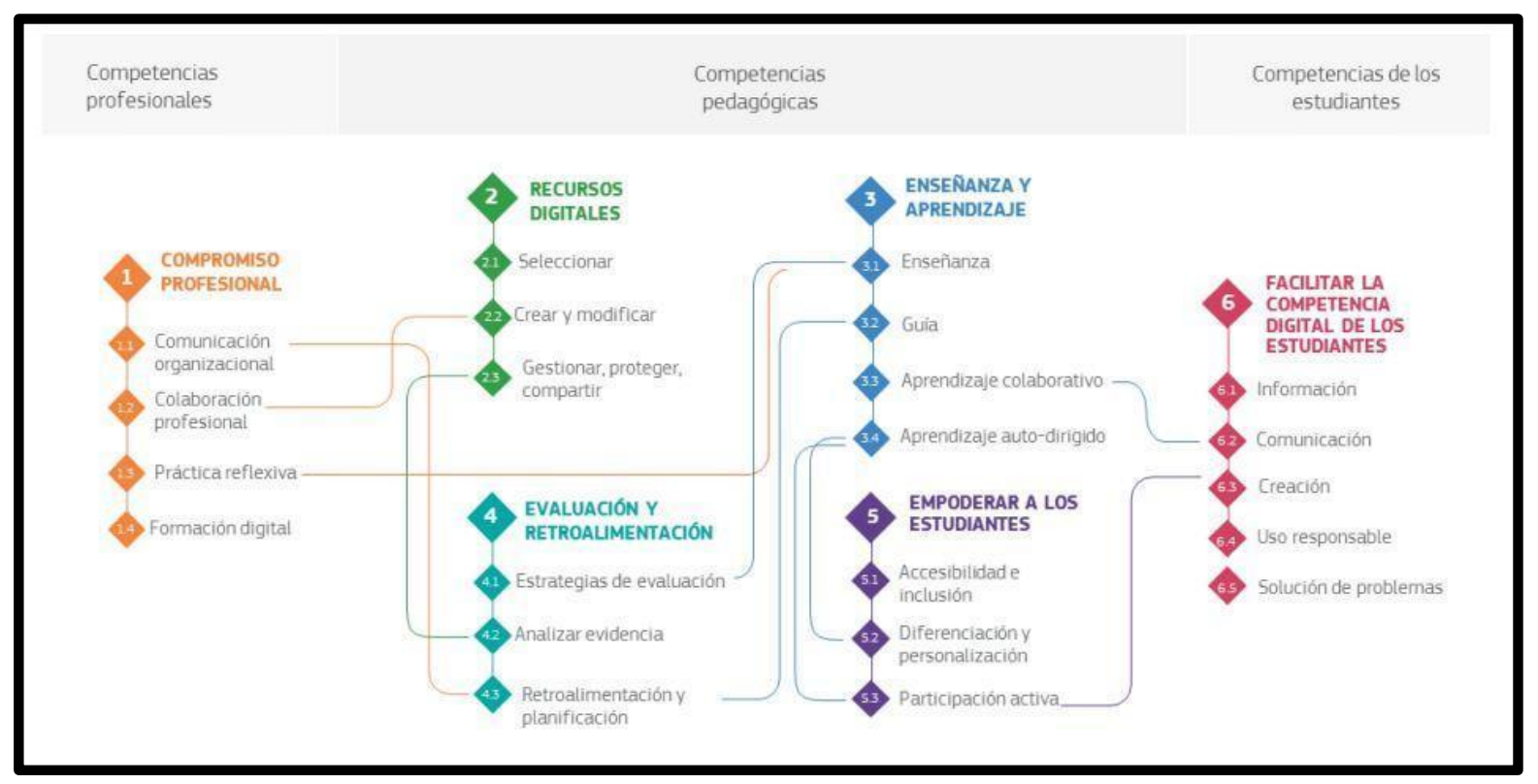

Nota. Adaptado de Evaluar la competencia digital docente, por Comisión Europea, 2017. Disponible en: https://ec.europa.eu/jrc/sites/jrcsh/files/digcompedu_leaflet_es-nov2017pdf.pdf

Este documento realiza una serie de sugerencias para el desarrollo y puesta en práctica de estrategias de enseñanza con recursos y herramientas digitales. Cabe destacar que lo que se entiende como pedagogía digital, por ejemplo, enuncia formas y recursos para prácticas de enseñanza. Se resalta esto, pues aparece el término "pedagogía” asociado a un enfoque diferente del que se plantea en este trabajo, en el que la pregunta está centrada en la formación del sujeto, tal como se ha venido desarrollando en capítulos anteriores. Tal como se muestra en la siguiente figura:

\section{Figura 5}

Visión conceptual 


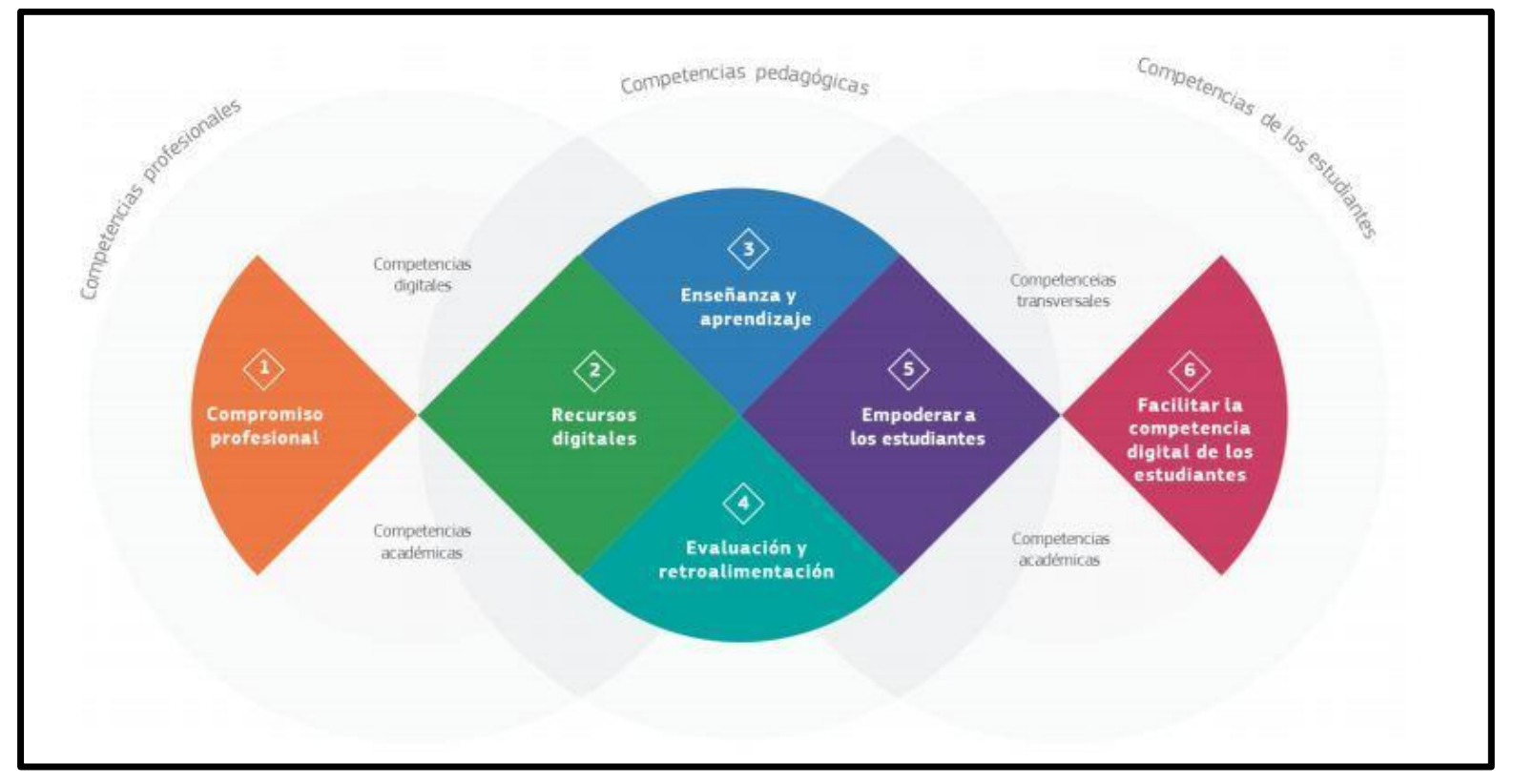

Nota. Adaptado de Evaluar la competencia digital docente, por Comisión Europea, 2017.

Disponible en: https://ec.europa.eu/jrc/sites/jrcsh/files/digcompedu_leaflet_es-nov2017pdf.pdf

Sobre el sexto eje de análisis de este marco en cuanto a facilitar la competencia digital para los estudiantes, el mismo constituye un aporte relevante para relacionarlo con la idea de PC como competencia digital. En este apartado se observan las siguientes líneas de acción: información y alfabetización mediática; comunicación y colaboración digital; creación de contenido digital; bienestar y solución digital de problemas. Todas esas líneas de acción estarían relacionadas con algunos de los elementos que constituyen al PC según Zapata Ros (2015), quien reconoce que los procesos son: alfabetización digital; métodos colaborativos; creatividad y resolución de problemas. Estos procesos son parte de las competencias que Zapata Ros (2015) describe y entiende como constitutivas del PC. Sin embargo, en el DigCompEdu, el PC no aparece mencionado ni desarrollado, tal como se observa en las figuras mostradas anteriormente.

\subsubsection{Marco de cooperación para la educación y la formación}


Este marco (ET, 2020) se encuentra aún en vigencia, pero los representantes de los países miembro se han reunido y producido documentos que sientan las bases para el nuevo marco titulado: Más allá de 2020 (Comisión Europea [CE], s.f). El último documento publicado por la Comisión Europea sobre el marco de cooperación es el resultado del Foro sobre el Futuro del Aprendizaje (tercera reunión del panel de expertos) que abordó la problemáticas: desafíos demográficos, inclusión y ciudadanía, cambio tecnológico y el futuro del trabajo, digitalización de la sociedad, desafíos ambientales e inversión, reformas y gobernanza. En este documento se expresa lo siguiente:

Se necesitan esfuerzos específicos para abordar cómo el mundo digital afecta las metodologías de enseñanza. La evidencia muestra claramente que, simplemente transferir contenido existente al formato digital no es suficiente. Sin embargo, los esfuerzos para combinar lo digital y lo tradicional han permanecido en gran medida fragmentados a pesar de los recientes esfuerzos del grupo de trabajo de la UE. Más allá de 2020, plantea nuevas metodologías de enseñanza y aprendizaje que aprovechan el potencial de lo digital educación y formación en cuenta, incluidas las destinadas al pensamiento computacional e incorporar habilidades y conocimientos básicos y avanzados en tecnologías digitales dentro de otros temas que deben recibir atención particular. (p.46)

En esta cita, se logra comprender la intencionalidad pedagógica en el marco de una política educativa que rescata la problemática de la transposición didáctica, en tanto se pregunta por el cómo y las metodologías sobre temáticas relacionadas con la tecnología digital, basadas en un concepto de competencias y habilidades. El pensamiento computacional figura como un conjunto de habilidades necesarias, pero sin problematizar el término ni su relevancia.

El presente marco está constituido por ocho prioridades: 1) Educación y cuidado de la primera infancia; 2) Política escolar; 3) Educación vocacional y entrenamiento; 4) Aprendizaje de adultos; 5) Educación más alta; 6) Cooperación internacional y diálogo político; 7) Multilingüismo; y 8) Educación y migrantes. 


\subsubsection{Erasmus+}

Esta estrategia, pionera de la UE, es una de las más reconocidas a nivel mundial por su difusión, impacto y trayectoria. Si bien está asociada a la movilidad de estudiantes, docentes y profesionales, sus objetivos son más amplios. En el sitio web del programa se explica "Erasmus + quiere también promover el desarrollo sostenible de los países asociados en el ámbito de la Educación Superior y contribuir a la realización de los objetivos de la estrategia de la UE para la juventud".

Dentro del programa se plantean los siguientes temas específicos:

- Reducir el desempleo, especialmente entre los jóvenes

- Fomentar la educación de adultos, especialmente en las nuevas competencias y cualificaciones exigidas por el mercado laboral

- Animar a los jóvenes a participar en la vida democrática de Europa

- Apoyar la innovación, la cooperación y las reformas

- Reducir el abandono escolar prematuro

- Promover la cooperación y la movilidad con los países asociados de la UE

De estos objetivos, solo el segundo de ellos explicita el enfoque de nuevas competencias para el mercado laboral; pero desde esa generalidad no aparecen datos claros ni precisos de la existencia de convocatorias específicas, ya sea para profesionales interesados, o como para carreras asociadas al PC. La información obtenida sobre este programa está relacionada a la convocatoria, selección y resultados sobre los beneficios de movilidad.

\subsection{Estudio de casos}

\subsubsection{Reino Unido}

La educación del Reino Unido (UK) constituye uno de los casos de análisis seleccionados para esta tesis; entre una de las razones más relevantes, por la composición compleja de cuatro países (Inglaterra, Escocia, Gales e Irlanda del Norte) en uno (Reino Unido de Gran Bretaña e Irlanda del Norte). De tal manera que el sistema de educación de UK cuenta con 
una estructura general para los cuatro países, pero cada uno de ellos lo regula y administra según sus variables y características específicas.

Este sistema cuenta con cuatro etapas de desarrollo: 1) Primaria; 2) Secundaria; 3) Complementaria y 4) Superior. La educación en UK es de carácter obligatoria y gratuita desde los cinco a los dieciséis años. La integración de los "contenidos base" en este sistema está garantizada por el Currículum nacional para primaria y secundaria. Tal documento sienta las bases de las áreas, contenidos y objetivos de una política educativa para todos, incluyendo la educación religiosa y la educación sexual ${ }^{14}$. Este diseño curricular contiene, además de los contenidos, los estándares para la evaluación en cada una de las etapas y niveles del sistema de educación.

La organización por bloques, denominadas "etapas clave" (Key States) marca el inicio y cierre de cada una de ellas con una evaluación en la que se analiza la calidad del aprendizaje, según lo que establece el estándar para esa etapa. El carácter de estas evaluaciones es un rasgo distintivo de este sistema educativo, ya que las evaluaciones son a nivel nacional y realizadas por el Estado, por lo tanto, se corrigen fuera de los colegios.

El currículum nacional establece las siguientes materias obligatorias: tres materias troncales para todos los ciclos: inglés, matemáticas y ciencia; nueve materias básicas que no están en todos los ciclos: diseño y tecnología, informática, historia, geografía, lengua extranjera, arte y diseño, música, educación física y educación cívica.

Para este trabajo se consultan y analizan: 1) los marcos normativos generales, primaria y secundaria y 2) los planes de estudios de las asignaturas mencionadas. La búsqueda y rastreo de estos documentos se propuso identificar la existencia de referencias al término PC en pos de un análisis posterior que lo relacione con las políticas educativas de la UE y al enfoque de competencia clave. A continuación, se muestra un cuadro explicativo sobre el sistema educativo de este país con sus especificaciones por edad, curso, etapa del currículum y el tipo de escuela correspondiente:

\footnotetext{
${ }^{14}$ La educación religiosa y la educación sexual en UK son de carácter obligatorio.
} 


\section{Cuadro 10}

Sistema educativo de UK

\begin{tabular}{|c|c|c|c|c|}
\hline \multicolumn{5}{|c|}{ REINO UNIDO } \\
\hline $\begin{array}{l}\text { Edad } \\
\text { (a 31/08) }\end{array}$ & Curso & $\begin{array}{l}\text { Etapa del } \\
\text { curriculum }\end{array}$ & \multicolumn{2}{|c|}{ Tipo de escuela } \\
\hline 3 años & Nursery & \multirow{2}{*}{$\begin{array}{l}\text { Foundation } \\
\text { Stage }\end{array}$} & \multicolumn{2}{|c|}{ Nursery School } \\
\hline 4 años & Reception & & \multirow{3}{*}{ Infant school } & \multirow{7}{*}{$\begin{array}{l}\text { Primary } \\
\text { School }\end{array}$} \\
\hline 5 años & Year 1 & Key stage 1 & & \\
\hline 6 años & Year 2 & (Etapa 1) & & \\
\hline 7 años & Year 3 & \multirow{4}{*}{$\begin{array}{l}\text { Key stage } 2 \\
\text { (Etapa 2) }\end{array}$} & \multirow{4}{*}{ Junior school } & \\
\hline 8 años & Year 4 & & & \\
\hline 9 años & Year 5 & & & \\
\hline 10 años & Year 6 & & & \\
\hline 11 años & Year 7 & \multirow{3}{*}{$\begin{array}{c}\text { Key stage } 3 \\
\text { (Etapa 3) }\end{array}$} & \multirow{5}{*}{$\begin{array}{l}\text { Secondary } \\
\text { school }\end{array}$} & \multirow{7}{*}{$\begin{array}{l}\text { Secondary } \\
\text { School }\end{array}$} \\
\hline 12 años & Year 8 & & & \\
\hline 13 años & Year 9 & & & \\
\hline 14 años & Year 10 & \multirow{2}{*}{$\begin{array}{c}\text { Key stage } 4 \text { - } \\
\text { GCSE }\end{array}$} & & \\
\hline 15 años & Year 11 & & & \\
\hline 16 años & Year 12 & \multirow{2}{*}{$\begin{array}{c}\text { Sixth Form } 7 \mathrm{~A}^{\prime} \\
\text { level }\end{array}$} & \multirow{2}{*}{$\begin{array}{l}\text { Sixth Form } \\
\text { college }\end{array}$} & \\
\hline 17 años & Year 13 & & & \\
\hline
\end{tabular}

Nota. Adaptado de British Summer, 2014.

\subsubsection{Documentos Marco para el Currículum Nacional}

En este apartado se realizará el análisis de tres documentos centrales para el desarrollo del Currículum Nacional del Reino Unido: 1) el documento Marco de 2014; 2) el Marco para Primaria; y 3) el Marco para Secundaria.

El marco para las etapas clase 1 a 4, establece los lineamientos pedagógicos generales para el desarrollo del Currículum Nacional, basado en lo establecido en la Ley de Educación de 2002. En este documento se describen los propósitos, objetivos y contenidos generales que son redactados en formato de metas estudio de las asignaturas que componen las cuatro etapas educativas y en las que se articula el sistema como puede observarse a continuación: 


\section{Cuadro 11}

Estructura del Plan de estudios de UK

\begin{tabular}{|l|c|c|c|c|}
\cline { 2 - 5 } \multicolumn{1}{c|}{} & Key stage 1 & Key stage 2 & Key stage 3 & Key stage 4 \\
\hline Age & $5-7$ & $7-11$ & $11-14$ & $14-16$ \\
\hline Year groups & $1-2$ & $3-6$ & $7-9$ & $10-11$ \\
\hline Core subjects & & & & \\
\hline English & $\checkmark$ & $\checkmark$ & $\checkmark$ & $\checkmark$ \\
\hline Mathematics & $\checkmark$ & $\checkmark$ & $\checkmark$ & $\checkmark$ \\
\hline Science & $\checkmark$ & $\checkmark$ & $\checkmark$ & $\checkmark$ \\
\hline & & & & \\
\hline Foundation subjects & $\checkmark$ & $\checkmark$ & $\checkmark$ & \\
\hline Art and design & & & $\checkmark$ & $\checkmark$ \\
\hline Citizenship & $\checkmark$ & $\checkmark$ & $\checkmark$ & \\
\hline Computing & $\checkmark$ & $\checkmark$ & $\checkmark$ & \\
\hline Design and technology & $\checkmark$ & $\checkmark$ & $\checkmark$ & \\
\hline Languages & & & & \\
\hline Geography & $\checkmark$ & $\checkmark$ & $\checkmark$ & \\
\hline History & $\checkmark$ & $\checkmark$ & $\checkmark$ & \\
\hline Music & & $\checkmark$ & $\checkmark$ & \\
\hline Physical education & $\checkmark$ & & \\
\hline
\end{tabular}

Nota. Adaptado de The national curriculum in England, 2014, Departamento de Educación, Reino Unido.

Sobre PC, este documento no expresa posicionamientos ni definiciones; sin embargo, desarrolla objetivos y propósitos que lo recuperan. La utilización del término sirve como argumento y fundamentación de una de las asignaturas obligatorias: Informática, que se halla reglada en el Currículum Nacional del Reino Unido y en este documento marco se establece su propósito en función de "una educación informática de alta calidad equipa a los alumnos para usar el pensamiento computacional y creatividad para entender y cambiar el mundo." (Departamento de Educación, Reino Unido [UK], 2014).

El eje central de esta propuesta es la enseñanza/aprendizaje de contenidos del campo de la informática para el desarrollo de conocimientos digitales y programación. En este sentido, todos los documentos analizados explican que a través del conocimiento informático los 
alumnos serán capaces de crear programas y sistemas, además de una gama de contenidos, ligado al desarrollo de las habilidades de programación. De esta forma se asegura que:

La informática garantiza que los alumnos sean alfabetizados digitales y puedan usar, expresarse y desarrollar sus ideas a través de las TIC de manera adecuada, pues ello incide positivamente en el desarrollo en futuros lugares de trabajo y activos participantes en un mundo digital. (2014, p. 230)

Más adelante, en el mismo documento citado anteriormente, se establecen los objetivos respecto de la incorporación de estos contenidos:

El plan de estudios nacionales de informática tiene como objetivos garantizar que todos los alumnos puedan: 1) comprender y aplicar los principios y conceptos fundamentales de la informática, incluida la abstracción, la lógica, los algoritmos y la representación de datos; 2) analizar problemas en términos computacionales y tener experiencia práctica repetida de escribir programas de computadora para resolver tales problemas; 3 ) evaluar y aplicar tecnología de la información, incluidas tecnologías nuevas o desconocidas, analíticamente para resolver problemas y 4) ser usuarios responsables, competentes, seguros y creativos de la tecnología de la información y la comunicación. (2014, p.178)

El sistema educativo del Reino Unido incluye la informática como materia obligatoria para todos los niveles y etapas. En los documentos que analizamos se regulan los contenidos mínimos aceptables que serán evaluados al finalizar cada una de las etapas. A continuación, se muestra un cuadro resumen de las etapas clave para el nivel primario de la asignatura Informática (1 y 2): 


\section{Cuadro 12}

Asignatura obligatoria: Informática en Primaria

\section{Nivel Primario}

Etapa Clave 1

Etapa Clave 2

1. Los alumnos deben entender qué son los algoritmos; cómo se implementan como programas en dispositivos digitales, y que los programas se ejecutan siguiendo instrucciones precisas y sin ambigüedades.

2. Los alumnos deben poder crear y depurar programas simples.

3. Los alumnos deben ser capaces de usar razonamiento lógico para predecir el comportamiento de programas simples.

4. Los alumnos deben utilizar la tecnología a propósito para crear, organizar, almacenar, manipular y recuperar contenidos digitales.

5. Los alumnos deben poder reconocer los usos comunes de la tecnología de la información, más allá de la escuela.

6. Los alumnos deben utilizar la tecnología de manera segura y respetuosa, manteniendo la información personal privada; identificar a dónde ir para obtener ayuda y soporte cuando tengan dudas sobre el contenido o el contacto en Internet u otras tecnologías en línea.
1. Los alumnos deben diseñar, escribir y depurar programas que cumplan objetivos específicos, incluido el control o la simulación de sistemas físicos; resolver problemas, descomponiéndolos en partes más pequeñas

2. Los alumnos deben poder usar secuencia, selección y repetición en programas; trabajar con variables y varias formas de entrada y salida.

3. Los alumnos deben utilizar el razonamiento lógico para explicar cómo funcionan algunos algoritmos simples, así como detectar y corregir errores en algoritmos y programas.

4. Los alumnos deben poder comprender el funcionamiento de las redes informáticas, incluido internet, así como las oportunidades que estas ofrecen para la comunicación y la colaboración.

5. Los alumnos deben poder utilizar las tecnologías de búsqueda de manera efectiva, apreciar cómo se seleccionan y clasifican los resultados y ser perspicaces al evaluar contenidos digitales.

6. Los alumnos deben poder seleccionar, usar y combinar una variedad de software (incluidos los servicios de Internet) en una variedad de dispositivos digitales para diseñar y crear una variedad de programas, sistemas y contenido que cumpla con objetivos claros, incluyendo recopilar, 
analizar, evaluar y representar datos e información.

7. Los alumnos deben utilizar la tecnología de manera segura, respetuosa y responsable; reconocer el comportamiento aceptable / inaceptable; identificar una variedad de formas de informar inquietudes sobre el contenido y el contacto.

Para la primera de las etapas clave, se definen seis metas clave que no desarrollan minuciosamente el contenido a trabajar; este estilo de contenidos/metas responde a una lógica generalista de reconocimiento de procesos educativos, más que de aprendizaje y a ello se debe su forma de enunciarlos. Tal como se mencionó anteriormente, estos marcos son regulatorios para los cuatro países que componen el Reino Unido (UK) y cada uno de ellos a su vez puede adaptarlos sin desatender lo que figura en la mínima y en los estándares de evaluación.

En el cuadro confeccionado a partir de la información en los marcos referenciados, se intenta dejar en evidencia la dinámica progresiva por la cual estos contenidos/metas van de lo simple a lo más complejo. En este sentido, lo que se complejizan son los procesos cognitivos que los estudiantes hacen sobre un mismo contenido. En esta investigación no se tuvo acceso a las formas de la enseñanza. En estudios a futuro, resultará valioso realizar una investigación sobre las didácticas específicas del campo para la evaluación en términos de impacto y también de aprendizajes.

De igual manera, para el nivel secundario hay etapas clave (3 y 4) en las cuales se establecen los contenidos, según se detalla en el siguiente cuadro resumen: 


\section{Cuadro 13}

Asignatura Obligatoria: Informática

\section{Nivel Secundario}

Etapa Clave 3

Tapa Clave 4

1. Los estudiantes deben poder diseñar, usar y evaluar abstracciones computacionales que modelen el estado y comportamiento de problemas del mundo real y sistemas físicos

2. Los estudiantes deben comprender varios algoritmos clave que reflejan el pensamiento computacional, por ejemplo: los utilizados para clasificar y buscar; utilizar el razonamiento lógico para comparar la utilidad de algoritmos alternativos en la resolución de un mismo problema

3. Los estudiantes deben utilizar dos o más lenguajes de programación (al menos uno textual) para resolver diversos problemas computacionales; hacer un uso apropiado de las estructuras de datos, por ejemplo; listas, tablas o matrices; diseñar y desarrollar programas modulares que utilicen procedimientos o funciones.

4. Los estudiantes deben comprender la lógica booleana simple, por ejemplo; AND, OR y NOT, y algunos de sus usos en circuitos de programación; entender cómo se pueden representar los números en binario, y poder realizar operaciones simples en números binarios, por ejemplo, suma binaria y conversión entre binario y decimal.

5. Los estudiantes deben comprender los componentes de hardware y software que componen los sistemas informáticos, así cómo se comunican entre sí y con otros sistemas.

1. Los estudiantes deben poder desarrollar su capacidad, creatividad y conocimiento en informática, medios digitales y tecnología de la información.
2. Los estudiantes deben desarrollar y aplicar su pensamiento analítico, de resolución de problemas, de diseño y computacional a través de sus habilidades. 
6. Los estudiantes deben comprender cómo se almacenan y ejecutan las instrucciones en un sistema informático; comprender cómo se pueden obtener datos de varios tipos (texto, sonidos e imágenes) representados y manipulados digitalmente, en forma de dígitos binarios.

7. Los estudiantes deben poder emprender proyectos creativos que impliquen seleccionar, usar y combinar múltiples aplicaciones -preferiblemente en una gama de dispositivos- para lograr objetivos desafiantes, como la recopilación y el análisis de datos y la satisfacción de las necesidades de los usuarios conocidos.

8. Los estudiantes deben crear, revisar y reutilizar artefactos digitales para una audiencia determinada con atención a la confiabilidad, diseño y usabilidad.

9. Los estudiantes deben comprender una variedad de formas de usar la tecnología de manera segura, respetuosa, responsable, incluida la protección de su identidad y privacidad en línea; reconocer contenidos inapropiados; establecer contacto y saber cómo informar inquietudes de forma óptima.

3. Los estudiantes deben entender cómo los cambios en la tecnología afectan la seguridad, incluidas las nuevas formas de proteger su privacidad e identidad en línea, así como identificar e informar una variedad de inquietudes.

Tal como puede apreciarse a partir de este segundo cuadro resumen, en la educación secundaria, la materia "Informática" promueve gran variedad de aspectos relacionados con el PC. Si bien este en todas sus definiciones, refiere al campo de la informática, no es común verlo de forma explícita en los diseños curriculares, pues su definición aún no tiene un consenso general y su aparición es relativamente reciente. Sin embargo, el sistema educativo del Reino Unido logra incorporarlo, siendo la etapa 4 en la que aparecen los rasgos más claros de su referencia. Es así que en el segundo contenido/meta se expresa que "Desarrollar y 
aplicar su pensamiento analítico, de resolución de problemas, de diseño y computacional a través de sus habilidades" (2014, p. 233).

Esta definición, en términos generales, permite dar cuenta de que el PC es considerado como la resultante de un proceso de formación. Es decir, se va trabajando contenido específico a lo largo de las cuatro etapas para que, en la última de ellas, se pongan de manifiesto esas habilidades. Si bien en todas las etapas, los contenidos siguen una línea de "adquisición de competencias", en el último tramo de la escuela secundaria aparece una idea más relacionada a la práctica o a la puesta en marcha de aquello que ya fue aprendido en etapas anteriores.

Dentro del Marco del Currículum Nacional aparece la materia Diseño y Tecnología, de carácter obligatoria para las etapas clave 1, 2 y 3. En estos documentos no se encontró referencia al PC en el desarrollo de los objetivos, contenidos/metas de esta asignatura, sin embargo, su propósito de estudio explica:

El diseño y la tecnología es un tema inspirador, riguroso y práctico. Al utilizar la creatividad y la imaginación, los alumnos diseñan y fabrican productos que resuelven problemas reales y relevantes dentro de una variedad de contextos, teniendo en cuenta las necesidades, deseos y valores propios y de los demás. Adquieren una amplia gama de conocimientos temáticos y recurren a disciplinas como las matemáticas, las ciencias, la ingeniería, la informática y el arte. Los alumnos aprenden a asumir riesgos, convirtiéndose en ciudadanos ingeniosos, innovadores, emprendedores y capaces. A través de la evaluación del diseño y la tecnología pasados y presentes, desarrollan una comprensión crítica de su impacto en la vida diaria y el mundo en general. El diseño de alta calidad y la educación tecnológica hacen una contribución esencial a la creatividad, la cultura, la riqueza y el bienestar de la nación. (2014)

Sus objetivos promueven y garantizan que todos los alumnos puedan:

Desarrollar la experiencia creativa, técnica y práctica necesaria para realizar las tareas cotidianas con confianza y participar con éxito en un mundo cada vez más tecnológico. Construir y aplicar un repertorio de conocimientos, comprensión y habilidades para diseñar y fabricar prototipos y productos de alta calidad para una 
amplia gama de usuarios. Criticar, evaluar y probar sus ideas y productos y el trabajo de otros. (Departamento de Educación, Reino Unido [UK], 2014, p.)

Estos apartados enuncian procesos que podrían relacionarse con el PC, como las habilidades necesarias para diseñar y fabricar prototipos. Es por ello que aquí se recupera el desarrollo que se propone para esta asignatura, sobre todo en función de los conocimientos técnicos que en estos documentos aparecen:

1) Aplicar su comprensión de cómo fortalecer, endurecer y reforzar estructuras complejas. 2) Comprender y utilizar sistemas mecánicos en sus productos, por ejemplo, engranajes, poleas, levas, palancas y articulaciones. 3) Comprender y utilizar los sistemas eléctricos en sus productos, por ejemplo, circuitos en serie incorporando interruptores, bombillas, zumbadores y motores. 4) Aplicar su comprensión de la informática para programar, monitorear y controlar sus productos. (Departamento de Educación, Reino Unido [UK], 2014, p.)

Esta asignatura presenta algunos elementos que nos permite asociarla a la robótica y a la programación, áreas primordiales para el desarrollo del pensamiento computacional. Es por eso que se destaca en este primer análisis.

\subsubsection{España}

El sistema educativo español constituye el segundo caso de análisis seleccionado en esta tesis. Regido actualmente por su normativa madre, la Ley Orgánica 8/1985reguladora del Derecho a la Educación, que establece educación obligatoria de 6 a 16 años, fija su principio democrático en su artículo 2, al exponer que:

a) La actividad educativa, orientada por los principios y declaraciones de la Constitución, tendrá, en los centros docentes a que se refiere la presente Ley, los siguientes fines: El pleno desarrollo de la personalidad del alumno; b) la formación en el respeto de los derechos y libertades fundamentales, de la igualdad entre hombres y mujeres y en el ejercicio de la tolerancia y de la libertad dentro de los principios 
democráticos de convivencia; c) la adquisición de hábitos intelectuales y técnicas de trabajo, así como de conocimientos científicos, técnicos, humanísticos, históricos y estéticos; d) la capacitación para el ejercicio de actividades profesionales; e) la formación en el respeto de la pluralidad lingüística y cultural de España; f) la preparación para participar activamente en la vida social y cultural; g) la formación para la paz, la cooperación y la solidaridad entre los pueblos y para la prevención de conflictos y para la resolución pacífica de los mismos y no violencia en todos los ámbitos de la vida personal, familiar y social. (Ley Orgánica 8/1985)

El sistema educativo español se organiza en tres niveles: Infantil, Primaria y Secundaria. Cada uno de estos niveles cuenta con un diseño curricular que sienta las bases de lo que se denominan “Enseñanzas mínimas” para cada caso.

La educación infantil se estructura en dos ciclos: 1) el primero de 0 a 3 años y, 2) el segundo ciclo de 3 a 6 años; ambos son de carácter voluntario. Sin embargo, solo el segundo ciclo de la educación infantil es gratuito.

La educación primaria va desde los 6 a los 12 años, es de carácter obligatoria y gratuita. En este nivel existen tres ciclos de dos años cada uno. El desarrollo de estos ciclos está reglado en seis áreas de conocimiento:

1. Conocimiento del medio natural, social y cultural

2. Educación artística

3. Educación física

4. Lengua castellana y literatura

5. Lengua extranjera

6. Matemática

A continuación, se muestra un cuadro del sistema educativo español en el que se visualizan las especificaciones mencionadas: 


\section{Cuadro 14}

Estructura general del sistema educativa español

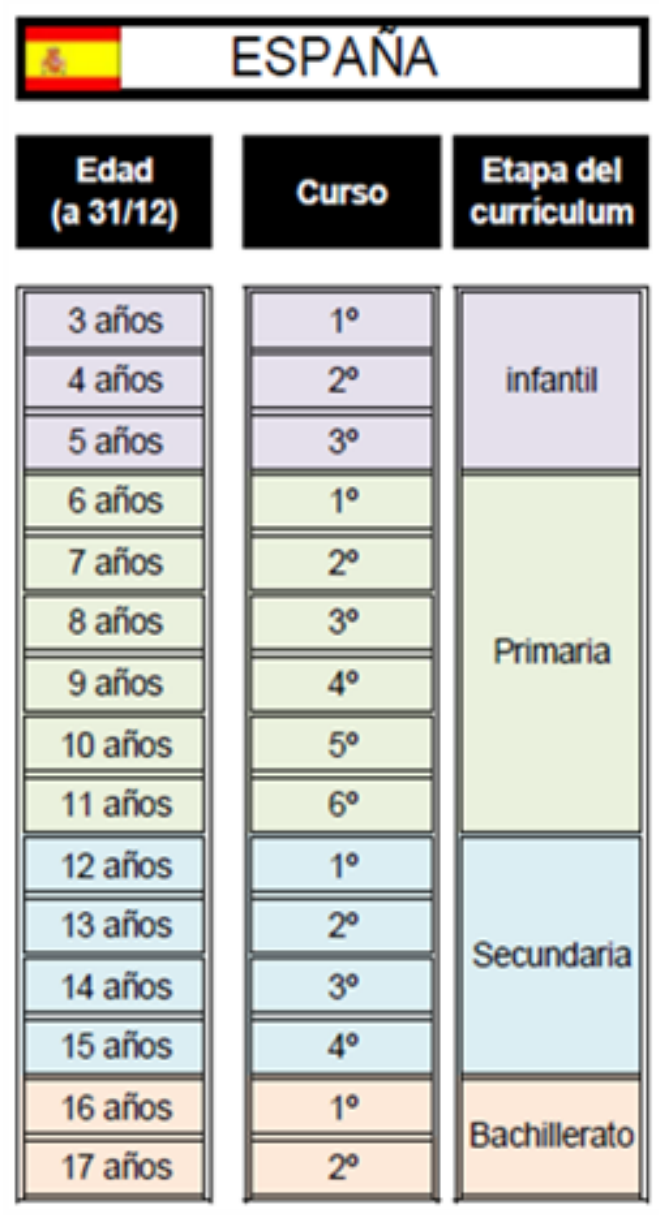

Nota. Adaptado de British Summer, 2014.

En el tercer ciclo de la educación primaria (11 y 12 años) se incluye el área de conocimiento

Educación para la ciudadanía y los derechos humanos. El documento que establece las enseñanzas mínimas de la educación primaria expone los objetivos, contenidos -según ciclos y por bloques temáticos-, criterios de evaluación y un marco de relación para el desarrollo de competencias. En este sentido, la producción de los marcos normativos, resulta amplia en términos del análisis de contenidos que posibilita.

La educación secundaria está estructurada en dos niveles: 1) Educación secundaria obligatoria (ESO) y 2) Bachillerato. La ESO está organizada en cuatro cursos que se 
corresponden con los primeros cuatro años de tramo secundario, y que a su vez, se regulan en dos ciclos: 1) el primero cubre los cursos de $1^{\circ}$ a $\left.3^{\circ} \mathrm{y}, 2\right)$ el segundo ciclo, el $4^{\circ}$ curso. Para la realización de estos cursos los estudiantes tienen tres bloques de asignaturas: 1) asignaturas obligatorias o troncales; 2) asignaturas específicas y 3) asignaturas de libre configuración autonómica. ${ }^{15}$

El $4^{\circ}$ curso de la ESO reviste una situación particular en relación con los tres cursos que lo anteceden, ya que los padres/tutores y estudiantes, deben elegir la modalidad de cursada, para lo cual tienen dos opciones:

a) Opción de enseñanzas académicas para la iniciación al Bachillerato

b) Opción de enseñanzas aplicadas para la iniciación a la Formación Profesional

Los recorridos que se proponen, cambian el enfoque de enseñanza y el tipo de competencia que los estudiantes deberán adquirir. A continuación, se presenta un cuadro, diseñado en esta investigación, en pos de comprender esos recorridos que en el diseño curricular para este nivel se presentan.

\footnotetext{
${ }^{15}$ Las asignaturas de libre configuración autonómica podrán ser materias del bloque de asignaturas específicas no cursadas, materias de ampliación de los contenidos de alguna de las materias de los bloques de asignaturas troncales o específicas, u otras materias a determinar. Estas materias del bloque de asignaturas de libre configuración autonómica podrán ser diferentes en cada uno de los cursos. (Ley Orgánica 8/1985)
} 


\section{Cuadro 15}

Tramo de la ESO

\begin{tabular}{|c|c|c|}
\hline \multicolumn{3}{|c|}{ Cuarto curso de ESO } \\
\hline Tipo de materias & $\begin{array}{l}\text { Opción de enseñanzas } \\
\text { académicas para la } \\
\text { iniciación al Bachillerato }\end{array}$ & $\begin{array}{l}\text { Opción de enseñanzas } \\
\text { aplicadas para la iniciación } \\
\text { a la Formación Profesional }\end{array}$ \\
\hline $\begin{array}{l}\text { Materias generales del } \\
\text { bloque de asignaturas } \\
\text { troncales }\end{array}$ & $\begin{array}{l}\text {-Geografía e Historia. } \\
\text {-Lengua Castellana y } \\
\text { Literatura. } \\
\text {-Matemáticas Orientadas a } \\
\text { las Enseñanzas } \\
\text { Académicas. } \\
\text {-Primera Lengua } \\
\text { Extranjera. }\end{array}$ & $\begin{array}{l}\text {-Geografía e Historia. } \\
\text {-Lengua Castellana y } \\
\text { Literatura. } \\
\text {-Matemáticas Orientadas a } \\
\text { las Enseñanzas Aplicadas. } \\
\text {-Primera Lengua Extranjera }\end{array}$ \\
\hline $\begin{array}{l}\text { Materias de opción del } \\
\text { bloque de asignaturas } \\
\text { troncales } \\
\text { (deben elegir dos materias) }\end{array}$ & $\begin{array}{l}\text {-Biología y Geología. } \\
\text {-Economía. } \\
\text {-Física y Química. } \\
\text {-Latín. }\end{array}$ & $\begin{array}{l}\text {-Ciencias Aplicadas a la } \\
\text { Actividad Profesional. } \\
\text {-Iniciación a la Actividad } \\
\text { Emprendedora y } \\
\text { Empresarial. } \\
\text {-Tecnología. }\end{array}$ \\
\hline Materias específicas & $\begin{array}{l}\text {-Educación Física. } \\
\text {-Religión o Valores Éticos }\end{array}$ & $\begin{array}{l}\text {-Educación Física. } \\
\text {-Religión o Valores Éticos. }\end{array}$ \\
\hline $\begin{array}{l}\text { Materias de las siguientes } \\
\text { del bloque de asignaturas } \\
\text { específicas } \\
\text { (deben elegir un mínimo de } \\
\text { una y máximo de cuatro) }\end{array}$ & $\begin{array}{l}\text {-Artes Escénicas y Danza. } \\
\text {-Cultura Científica. } \\
\text {-Cultura Clásica. } \\
\text {-Educación Plástica, Visual } \\
\text { y Audiovisual. } \\
\text {-Filosofía. } \\
\text {-Música. } \\
\text {-Segunda Lengua } \\
\text { Extranjera. } \\
\text {-Tecnologías de la } \\
\text { Información y la } \\
\text { Comunicación. } \\
\text {-Religión. }\end{array}$ & $\begin{array}{l}\text {-Artes Escénicas y Danza. } \\
\text {-Cultura Científica. } \\
\text {-Cultura Clásica. } \\
\text {-Educación Plástica, Visual } \\
\text { y Audiovisual. } \\
\text {-Filosofía. } \\
\text {-Música. } \\
\text {-Segunda Lengua } \\
\text { Extranjera. } \\
\text {-Tecnologías de la } \\
\text { Información y la } \\
\text { Comunicación. } \\
\text {-Religión. }\end{array}$ \\
\hline
\end{tabular}


El Bachillerato en España comprende el último ciclo de la Educación Secundaria. Para acceder es necesario contar con el título del tramo de la ESO, es voluntario y combina una serie de modalidades para su recorrido que lo hacen más flexible y dinámico. En su artículo 24 el Currículo Básico para la Educación Secundaria (2014) establece:

El Bachillerato tiene como finalidad proporcionar al alumnado formación, madurez intelectual y humana, conocimientos y habilidades que les permitan desarrollar funciones sociales e incorporarse a la vida activa con responsabilidad y competencia. Asimismo, capacitará al alumnado para acceder a la Educación Superior. (p. 21)

El Bachillerato se organiza en dos cursos que tienen un máximo de cuatro años para su recorrido. Las modalidades sobre las que se puede optar son tres: Ciencia, Ciencias Sociales y Humanidades y Arte. Todas están condicionadas a la disponibilidad en cada centro educativo. Aquí los recorridos son libres, exceptuando el primer grupo de materias obligatorias; después, cada estudiante arma su recorrido en función de sus intereses propios y de la modalidad seleccionada.

La estructura del sistema escolar español, en general, reviste un marco de complejidad que tiene que ver con la especificidad de sus niveles, pero además con un enfoque de enseñanza basado en competencias, para lo cual el desarrollo de documentos normativos resultó fundamental en dicha estructura.

\subsubsection{Documentos de enseñanzas mínimas y currículo básico}

En el rastreo realizado en la presente investigación sobre la utilización del término pensamiento computacional y sus implicancias en el desarrollo de la competencia digital en la educación española, se analizarán los documentos públicos del Ministerio de Educación que a continuación se detallan:

- Real Decreto 1630/2006, de 29 de diciembre de 2006, mediante el que se establecen las enseñanzas mínimas del segundo ciclo de Educación Infantil. 
- Real Decreto 1513/2006, de 7 de diciembre de 2006, en el que se establecen las enseñanzas mínimas de la Educación Primaria.

- Real Decreto 126/2014, de 28 de febrero de 2014, en el que se establece el currículo básico de la Educación Primaria.

- Real Decreto 1105/2014, de 26 de diciembre de 2014, en el que se establece el currículo básico de la Educación Secundaria Obligatoria y del Bachillerato (versión resumen).

- Real Decreto 1105/2014, de 26 de diciembre de 2014, por el que se establece el currículo básico de la Educación Secundaria Obligatoria y del Bachillerato (versión boletín oficial).

En la Educación Infantil no se encuentran referencias al PC en documento que establece las enseñanzas mínimas del segundo ciclo; sin embargo, resulta llamativa la incorporación del uso de TIC. Así, por ejemplo, lo que aparece con mayor claridad es la idea de pensar las tecnologías como nuevas formas de lenguaje. Entre de los argumentos que se establecen para el área de Lenguaje (comunicación y representación) se destaca que "Las diferentes formas de comunicación y representación que se integran en esta área son: el lenguaje verbal, el lenguaje artístico, el lenguaje corporal, el lenguaje audiovisual y de las tecnologías de la información y la comunicación.” (2006, p.12). Siguiendo la línea propuesta es que se expresa: "El lenguaje audiovisual y las tecnologías de la información y la comunicación presentes en la vida infantil, requieren un tratamiento educativo que, a partir del uso apropiado, inicie a niñas y niños en la comprensión de los mensajes audiovisuales y en su utilización adecuada.” (p. 13).

Al mismo tiempo, se desarrolla un bloque temático en referencia llamado: Bloque 2, Lenguaje Audiovisual y Tecnologías de la Información y la Comunicación, donde lo que se establece en relación a las TIC es:

Iniciación en el uso de instrumentos tecnológicos como ordenador, cámara o reproductores de sonido e imagen, como elementos de comunicación. Acercamiento a producciones audiovisuales como películas, dibujos animados o videojuegos. Valoración crítica de sus contenidos y de su estética. Distinción progresiva entre la 
realidad y la representación audiovisual. Toma progresiva de conciencia de la necesidad de un uso moderado de los medios audiovisuales y de las tecnologías de la información y la comunicación. (pp. 14-15)

Esta incorporación de contenidos, denota una intencionalidad de acercamiento de la temática en los niveles iniciales. Si bien no es correcto hablar de PC, en tanto no hay elementos suficientes para su identificación, estos contenidos pueden asociarse al desarrollo de la competencia digital.

Respecto de la Educación Primaria, el documento sobre enseñanzas mínimas desarrolla el enfoque de competencias de manera explícita, citando las competencias clave difundidas por la UE. En este sentido sobre la competencia digital que es la que interesa destacar en su relación con el PC expresa:

En definitiva, la competencia digital comporta hacer uso habitual de los recursos tecnológicos disponibles para resolver problemas reales de modo eficiente. Al mismo tiempo, posibilita evaluar y seleccionar nuevas fuentes de información e innovaciones tecnológicas a medida que van apareciendo, en función de su utilidad para acometer tareas u objetivos específicos. En síntesis, el tratamiento de la información y la competencia digital implican ser una persona autónoma, eficaz, responsable, crítica y reflexiva al seleccionar, tratar y utilizar la información y sus fuentes, así como las distintas herramientas tecnológicas; también tener una actitud crítica y reflexiva en la valoración de la información disponible, contrastándola cuando es necesario, y respetar las normas de conducta acordadas socialmente para regular el uso de la información y sus fuentes en los distintos soportes. (p.15)

En el desarrollo de esta competencia y sus argumentos para el desarrollo de su tratamiento transversal a lo largo de toda la educación primaria, resulta interesante la articulación que se hace entre un enfoque basado en las TIC y un enfoque de producción y resolución de problemas. El término PC no aparece en este documento, pero como ya se viene desarrollando en esta tesis, comprendemos que los elementos enunciados para definir a la competencia digital, son motivo de análisis. 
El segundo documento consultado: el Currículo Básico de la Educación Primaria, fortalece el enfoque de competencias, en tanto establece un nuevo listado que recupera siete competencias del currículo "1) Comunicación lingüística; 2) Competencia matemática y competencias básicas en ciencia y tecnología; 3) Competencia digital, Aprender a aprender; 4) Competencias sociales y cívicas; 5) Sentido de iniciativa y espíritu emprendedor y, 6) Conciencia y expresiones culturales" (p.5).

Además de establecer competencias para el desarrollo sugiere orientaciones relacionadas a las metodologías para su enseñanza.

En este diseño curricular, la transversalidad cuenta con un artículo que la define y enuncia, dejando establecidos los contenidos y las formas de su implementación. Así, por ejemplo, el artículo 10 de este documento establece:

Elementos transversales: sin perjuicio de su tratamiento específico en algunas de las asignaturas de cada etapa, la comprensión lectora, la expresión oral y escrita, la comunicación audiovisual, las Tecnologías de la Información y la Comunicación, el emprendimiento y la educación cívica y constitucional se trabajarán en todas las asignaturas. (p.9)

Si bien no es posible asegurar cuáles son los contenidos transversales que se incluyen, hay indicios en estos documentos que dan lugar la identificación de un enfoque TIC. En este sentido lo que se mantiene en cada una de las áreas es una incorporación de tecnologías (herramientas, recursos, software) en pro del desarrollo de procesos de enseñanza/aprendizaje. Esto no nos permite hacer una relación sólida con el término PC, en tanto se considera que su existencia va más allá de la mera incorporación de herramientas. En ambos documentos del nivel primario de este país, no se encuentran registros sobre el uso del PC.

En cuanto a la Educación Secundaria, los documentos consultados que se analizaron, no evidencian la utilización del término pensamiento computacional. Sí se encuentran referencias en relación a la competencia digital, pues como se explicó anteriormente, estos programas curriculares están basados en el esquema de competencias, adoptando las 
competencias claves definidas por la UE. A partir de esta referencia, se analizarán las asignaturas que destacan explícitamente, el fortalecimiento de esta competencia:

\subsubsection{Matemática orientada a las enseñanzas aplicadas y Matemática orientada a las enseñanzas académicas}

Estas asignaturas presentan dos enfoques diferentes de una misma disciplina, su elección radica en la orientación que los estudiantes realicen para el cursado del último año de la ESO. En ambas se trabaja en línea de objetivos, siendo la competencia digital, un eje transversal. al respecto se establece:

La resolución de problemas y los proyectos de investigación deben ser ejes fundamentales en el proceso de enseñanza y aprendizaje de las Matemáticas. La habilidad de formular, plantear, interpretar y resolver problemas es una de las capacidades esenciales de la actividad matemática, ya que permite a las personas emplear los procesos cognitivos para abordar y resolver situaciones interdisciplinares reales, lo que resulta de máximo interés para el desarrollo de la creatividad y el pensamiento lógico. En este proceso de resolución e investigación están involucradas muchas otras competencias, además de la matemática, entre otras, (...) la competencia digital, al tratar de forma adecuada la información y, en su caso, servir de apoyo a la resolución del problema y comprobación de la solución. (Real Decreto 1105/2014, p. 338)

Además de la referencia a la competencia digital, aparece por primera vez enunciado el "pensamiento matemático". Aquí se destaca por su relación con el pensamiento computacional, y por la forma en que se relaciona su adquisición en términos de habilidades. Al respecto, el mismo documento expresa:

El alumnado que curse esta asignatura, progresará en la adquisición de algunas habilidades de pensamiento matemático, en concreto, en la capacidad de analizar, interpretar y comunicar con técnicas matemáticas diversos fenómenos y problemas en distintos contextos, así como de proporcionar soluciones prácticas a los mismos; 
también debe desarrollar actitudes positivas hacia la aplicación práctica del conocimiento matemático, tanto para el enriquecimiento personal como para la valoración de su papel en el progreso de la humanidad. (p.399)

\subsubsection{Primera Lengua Extranjera}

En esta asignatura se hace alusión a la competencia digital como parte de la competencia comunicativa, a pesar de no ser tangible en los contenidos, el cómo se desarrolla esa relación. Sobre ello se expone:

En este y en cualquier otro ámbito, la actividad lingüística se realiza en gran parte hoy en día a través de medios tecnológicos. Estos medios están recogidos en el currículo básico como soportes naturales de los textos orales o escritos que el estudiante habrá de producir, comprender y procesar, por lo que la competencia digital se entiende como parte sustancial de la competencia comunicativa. (p. 448)

\subsubsection{Tecnologías de la Información y la Comunicación}

Esta asignatura está en el tramo de la ESO y también en el Bachillerato según la elección que realice el estudiante. En la fundamentación que aparece en el currículo básico de la educación secundaria, se hace referencia a la competencia digital y cómo deben formarse los estudiantes:

(...) Los alumnos y alumnas deben estar preparados para adaptarse a un nuevo mapa de sociedad en transformación. La formación en competencias es un imperativo curricular que, en el caso de la competencia digital, ha tenido hasta ahora, una especificación poco desarrollada y diversa en sus descriptores al no existir un marco de referencia común. Desarrollar la competencia digital en el sistema educativo requiere una correcta integración del uso de las TIC en las aulas y que los docentes tengan la formación necesaria en esa competencia. Es probablemente este último 
factor el más importante para el desarrollo de una cultura digital en el aula y la sintonía del sistema educativo con la nueva "sociedad red".

En este mismo documento se hace un reconocimiento a una de las problemáticas clave: la formación de docente en el área, sobre todo en nuevas formas de enseñanza. La asignatura propone diferentes niveles de adquisición de conocimientos en tanto que propone:

En $4^{\circ}$ de ESO se debe proveer al alumno con las habilidades necesarias para adaptarse a los cambios propios de las TIC, a fin de que el alumno adquiera la soltura necesaria con los medios informáticos actuales para incorporarse con plenas competencias a la vida activa o para continuar estudios. En Bachillerato, la materia debe proponer la consolidación de una serie de aspectos tecnológicos indispensables, tanto para la incorporación a la vida profesional, como para proseguir estudios superiores (...) Dentro del bachillerato, existen dos niveles sobre esta asignatura, para cada uno de los ciclos. En estos diseños aparecen contenidos relacionados a las ciencias de la computación como la programación, redes y seguridad. Lo que deja ver el salto de un enfoque centrado en las TIC y en la producción con herramientas digitales a un enfoque más asociado a la informática y programación. (p.551)

\subsubsection{Tecnología}

En esta asignatura se articulan los contenidos de la técnica asociados al desarrollo de la competencia digital, haciendo hincapié en su incidencia social y cultural. Para ello se reconoce el avance tecnológico, pero también la necesidad de apostar la formación de un sujeto con capacidad crítica respecto de lo que se produce con tecnologías. Al respecto, el documento expone que:

El desarrollo tecnológico configura el mundo actual que conocemos. En muchas ocasiones, la tecnología interactúa en nuestra vida, aunque pasa desapercibida por lo habituados que estamos a ella. Este contexto hace necesaria la formación de ciudadanos en la toma de decisiones relacionadas con procesos tecnológicos, con sentido crítico, con capacidad de resolver problemas relacionados con ellos y, en 
definitiva, para utilizar y conocer materiales, procesos y objetos tecnológicos que facilitan la capacidad de actuar en un entorno tecnificado que mejora la calidad de vida. (...) Por este motivo, la sociedad en la que vivimos necesita una educación tecnológica amplia que facilite el conocimiento de las diversas tecnologías, así como las técnicas y los conocimientos científicos que los sustentan. El desarrollo tecnológico se fundamenta en principios elementales y máquinas simples que, sumados convenientemente, crean nuevas máquinas y generan la realidad que nos rodea. (p.452)

Los contenidos de esta asignatura son de índole general y abarcan elementos físicos y abstractos como el desarrollo de circuitos eléctricos y conceptos de programación. Su relación con la competencia digital tiene que ver con desnaturalizar los procesos de automatización para lograr el mejoramiento de la resolución de problemas de la vida real a partir de herramientas digitales.

\subsection{Conclusiones}

En este capítulo se realizó un análisis de diez políticas de la Unión Europea, lo que representa para esta investigación un panorama de variados documentos que recorren los ámbitos educativos, laborales y profesionales. Las mismas fueron seleccionadas según relevancia, temporalidad y su relación con los procesos de enseñanza-aprendizaje. El recorrido de cada una de ellas permitió rastrear si el PC se trabaja en la UE, así como el enfoque sobre el cual se fundamenta su apoyo a las políticas educativas de los países miembros. Lo investigado hasta ahora demuestra que el término PC es muy poco utilizado en el corpus de los documentos seleccionados y que, en todo caso, para la UE la comparación del PC con la competencia digital podría ser legítima y viable en términos operativos y de implementación.

A los fines de esta investigación, la posible relación entre competencia digital y PC es la que permitiría el reconocimiento del proceso de alfabetización digital como competencia clave. En este sentido, se reconoce el consenso respecto de las competencias digitales y la necesidad de formar en habilidades, en las que lo digital aparece como central. A su vez se destaca que 
el desarrollo de la competencia digital y del PC como una relación explícita, constituye un área de vacancia en los documentos analizados.

En este capítulo, además, se realiza el estudio de los casos seleccionados, Reino Unido y España, como materialidad de análisis respecto de los usos que del término pensamiento computacional hacen los ministerios, órganos responsables en ambos países de la escritura de las estructuras y contenidos de los currículos nacionales en estos países. Se realiza un recorrido por 4 documentos gubernamentales que corresponden los curriculum nacionales vigentes, y se pudo apreciar que es muy escasa la aparición del PC en ambos países. A su vez, se puede identificar que existe una diferencia significativa en términos de la presencia y conceptualización que del PC se realiza en el Curriculum Nacional del Reino Unido.

De este primer acercamiento se pueden reconocer dos perspectivas diferentes de incorporación de contenidos relacionados al PC: 1) desde una perspectiva disciplinar como en el Reino Unido que apuesta a una estrategia de curricularización, mientras que 2) en España se hace fuerte la perspectiva de transversalidad. Ambos enfoques constituyen un tema de debate en la actualidad, pues, tanto profesionales del área de Informática, como docentes y equipos de gestión educativa, discuten abiertamente sobre las posibilidades de trabajo áulico en pos del desarrollo del PC.

En los documentos españoles se reconoce una fuerte aparición del concepto de competencia digital, asociado al PC, ello debido a los aspectos inherentes a esta competencia que son familiares a la noción que se ha analizado en esta investigación del término estudiado. Aun así, las referencias en los documentos que describen el sistema educativo español no son claras al tomar un posicionamiento o referirse al PC de forma explícita.

Es importante destacar que, al no existir en ninguno de los países analizados, estudios concretos sobre el impacto de estas dos estrategias, es difícil proyectar su resultado. Sin embargo, la evaluación respecto de la incorporación del PC en la enseñanza es uno de los temas que se proponen como línea de investigación para continuar con el desarrollo de esta temática. 


\section{Capítulo 6: Dimensiones transversales y problemáticas sobre el PC, la enseñanza de las CC y la educación}

\subsection{Introducción: definición de las dimensiones de análisis}

En este capítulo se definen diferentes abordajes que tratan la enseñanza del PC. Los mismos se desarrollan en función de los sistemas de educación de los países considerados para Reino Unido y España, y se articulan con trabajos de desarrollo académico sobre el tema.

Se realizará un análisis que profundice algunos de los debates actuales que presenta el PC y su enseñanza a los fines de promover una línea de diálogo y problematización entre lo que se hizo, se hace y se proyecta respecto de esta temática. El ordenamiento y selección se piensan como articuladoras de los campos de educación, informática y comunicación, en tanto que los procesos educativos son ámbitos de desarrollo para el PC, la competencia digital y el proceso de alfabetización digital. En el abordaje se identificarán las tensiones existentes entre las perspectivas y enfoques sobre la incorporación del PC en las propuestas educativas, desde la curricularización, la enseñanza y su didáctica y las estrategias. A su vez, se integrará en este apartado, la problemática respecto de la enseñanza de las Ciencias de la Computación como campo disciplinar fundante del PC.

\subsubsection{Curricularización de los contenidos}

El auge del desarrollo tecnológico y su implicancia en todos los ámbitos de la vida cotidiana, promueve la reflexión respecto de la incorporación de un campo disciplinar sobre contenidos específicos de $\mathrm{CC}^{16}$ en espacios curriculares de la educación formal. Es un tema de debate actual dentro del cual la incorporación del PC resulta fundamental y que pone en evidencia una redefinición de las consideraciones sobre el currículum moderno.

\footnotetext{
${ }^{16}$ Abreviatura que hemos utilizado en otros capítulos para referirnos a las Ciencias de la Computación.
} 
Son pocos los sistemas europeos que han optado por la vía de la curricularización de los contenidos de esta área, y hacerlo no implica per se la adopción de un enfoque de desarrollo del pensamiento computacional. En esta investigación se aborda la inclusión del PC como una competencia clave que involucra un proceso de alfabetización digital en sentido amplio. $\mathrm{Al}$ respecto, Valverde et al. (2015) afirma:

La alfabetización digital ofrece la oportunidad de adquirir competencias que permiten conocer y comprender los procesos de comunicación a través de dispositivos digitales; valorar reflexivamente qué recursos, contenidos y artefactos ofrecen un servicio de calidad adecuado a las necesidades personales y sociales; reconocer los principios ideológicos y los intereses económicos que están unidos a organizaciones e individuos que forman parte de la sociedad-red y, por último, construir y difundir mensajes en diferentes lenguajes como medio de expresión propia, libre, crítica y responsable con su comunidad. (p.2)

Las propuestas curriculares analizadas en esta tesis presentan diferencias claves en relación con el contexto en el que se adoptan y a los procesos de desarrollo de estas discusiones. Así, por ejemplo, el Reino Unido es uno de los primeros países en incluir materias con contenido en CC. La materia Informática, que es de carácter obligatorio, se dicta a lo largo de la formación primaria y secundaria. En esos espacios se prevé la enseñanza de la programación como actor clave para el desarrollo del PC; es decir, lo que se busca es fortalecer el PC, siendo el contenido para lograrlo las CC, especialmente programación.

En propuestas más generales tenemos el caso del currículum español que ha resuelto, recientemente, trabajar el contenido asociado a las tecnologías de forma transversal a través de la incorporación de propuestas áulicas innovadoras que fortalezcan el desarrollo del PC, asociado a la competencia digital. Como puede observarse, aún no hay consensos sobre la curricularización ni sobre la medición de su impacto.

Sin embargo, el dilema sobre la incorporación del pensamiento computacional en los diseños curriculares radica, principalmente, en su campo de origen: las CC. El enfoque que fomenta la inclusión del PC en ámbitos educativos a partir de una asignatura o espacio curricular específico está ligado a la inclusión de contenidos de CC. Así, esa mirada comprende una 
relación lineal entre los contenidos de las CC y el desarrollo del PC. Otra de las situaciones de tensión en relación a esta problemática es la asociación directa del PC a las acciones de programación y robótica, pues se considera el desarrollo del PC central en los contenidos de estas dos disciplinas. Esta idea es muy recurrente en trabajos que abordan la problemática sobre su enseñanza; de este modo, la discusión sobre la curricularización tiene doble entrada: por un lado, la pregunta sobre la inclusión de un espacio curricular propio; por el otro, los contenidos que deben incluirse en este espacio. Como puede apreciarse, es fundamental el enfoque a partir del cual se incorpore el PC. En términos pedagógicos, el paradigma sobre el cual se refleje la direccionalidad de ese espacio específico será lo que modifique o impacte en las lógicas de su enseñanza y en los procesos educativos que se generen.

$\mathrm{Al}$ respecto, existen al menos tres formas de curricularización para la inclusión del PC en ámbitos educativos:

1. Materias de carácter general: en estos espacios lo que predomina es un enfoque generalista sobre tecnologías asociadas a un paradigma de inclusión TIC (Dussel, 2012; Terigi, 2010). En estos espacios se formaron parte de los primeros diseños curriculares producto de la incorporación de equipamiento tecnológico en los establecimientos educativos. Esta estrategia es la que se adopta en el currículo español, donde se encuentran materias con un enfoque más abocado a las TIC.

2. Materias de campo disciplinar específico: con el avance en líneas investigación y de desarrollo de experiencias áulicas con tecnologías, se comprende que el uso de TIC no es equivalente al manejo de lenguajes. Esta línea de trabajo sobre las currículas escolares estuvo fuertemente ligada a las necesidades del mercado laboral y a la divulgación de las carreras relacionadas con la Informática. Así, por ejemplo, la necesidad de contar con programadores y con mayor cantidad de estudiantes en las carreras afines hacen posible que se integren materias de contenido específico en la educación básica. De esta forma se fortalece un enfoque que destaca la formación disciplinar en el campo de las CC y que sostienen la integración de la tecnología a través de la Programación. Aquí son interesantes la propuestas que promueven la 
formación de profesionales. ${ }^{17}$ El currículum de Reino unido está basado en una estrategia de estas características.

3. Materias asociadas a otros campos disciplinares: este enfoque resulta similar a la propuesta que entiende al PC como estrategia de enseñanza, en tanto es abordado a partir de materias que tienen como prioridad el desarrollo de otros contenidos. Aquí la incorporación del PC está relacionada con la utilización de tecnologías para la enseñanza-aprendizaje, como el caso de los espacios destinados a Diseño Industrial, Robótica Educativa o Electrónica. Estas asignaturas son más frecuentes en los espacios destinados a la formación pre profesional y son la estrategia de curricularización menos presente.

En todos los casos, el PC no es objeto directo en términos de contenidos y objetivos meta para el desarrollo de una propuesta curricular. Lo que se incorporan son contenidos para su promoción y fortalecimiento o estrategias que lo resaltan en la enseñanza de otros contenidos. En este punto es importante reconocer la dificultad que implica para el establecimiento de una propuesta concreta, que el PC no tenga una única definición que permita comprenderlo en su integridad, más allá de los enfoques pedagógicos y el impacto en el desarrollo de contenidos específicos.

La novedad que representa su inclusión en los diseños curriculares debería ser considerada como referencia en las modificaciones curriculares que están siendo realizadas en algunas disciplinas; ello implica que las evaluaciones sobre el impacto de estas estrategias sea todavía un campo de vacancia. (Arranz y Pérez, 2017, p.25)

En este escenario sobre diferentes formatos de implementación para el desarrollo del PC dentro de espacios educativos formales deja de manifiesto que, por el momento, estas propuestas trabajan sobre el fortalecimiento de alguno de los elementos que lo constituyen. El primero, las materias sobre programación como las más efectivas a la hora de promover procesos relacionados con el desarrollo del pensamiento lógico, matemático, recursivo y abstracto. Sin embargo, aún no se cuenta con estudios que den cuenta del desarrollo del PC

\footnotetext{
${ }^{17}$ Se hace referencia a los tramos de Formación Profesional del Sistema Español, por ejemplo, el recorrido curricular que ofrece el título de Técnico superior en desarrollo de aplicaciones multiforma.
} 
integral. Y al mismo tiempo, sólo considera de manera restrictiva el desarrollo de una práctica concreta: la programación.

El segundo caso son aquellas materias de índole más generalistas, donde se plantean promover procesos mediados por tecnologías que, dependiendo de las propuestas pedagógicas que en estos espacios se desarrollen, tenderán a superar o no el mero uso de tecnologías para producir con ellas.

\subsubsection{Enseñanza de las ciencias de la computación ¿una didáctica específica?}

En el recorrido de las propuestas que se han analizado a lo largo de esta tesis, se observa una situación clave: “enseñar a enseñar”. El desarrollo de estrategias de reforma curricular para la incorporación de espacios donde se aborden contenidos propios de las CC contienen la pregunta pedagógica respecto de los procesos de enseñanza. Enseñar CC actualmente es una preocupación global, pues por un lado están las enormes oportunidades que brindan las tecnologías y el software como motor de desarrollo económico y social y, por otro, resulta esencial que los ciudadanos comprendan los elementos constitutivos de esta disciplina para que, tanto estudiantes como docentes, sean capaces de adaptarlos y modificarlos a sus necesidades específicas en el aula, ya que se habita un mundo cada vez más conectado en el que la computación es ubicua. A sabiendas de ambas situaciones, lo que hoy se discute se centra más con las formas de la integración de estos contenidos que con los contenidos en sí mismos.

La necesidad de una didáctica específica para el campo de las CC rescata las tensiones ya señaladas en los escenarios donde la discusión por la curricularización ya fue saldada. Aun así, las dudas devienen en lo que en palabras de Daniel Feldman (2000) se explica:

Cualquier planteo sobre la didáctica enfrenta hoy varios problemas. Uno es el de los cambios de sus preocupaciones iniciales: de una disciplina del método se derivó en un campo fragmentado en preocupaciones crítico-analíticas, especialización de la tarea en áreas (las “didácticas de” la matemática, las ciencias naturales, la lengua, etc.) dependencia de avances científicos en campos no educativos sobre todo 
provenientes de las teorías cognitivas $\mathrm{y}$, en el caso del trabajo con maestros y profesores, la influencia de las tendencias "reflexivas" basadas en las ideas del profesor como investigador. (p.3)

Esta problemática del campo de la didáctica general resulta interesante de ser analizada en relación a la enseñanza de Informática en las escuelas, que pone el acento en la teoría detrás de la computación y en el uso de herramientas, que no siempre entran en relación con las prácticas cotidianas de los sujetos. Al respecto de esto, Queiruga et al. (2019) expresan que trabajar desde el enfoque del pensamiento computacional permite abordar la temática desde el proceso de reconocimiento de los aspectos de la computación en el mundo que nos rodea y la aplicación de herramientas y técnicas de computación para entender y razonar sobre sistemas y procesos naturales y artificiales.

Es por ello que la incorporación del PC a los sistemas formales de educación inaugura nuevos desafíos en la formación docente, pues se requieren profesionales idóneos para afrontar la enseñanza de estos nuevos conocimientos en el contexto actual en el que se busca incorporar herramientas para el futuro. La idoneidad a la que nos referimos es sobre los contenidos, pero fundamentalmente sobre su enseñanza. No es lo mismo enseñar a programar que enseñar a enseñar programación. Esta situación no es nueva en tanto deviene de la herencia del campo de las $\mathrm{CC}$, el cual no tiene tradición en la formación pedagógica académica, sino que la formación docente es experiencial o generalista. Si a esto sumamos que las carreras relacionadas con la informática son relativamente jóvenes, pues aparecen en la década del 60, y la problemática respecto de la enseñanza del campo es de los años 90 . En este sentido, se reconoce que uno de los principales nodos de la implementación de estos contenidos tiene que ver con la formación de los docentes. Los países que asumieron el desafío de la incorporación de estos contenidos en espacios del currículo oficial, expresan que la exigua cantidad de docentes formados en esta área resulta ser uno de los principales impedimentos y/u obstáculos para llevar adelante esta política educativa.

Así, pues, la enseñanza de estos contenidos reviste un problema de carácter urgente, ya que la velocidad de los cambios tecnológicos ha dejado a los sistemas educativos muy lejos de las demandas de los mercados e incluso de la gobernabilidad. A nivel internacional existen múltiples experiencias que trabajan sobre la enseñanza de las CC en la educación formal 
como el Reino Unido que desde 2014 ha incorporado la enseñanza de la programación en su sistema de educación escolar a partir de los 5 años. Otra referencia es Estonia, una de las economías europeas que más apuesta al desarrollo tecnológico y que viene impulsando, a través de diferentes iniciativas estatales, la enseñanza de la programación en la escuela. Otras experiencias pueden observarse en varios estados de los EE.UU. que también han implementado políticas activas en respuesta al respaldo de la industria tecnológica, mediante el movimiento LearnToCode, liderado fundamentalmente por las iniciativas globales code.org y codeacademy. Israel, Australia, Japón y Finlandia son otros países que cuentan con iniciativas similares en relación con la incorporación de la enseñanza de las CC en las escuelas. Estos antecedentes refuerzan la necesidad de asumir los desafíos que estas iniciativas abren frente a la formación docente, en tanto políticas de estado. El desarrollo de propuestas curriculares requiere de forma imperiosa profesionales formados en el campo de la enseñanza. Enseñar CC desde el paradigma que incluya el pensamiento computacional implica el reto de trabajar desde una pedagogía con sentido crítico, que valore la potencia de los procesos de múltiples condicionamientos del sujeto, en pos de contribuir al desarrollo de una nueva forma de entender la tecnología y sus procesos. Esta nueva forma implica apropiación, interés, entusiasmo y compromiso puestos en la superación de los enfoques más tradicionales, asociados a la adquisición y manejo de recursos para el desarrollo de procesos de producción y creación.

Propuestas como la Escuela de Pensamiento Computacional 2018-2019, impulsada por el Ministerio de Educación y Formación Profesional de España, tienen como objetivo ofrecer recursos educativos abiertos, formación y soluciones tecnológicas que ayuden a los docentes a incorporar habilidades de pensamiento computacional, drones, robótica y programación en el aula.

Si bien la formación docente dentro del enfoque que recupera el PC para la enseñanza es clave, resulta preciso señalar la pertinencia de la construcción colaborativa de un campo didáctico que dé respuestas a las necesidades en el proceso de trasposición didáctica que supone no sólo favorecer intervenciones adecuadas para el desarrollo de las capacidades en $\mathrm{CC}$, sino también, promover la observación epistemológica del campo. 


\subsubsection{Programación y robótica educativa como estrategia didáctica}

La enseñanza de la programación en escuelas constituye toda una corriente de trabajo cuando se la asocia al desarrollo del pensamiento computacional. El estudio de las CC, su relación con la producción y la creación están íntimamente relacionados con las actividades lúdicas que implican la programación y la robótica.

Es necesario comprender la programación como alternativa pionera en el desarrollo de propuestas curriculares superadoras, más allá de un enfoque generalista que pregona un enfoque más asociado a las TIC. La programación sienta las bases para la pregunta sobre la inclusión de contenidos específicos de un campo disciplinar para la enseñanza de una acción concreta de ese campo: la programación y sus lenguajes. Esta discusión se ve favorecida por el desarrollo de los lenguajes de programación por bloques que buscaban acercar a los niños en edad escolar temprana a un lenguaje de programación más amigable.

Es así que los entornos de programación como Scratc, ScratchJr y Alice, entre otros, desempeñan un papel esencial en este proceso. Estos entornos permiten la creación de programas que podrían ser descritos como juegos, historias o como la combinación de historias interactivas y juegos. Scratch, ScratchJr y otros entornos de programación gráfica fueron diseñados específicamente para abordar las necesidades de desarrollo y aprendizaje de niños (edades 5-7) y jóvenes (edades 8-15), (Flannery et al. 2013; Resnick et al. 2009; Sáez López, González \& Cano, 2016).

Otras iniciativas relacionadas con la enseñanza de la programación pero en ámbitos que no necesariamente son los de la escuela, son las estrategias mediáticas para el desarrollo de desafíos en línea, como por ejemplo Code for Hour. Definida como La Hora del Código por su traducción es una introducción a las Ciencias de la Computación, diseñada por Code.org

para mostrar que todo el mundo puede aprender a programar y así comprender los fundamentos básicos de la disciplina. Es una estrategia de difusión, pensada para promover la programación a partir de que todos los interesados puedan comenzar dedicando una hora a la programación. 
La evidencia de que la programación instala, desde su incorporación en escuelas, un cambio de paradigma para pensar prácticas educativas, formación con tecnologías y competencias, se ve fortalecida con la aparición de un campo que en la escuela no tenía referencias significativas: las ciencias de la computación. El desarrollo del pensamiento computacional se ve rápidamente arraigado en la producción de código y la acción de programar es entendida como inherente al PC. Este, sin dudas, constituye un posicionamiento frente al problema de la enseñanza de un campo disciplinar específico, atravesado por la tensión entre su curricularización y su transversalidad. Lo que aquí se quiere señalar es que la incorporación de la programación funda las bases de estas ideas, y constituye uno de los argumentos más fundamentados para la inserción de contenidos de CC desde un enfoque que defiende su curricularización. Sobre este tema, Valverde et al. (2015) sostiene:

En este contexto ha resurgido en los últimos años un movimiento educativo a nivel internacional relacionado con la introducción del pensamiento computacional, la programación informática y la robótica en las escuelas. En la historia de la Tecnología Educativa se describe cómo los primeros pasos de la informática en las aulas, en la década de los ochenta del siglo XX, estuvieron ligados al aprendizaje de la geometría mediante el uso de un lenguaje de programación denominado «Logo» y su famosa «tortuga», dentro de un proyecto educativo conformado por las ideas de Dewey, Piaget o Vygotsky, y materializado por Seymour Papert. (p.3)

Recientemente, la robótica educativa ha logrado constituirse como una alternativa en el trabajo articulado con los contenidos de programación y los denominados contenidos STEAM. ${ }^{18}$ La robótica es un área de las CC que involucra tecnología de sensores, inteligencia artificial, automatización de tareas y programación. Sin embargo, la utilización, de robots en ámbitos educativos potencia el desarrollo del trabajo en equipo, la colaboración y por ello se constituye como "medio para". Al respecto de esto, Del Mar Raga (2006) explica:

La robótica en el ámbito educativo se convierte en un recurso para facilitar el aprendizaje y desarrollar competencias generales como la socialización, la

\footnotetext{
${ }^{18}$ Science, Technology, Engineering Arts and Mathematics, por su referencia en inglés.
} 
creatividad y la iniciativa, que permitan al estudiante dar una respuesta eficiente a los entornos cambiantes del mundo actual. (p.122)

La conjugación de estos procesos permite ir más allá del funcionamiento del robot, promoviendo el desarrollo de competencias relacionadas con la toma de decisiones, la formación científico-tecnológica y el desarrollo social. Como característica fundamental, la robótica educativa, favorece los procesos de creación a partir del uso y manipulación de diversos materiales (Vivet, 1989).

Las estrategias de programación y robótica se constituyen hoy como fundamentales para el cultivo de actitudes científicas básicas como el asombro, la curiosidad, el análisis y la investigación. Sin embargo, es su característica manual - artesanal la que suele conquistar el interés de los estudiantes dentro de las aulas, la confección de robots con diversos materiales, el armado de los circuitos eléctricos, el pasaje de la idea a la materialidad de la misma, suele generar empatía y fortalece la capacidad creativa de los sujetos. A su vez, impulsan el desarrollo de otras habilidades fundamentales relacionadas con la resolución de problemas y la toma de decisiones, y las inherentes al desempeño social como la seguridad en uno mismo, el liderazgo, la autoestima, la búsqueda de desafíos y la habilidad para trabajar en equipo

En consecuencia, ambas propuestas aparecen como estrategias de enseñanza ya sea en espacios curriculares de contenidos específicos de CC como en otras áreas. Programación y robótica no son solo una competencia cognitiva que se utiliza para el diseño y desarrollo de códigos. Sino que constituyen competencias sociales y culturales que se usan para participar en grupos. Según Valverde et al. (2015, p. 7) "Este «aprendizaje conectado» es algo más que lenguaje de programación porque nos permite comprender cómo funciona la tecnología y cómo el diseño puede incorporar nuevas posibilidades y soluciones a problemas de la vida cotidiana". En este sentido, los autores explican que el secreto de éxito para estas propuestas radica en la desestructuración de un sistema de enseñanza tradicional que recupere al estudiante en el centro de la escena educativa y donde se reconozcan los condicionamientos que constituyen esas prácticas educativas (contexto, cultura, prácticas sociales, percepciones, etc.) La clave de la explicación de las dificultades de introducir el pensamiento computacional en las aulas se encuentra en estas dimensiones del «aprendizaje conectado» y 
deberían ser consideradas en cualquier iniciativa futura (Kafai \& Burke, 2014; Valverde et al. 2015, p. 7).

\subsubsection{Transversalidad}

El paradigma de enseñanza que incorpora el PC no cuenta aún con una vasta cantidad de trabajos, pero existen experiencias y herramientas para su materialización, aunque el desarrollo interdisciplinario es otra de las ausencias en este tema. La falta de trabajos del campo de la didáctica y la comunicación sobre la enseñanza de las CC y PC constituyen un área de vacancia. El fenómeno tecnológico, su avance y el escenario de transformaciones socioculturales implican el esbozo de una teoría social que recupere la técnica desde un enfoque de articulación interdisciplinaria. Al mismo tiempo que se piensan en las nuevas tecnicidades, es necesario reflexionar sobre el impacto de su desarrollo a nivel intra y supra subjetivo.

Los primeros modelos curriculares que incorporan contenidos de tecnologías se fundamentaron en la transversalidad o ejes transversales que se insertan en los currículos con el fin de cumplir objetivos específicos de proporcionar lineamientos para la transformación de la educación. Sin embargo, esta perspectiva sigue vigente y constituye uno de los puntos de tensión señalados en varios apartados de esta tesis. La condición de transversalidad permite establecer una articulación entre la educación fundamentada en las disciplinas del saber, los temas y las asignaturas con las carreras de Educación Superior y la formación de

profesionales integrales. Así, por ejemplo, es de vital importancia transversalizar los contenidos de tecnologías, convirtiéndola en una herramienta didáctica que dinamice las estrategias metodológicas aplicadas en las dinámicas de enseñanza y aprendizaje para el desarrollo del PC.

Esta lógica implica reconocer al PC con un carácter transversal, una forma de pensar que puede trabajarse desde distintas disciplinas, y sobre todo en el caso educativo, promover la mejora de enseñanza a partir de la incorporación del PC como paradigma de enseñanza. Ahora bien, aquí existen varias tensiones: por un lado, el problema de enseñar PC sin destinar 
tiempo a la enseñanza de contenidos de $\mathrm{CC}$, sin los cuales muchos autores aseguran que es inviable su desarrollo. Por otro lado, la incorporación de una forma de enseñanza que es poco conocida y que además es susceptible según el campo disciplinar desde el cual se trabaje, y finalmente, la falta de legitimidad con la que cuenta el desarrollo del PC al interior de otras áreas o asignaturas.

\subsection{Conclusiones}

Los rasgos que constituyen los problemas y desafíos de la enseñanza del PC se fueron desarrollando a lo largo de esta tesis y fundamentalmente en este capítulo, sin embargo, este apartado es a modo de síntesis. La inclusión del pensamiento computacional en la enseñanza responde a un paradigma que es posterior al de inclusión de tecnologías y que se denomina TIC. Luego de la aparición del término PC con una definición que ponía de manifiesto una idea de resolución de problemas de la forma computacional, la necesidad de su integración desde un campo disciplinar específico fue cada vez más legitimada.

A menos de 15 años de la primera definición sobre PC, la comunidad educativa a nivel internacional se encuentra en el centro del desarrollo de los debates que tensionan un campo de acuerdos sobre el que aún no hay definición y puede que no terminen de definirse, en tanto se constituyan como enfoques de enseñanza posible. De los documentos analizados y los planes de estudios consultados se concluye que los problemas en este campo incluyen:

1. La formación de docentes en PC asumiendo el problema de su enseñanza

2. El desarrollo de políticas educativas que fortalezcan su inclusión más allá de las formas

3. La articulación con otros contenidos que demuestren con casos concretos su transversalidad

4. La evaluación sobre el impacto de las políticas desarrolladas (currículos específicos de CC, materias transversales, metodologías de aprendizaje basado en proyectos, etc.)

Se considera que la puesta en marcha de todas las acciones que se recuperan en esta tesis constituyen un reto en sí mismas, por el impacto que puedan generar en el campo de estudios 
sobre esta temática. Para ser precisos, la articulación entre los campos de la educación y las CC resulta un tema impostergable para continuar pensando la educación, la formación de ciudadanos y la formación como competencia digital. La vigencia y trascendencia de estos contenidos en las políticas educativas a nivel mundial y su impacto en los currículos nos permiten reconocer que existen experiencias en desarrollo, en casi todos los niveles del sistema. 


\section{Capítulo 7: Conclusiones}

El presente trabajo de investigación tuvo como objetivo principal describir y sistematizar la configuración del pensamiento computacional, su incidencia y vigencia en el campo educativo a partir del comparativo de políticas públicas, desde un enfoque interdisciplinario. A partir del trabajo de investigación realizado se detallan las conclusiones según los temas propuestos:

- Se desarrolló una revisión sistemática sobre el estado de la cuestión en relación al pensamiento computacional y su desarrollo en ámbitos educativos;

- Se realizó un ordenamiento que permitió reconstruir el proceso de transformación del término (PC) desde su aparición en 2006, logrando identificar siete enfoques vigentes que recuperan la relación PC y educación;

- Se elaboraron cuadros de sistematización, lo que constituye un aporte, ya que permite una síntesis de dimensiones por enfoques donde quedan explícitas las ideas centrales que definen la posición sobre el término, los autores y los contextos en que se dan dichas definiciones;

- Se desarrolló una línea de abordaje interdisciplinario que permite establecer una relación entre PC y competencia digital, a partir del análisis articulado de los elementos que constituyen ambos términos y que dan lugar la idea de alfabetización digital propuesto por Zapata-Ros (2015);

- Se clasificaron y seleccionaron diez políticas públicas para análisis y reflexión sobre las formas en que se recupera el PC en ellas, a partir de un relevamiento cronológico que deja en evidencia la evolución que se realiza sobre el término "competencia" para la integración de la competencia digital y, finalmente, la enunciación del pensamiento computacional como proceso de desarrollo cognitivo;

- Se logran articular categorías propias de la educación (competencia) y la comunicación (mediación), lo que fortalece la idea de que el pensamiento computacional es una competencia clave (como la competencia digital definida por la UE); 
- A partir de las zonas de articulación que se establecen entre educación, comunicación y CC, se constituyen aportes para el abordaje interdisciplinario sobre el PC y su desarrollo a partir de un proceso de alfabetización digital. Se consolida la idea de complejidad para el reconocimiento de los procesos educativos que impliquen desarrollo de $\mathrm{PC}$, como un enfoque ético pedagógico que contribuya al reconocimiento de los procesos subjetivos;

- Se revisaron documentos oficiales de los currículum nacionales de dos países miembro de la UE, lo que permitió establecer una clasificación de estrategias de curricularización para identificar el tratamiento de los contenidos asociados a la competencia digital;

- Se pudo reconocer que la apuesta del campo de las CC en la incorporación de contenidos para el desarrollo del PC trajo aparejada la pregunta por la interdisciplinariedad para leer los procesos sobre la enseñanza, la formación en competencias y nuevas formas de pensamiento del mundo digital.

\section{1. Líneas de trabajo o de investigación a futuro}

Lo realizado afianza un nuevo campo de preguntas que movilizan una nueva propuesta de investigación y se concretan en mi propuesta de admisión al Doctorado en Comunicación. La pregunta por los sentidos sobre la formación en pensamiento computacional y las percepciones que los sujetos realicen respecto de esta competencia digital en sus espacios cotidianos, abren un interrogante que pretende ser indagado.

Es necesaria la definición de una línea de investigación interdisciplinaria que recupere el problema de la constitución de la subjetividad mediada por las tecnologías en el escenario digital y que promuevan estudios sobre las formas en que la educación posibilita o no ese desarrollo.

La ausencia de evaluaciones claras sobre el desarrollo del PC como competencia en sentido amplio constituye un área de desarrollo pendiente. A su vez, la agenda de temas en una época en que el desarrollo de una cultura digital nos enfrenta al desafío de pensar las formas en que se produce y circula el conocimiento, a la vez que se constituyen los sujetos en estos procesos. 
Conceptualizar para reflexionar sobre los procesos relacionados con la adquisición, procesamiento, análisis, recreación y comunicación de la cultura y especialmente en la era de la información como eje transversal de este eje de contenidos.

Nos motiva seguir pensando y reflexionando sobre los procesos de formación de los sujetos en estos ecosistemas digitales, lo que nos coloca ante la necesidad de hablar de educación, más precisamente de procesos educativos y producción de subjetividad para pensar la relación con las tecnicidades. Finalmente, es medular abordar los alcances de la tecnología en los procesos de control y dominación social. ¿Cuáles son las libertades de los sujetos? ¿Hasta dónde es posible pensar en estrategias de resistencia? El moldeamiento de la subjetividad en aspectos poco perceptibles de la vida cotidiana nos obliga a estar alertas frente al alcance de los procesos de totalitarismo global para dar lugar a algunas reflexiones que promueven la resistencia cultural como la "teoría de la desconexión". Sin embargo, pensar la tecnología como una posibilidad es reconocer a un sujeto en sus capacidades decisorias, entonces ¿cómo promovemos espacios de formación critica que ayuden a los sujetos a reconocer los rasgos de unas tecnologías al servicio del humanismo?

Es importante aportar reflexiones y producir conocimiento que ayude a la comprensión de la complejidad del proceso educativo, con el propósito de potenciar prácticas que, basadas en paradigmas emancipatorios, promuevan sujetos sociales curiosos, activos, comprometidos desde y con su cotidianeidad para transformarla, y eso implica pensar en las tecnologías, sus usos y consumos. 


\section{Referencias Bibliográficas}

\section{A) Textos consultados}

Adell, J. S., Llopis, M. A. N., Esteve, M. F. M., y Valdeolivas, N. M. G. (2019). "El debate sobre el pensamiento computacional en educación", en RIED. Revista Iberoamericana de Educación a Distancia, 22(1), pp. 171-186. doi:http://dx.doi.org/10.5944/ried.22.1.22303

ACM \& CSTA (2010). Running On Empty: The Failure to Teach K-12 Computer Science in the Digital Age. Disponible en: https://runningonempty.acm.org/

Apple, M. (1996). "Educación, identidad y patatas fritas baratas". Cap. 1. En: Política cultural y educación, pp.26-46. Madrid: Ediciones Morata.

Banchoff Tzancoff, Martin, S; Gómez, S; López, F (2019) Experiencias en robótica educativa. Presentado en TE\&ET 2019. Disponible en: http://redunci.info.unlp.edu.ar/teyet/Libro-de-Actas-2019.pdf

Barbero J.M. (2003). Saberes hoy: diseminaciones, competencias y transversalidades. En Revista Iberoamericana de Educación (OEI), núm. 32 (2003), p. 17-34.

Bell T., Witten H. y Fellows M. (2018) Computer Science Unplugged Un programa de extensión para niños de escuela primaria. Disponible en : https://classic.csunplugged.org/wpcontent/uploads/2014/12/unpluggedTeachersDec2008-Spanish-master-ar-12182008.pdf

Berrocoso J. V., Fernández Sánchez M. R. y Garrido Arroyo M. C. (2015). El pensamiento computacional y las nuevas ecologías del aprendizaje. En RED-Revista de Educación a Distancia, Año XIV, Número 46, 15 de Septiembre de 2015. https://www.um.es/ead/red/46/valverde_et_al.pdf

Bocconi, S., Chioccariello, A., Dettori, G., Ferrari, A., Engelhardt, K. (2016). "Developing computational thinking in compulsory education - Implications for policy and practice"; EUR 28295EN; doi: 10.2791/792158.

Brecko B., Ferrari A. (2016). The Digital Competence Framework for Consumers. Joint Research Centre Science for Policy Report; Editado by Vuorikari R. y Punie Y. doi:10.2791/838886.

Buenfil Burgos, R. N. (1992). El debate sobre el sujeto en el discurso marxista: Notas críticas sobre el reduccionismo de clase y educación. [Tesis de Maestría DIE 12] Centro de Investigaciones y Estudios Avanzados del Instituto Politécnico Nacional, México. 
Buenfil Burgos, R. N. (1993). “Análisis de discurso y educación”. Documento DIE 26, Centro de Investigaciones y Estudios Avanzados del Instituto Politécnico Nacional, México. Disponible en: https://perio.unlp.edu.ar/catedras/system/files/buenfil_burgos __analisis_de discurso_y_educacion_1.pdf

Carr, W y Kemmis, S. (1988). "Una aproximación crítica a la teoría y la práctica". En: Carr, W. y Kemmis, S. Teoría crítica de la enseñanza, cap. 5, pp.142-166. Barcelona: Editorial Martínez Roca.

Carretero Gómez S., Vuorikari R., Punie Y. (2017). DigComp 2.1: The Digital Competence Framework for Citizens with eight proficiency levels and examples of use. doi: $\underline{10.2760 / 38842}$.

CTSA (2016) K-12 Computer Science Standards, Revised 2017. Disponible en : https:/www.doe.k12.de.us/cms/lib/DE01922744/Centricity/Domain/176/CSTA\%20Compu ter $\% 20$ Science $\% 20$ Standards $\% 20$ Revised $\% 202017$.pdf

Da Porta (2018) "Habitares narrativos de prácticas docentes. La clase universitaria como territorio de libertad, creación e innovación." Disponible en: https://perio.unlp.edu.ar/ojs/index.php/revcom/article/download/5048/4070/

Denning, P. J. (2017). Remaining trouble spots with computational thinking. Communications of the ACM, 60(6), 33-39. doi: https://doi.org/10.1145/2998438

Díaz Barriga A. (2006). El enfoque de competencias en la educación. ¿Una alternativa o un disfraz de cambio? Perfiles Educativos, vol. XXVIII, núm. 111, enero-marzo, 2006, pp. 736. Instituto de Investigaciones sobre la Universidad y la Educación, Distrito Federal, México. Disponible en: http://academicos.iems.edu.mx/cired/docs/tg/macroacademiaquimica/Competencias\%20en $\% 20$ educacion.alternativa $\% 200 \% 20$ disfraz_A.DiazBarriga.pdf

Díaz Barriga F. (2003). Cognición situada y estrategias para el aprendizaje significativo. Revista Electrónica de Investigación Educativa, 5(2). Disponible en https://bit.ly/1JSJZpG

Drucker, P. (1994). La sociedad poscapitalista. Buenos Aires: Editorial Sudamericana.

Dussel, I. (2004) ¿Es el curriculum escolar relevante en la cultura digital? Debates y desafíos sobre la autoridad cultural contemporánea. Revista EPAA / AAPE Volumen 22 Número 24 28 de Abril 2014 ISSN 1068-2341. Disponible en: https://dialnet.unirioja.es/servlet/articulo?codigo $=5650449$

Echeveste M.E. y Martínez M.C. (2016). Desafíos en la enseñanza de Ciencias de la Computación. Virtualidad, Educación y Ciencia, 12 (7), pp. 34-48. Disponible en: https://revistas.psi.unc.edu.ar/index.php/vesc/article/view/14796 
Feito, Rafael. (2008) Competencias educativas: hacia un aprendizaje genuino. Andalucía Educativa (66). Último acceso 15/09/2020 de https://www.juntadeandalucia.es/educacion/portals/delegate/content/0732b873-909c-462a$\underline{\mathrm{b} 46 \mathrm{e}-6492462 \mathrm{a} 0020}$

Ferry, G. (1997). “Acerca del concepto de formación”. En: Pedagogía de la formación, capítulo 1, pp.53-58). Buenos Aires: Facultad de Filosofía y Letras-UBA. Disponible en: https://isft75.edu.ar/wpcontent/uploads/files/ferrygilles_acerca_del_concepto_de_formacion_2.pdf

Fox, E. A., Sheetz, S. D., Chung, W., \& Yang, S. (2010). Integrating computational thinking into information systems and other curricula. Disponible en: http://aisel.aisnet.org/cgi/viewcontent.cgi?article $=1050 \&$ context $=$ siged2010

Freire, P. (1994). "Primeras palabras". En Política y Educación, pp.11-17. México: Siglo XXI.

Gros B. y Contreras D. (2006). La alfabetización digital y el desarrollo de competencias ciudadanas. En Revista Iberoamericana de Educación (OEI), núm. 42 (2006), p. 103-125. Disponible en: https://rieoei.org/historico/documentos/rie42a06.pdf

Gimeno Sacristán J. (2008). Diez tesis sobre la aparente utilidad de las competencias en educación. En GIMENO, José, 2008, comp. Educar por competencias, ¿qué hay de nuevo?, Madrid, Morata, pág.15-58.

Giroux, H. (1996). Placeres inquietantes. Barcelona: Paidós.

Guzmán Marín F. (2012). El concepto de competencias. En Revista Iberoamericana de Educación, Vol. 60 Núm. 4. Disponible en: https://rieoei.org/RIE/article/view/1289.

Grover S. y Pea R. (2013). Computational thinking in K-12: A review of the state of the field. Educational Researcher, Vol. 42 Num 1, pág. 38-43. Disponible en: https://journals.sagepub.com/doi/abs/10.3102/0013189x12463051

Informatics Europe and ACM Europe (2013). Informatics education: Europe cannot afford to miss the boat. Report of the joint Informatics Europe \& ACM Europe Working Group on Informatics Education. Disponible en: https://www.informaticseurope.org/images/documents/informatics-education-acm-ie.pdf

Harr, D., Harrison, J. y Conery, L. (2011). Computational Thinking: A Digital Age Skill for Everyone. Learning \& Leading with Technology. Disponible en: https://id.iste.org/docs/learning-and-leading-docs/march-2011-computational-thinking11386.pdf 
ISTE, y CSTA. (2011). Operational Definition of Computational Thinking. Report, 1030054. Disponible en: https://csta.acm.org/Curriculum/sub/CompThinking.html

Larrosa, J. (2000). Pedagogía profana. Estudios sobre lenguaje, subjetividad, formación. Buenos Aires: Ediciones Novedades Educativas.

Larrosa, J. (1995). “Tecnologías del yo y educación”. En: Larrosa, J. Poder, Escuela y Subjetividad. Madrid: Ediciones La Piqueta.

Levis D. (2007) "Enseñar y aprender con informática/ enseñar y aprender informática. Medios informáticos en la escuela argentina" en Cabello, R. y Levis D., edits. (2007) Tecnologías informáticas en la educación a principios del siglo XXI Buenos Aires: Prometeo. Recuperado de: https://1library.co/document/9ynm4opz-ensenar-y-aprender-coninformatica-ensenar-y-aprender-informatica-medios-informaticos-en-la-escuelaargentina.html

Libaneo, J. C. (1986). “Tendencias pedagógicas en la práctica escolar”. En: Revista de Associacao Nacional de Educacao, N6 Año 3. Sao Paulo, Brasil.

Linn;, M. C., Aho;, A. V, Blake;, M. B., Constable;, R., Kafai;, Y. B., Kolodner;, J.L., Bradley, S. (2010). Report of a Workshop on The Scope and Nature of Computational Thinking. Thinking (Vol. 1). Disponible en: doi.org/10.17226/12840

Lizárraga Bernal, A. (1998). "Formación humana y construcción social: una visión desde la epistemología crítica”, en Revista de Tecnología Educativa, Vol. XIII, N”2, Santiago, Chile.

Magro Carlos (2018) Educación digital no es alfabetización digital. Disponible en: http://lab.cccb.org/es/educacion-digital-no-es-alfabetizacion-digital/

Meirieu, P. (1998). “A mitad de recorrido por una verdadera 'Revolución Copernicana' en Pedagogía". En: Frankenstein educador, pp.67-96. Barcelona: Editorial Alertes Psicopedagogía.

Meirieu, P. (2011). "Educar en la Incertidumbre" [Conferencia]. Extraída 02/02/2013 en: http://www.me.gov.ar/curriform/

Mc Laren, P. (1998). "Desde los márgenes geografías de la identidad, la pedagogía y el poder". En: Pedagogía identidad y poder en el multiculturalismo, pp.2-15. Santa Fe, Argentina: Ediciones Homo Sapiens.

Morin, E. (1996). "El paradigma de la complejidad". En: Introducción al pensamiento complejo, cap. 3, pp.85-110. Barcelona: Gedisa.

Moursund, D. (2009). Introduction to Problem Solving in the Information Age. (D. Morsund, Ed.). Recuperado de http://uoregon.edu/ moursund/dave/index.htm

Moursund, D. (2006). Computational Thinking and Math Maturity : Improving Math $\begin{array}{lllll}\text { Education } & \text { in } & \mathrm{K}-8 & \text { Schools. } & \text { Recuperado }\end{array}$ 
https://scholarsbank.uoregon.edu/xmlui/bitstream/handle/1794/3182/K8-

Math.pdf?sequence $=1$

Moursund, D. (2006). Introduction to using games in education: A guide for teachers and parents. Recuperado de https://scholarsbank.uoregon.edu/xmlui/handle/1794/3177

Nassif, R. (1982). Teoría de la educación, pp.17-24/65-79/247-266. Cincel-Kapelusz: Madrid.

Nassif, R (1958) Pedagogía General. Pp. 3-16. Kapeluz Buenos Aires.

National Research Council (2010) "Report of a Workshop on the Scope and Nature of Computational Thinking. Washington", DC: The National Academies Press. Disponible en: https://www.nap.edu/catalog/12840/report-of-a-workshop-on-the-scope-and-nature-ofcomputational-thinking.

Palacios, J. (1982). La cuestión escolar. Barcelona: Ediciones Laia.

Papert S. (1980). Mindstorms: Children, computers, and powerful ideas. New York, NY: Basic Books.

Papert S. (1991). Situating constructionism. En S. Papert \& I. Harel (Eds.), Constructionism. Cambridge: MIT Press.

Pérez Gómez, A. (2012) Educarse en la era digital. Ed. Morata España.

Pérez Gómez, A. (2007): "La naturaleza de las competencias básicas y sus aplicaciones pedagógicas". Cuadernos de Educación de Cantabria. Disponible en: https://www.educantabria.es/docs/info institucional/publicaciones/2007/Cuadernos Educa cion 1.PDF? phpMyAdmin=DxoCAdBlc $\% 252 \mathrm{CANuNIkvc-WZcMiFvc}$

Pérez Gómez, Á. (1998). "Las funciones sociales de la escuela: de la reproducción a la reconstrucción crítica del conocimiento y la experiencia". En Pérez Gómez, Á. y Gimeno Sacristán, J. Comprender y transformar la enseñanza, pp.17-30. Madrid: Ediciones Morata.

Phillips, P. (2009). Computational Thinking: a Problem - Solving Tool for Every Classroom. CSTA, Microsoft. Disponible en http://education.sdsc.edu/resources/CompThinking.pdf

Perrenaud P. (1999). Construir competencias desde la escuela, Santiago, Dolmen. Disponible en: $\quad$ http://sitios.educando.edu.do/revisioncurricular/data/uploads/pag-10-en-adelanteperrenaud.pdf

Perrenaud P. (2005). Diez nuevas competencias para enseñar. Ed.Siglo XXI, 23. Disponible en:: $\quad$ https://www.uv.mx/dgdaie/files/2013/09/Philippe-Perrenoud-Diez-nuevascompetencias-para-ensenar.pdf

Queiruga, Banchoff Tzancoff, Gómez y Venosa (2019) Enseñar a Enseñar Ciencias de la Computación. Una experiencia sobre políticas educativas y contenidos de Ciencias de la Computación. Aceptado para su publicación en JADiPRO 2019 (Jornadas Argentinas de Didáctica de la Programación). 
Redecker C., Punie Y. (2017). European Framework for the Digital Competence of Educators:DigCompEdu. Joint Research Centre Science for Policy Report; Editado por Punie Y.

DOI:

\section{$\underline{10.2760 / 178382}$}

Resnick, M. (2012).Reviving Papert’s Dream. Educational Technology, vol. 52, no. 4, pp. $42-46$.

Resnick, M. (2012). Mother's Day, Warrior Cats, and Digital Fluency: Stories from the Scratch Online Community. Proceedings of the Constructionism 2012 Conference., 1-7.

Resnick, M. (2007). All I really need to know (about creative thinking) I learned (by studying how children learn) in kindergarten. Proceedings of the 6th ACM SIGCHI Conference on Creativity \& Cognition - C\&C '07, 1-6.

Resnick, M., Silverman, B., Kafai, Y., Maloney, J., Monroy-Hernández, A., Rusk, N., Silver, J. (2009). Scratch. Communications of the ACM, 52(11), 60.

Sadosky, F. (2013). CC-2016. Una propuesta para refundar la enseñanza de la computación en las escuelas Argentinas.

Sarmiento, Maira (2017) “Análisis de experiencias y estrategias educativas con TIC para el desarrollo del pensamiento computacional en estudiantes de secundaria y primeros años de universidad en Iberoamérica." Trabajo Final presentado para obtener el grado de Especialista en Tecnología Informática Aplicada en Educación. UNLP. Disponible en:: http://sedici.unlp.edu.ar/bitstream/handle/10915/60186/Documento completo.pdfPDFA.pdf? sequence $=3 \&$ isAllowed $=y$

Saviani, Dermeval (1983). "Las teorías de la educación y el problema de la marginalidad en América Latina”, en Revista Argentina de Educación, Asociación de Graduados en Ciencias de la Educación., Año II, No 3.

Selby C. y Woollard J. (2014). Computational Thinking: The developing definitions. In Proceedings of the 45th ACM Technical Symposium on Computer Science Education, SIGCSE 2014. ACM the Royal Society (2012). Shut down or restart? The way forward for computing in UK schools. Disponible en::: https://www.researchgate.net/publication/299364602 Refining an understanding of com putational thinking

Scolari, 2018. "La 4ta revolución industrial", en Hipermediaciones. Disponible en::: https:/hipermediaciones.com/2018/06/10/la-4o-revolucion-industrial/

Silber, J. (2000). "Acerca del campo pedagógico desde un paradigma crítico". En [Acta Congreso] I Congreso Internacional de Educación Educación, crisis y utopías. Buenos Aires, 
Universidad de Buenos Aires. Facultad de Filosofía y Letras. Instituto de Investigaciones en Ciencias de la Educación.

(2006). “Algunas cuestiones relativas a la especificidad del saber pedagógico”. En [Acta Congreso] V Encuentro de Cátedras de Pedagogía de Universidades Nacionales. Universidad Nacional de Río Cuarto, Córdoba, Argentina.

-------(2009). “Campo pedagógico: disquisiciones epistemológicas y categorías básicas” [Ficha de cátedra]. La Plata, Facultad de Periodismo y Comunicación Social, UNLP.

Southwell, M. (2013) “La escuela ante nuevos desafíos: participación, ciudadanía y nuevas alfabetizaciones". Editorial Santillana. Disponible en: http://biblioteca.clacso.edu.ar/Argentina/flacso-ar/20171109032145/pdf 727.pdf

Tedesco, J. C. (2000). Educar en la sociedad del conocimiento. Buenos Aires: Fondo de Cultura Económica.

Tejada Zabaleta (2007). "Desarollo y formación de competencias un acercamiento desde la complejidad, en Acción Pedagógica", ISSN-e 1315-401X, Vol. 16, №. 1, 2007, págs. 40-47. Disponible en:: https://dialnet.unirioja.es/servlet/articulo?codigo=2968571

Tellez Ramírez (2019) "Pensamiento computacional: una competencia del siglo XXI", en Edu. Sup. Rev. Cient. Cepies vol.6 no.1 La Paz. Disponible en: http://www.scielo.org.bo/scielo.php?pid=S2518-82832019000100007\&script=sci arttext

The Royal Society. (2012). Shut down or restart? The way forward for computing in UK schools. Technology, (January), 1-122. Disponible en: https://royalsociety.org/ /media/education/computing-in-schools/2012-01-12-computingin-schools.pdf

UNESCO ICT Competency Framework for Teachers (2011). United Nations Educational, Scientific and Cultural Organization. Impreso en Francia. Disponible en: https://unesdoc.unesco.org/ark:/48223/pf0000265721_eng

Wilensky, U. (2013). Computational Thinking through Modeling and Simulation,1-5. Disponible en: $\underline{\text { http://citeseerx.ist.psu.edu/viewdoc/download?doi=10.1.1.676.8804\&rep=rep1\&type=pdf }}$

Wing J. (2006). Computational Thinking. In Communications of the ACM, vol. 49, 33-35. Disponible en: http://www.cs.cmu.edu/afs/cs/usr/wing/www/publications/Wing06.pdf

Wing J. (2008). Computational thinking and thinking about computing. In Philosophical Transactions of the Royal Society A, vol. 366, 3717-3725. Disponible en: https://royalsocietypublishing.org/doi/full/10.1098/rsta.2008.0118 
Wing, Jeanette (2011) "Research Notebook: Computational Thinking--What and Why?" Disponible en: https://www.cs.cmu.edu/link/research-notebook-computational-thinkingwhat-and-why

Zapata-Ros, Miguel (2014) "Pensamiento computacional y precoding". Tomado de: https:/miguelzapataros.tumblr.com/post/89198291595/pensamiento-computacional-yprecoding

Zapata-Ros M. (2015). Pensamiento computacional: Una nueva alfabetización digital. En RED (Revista de Educación a Distancia). Año XIV. Número 46. Disponible en: https://www.um.es/ead/red/46/zapata.pdf

Zorrilla, Margarita (2010) "Investigación educativa, políticas públicas y práctica docente. triángulo de geometría desconocida", en Revista Iberoamericana sobre Calidad, Eficacia y Cambio en Educación. Volumen 8, Número 2. Disponible en: https://www.redalyc.org/pdf/551/55114080005.pdf

Zukerfeld M. (2010). El Materialismo Cognitivo y la Tipología de los Conocimientos. Capítulo VI y VII, del Volumen I de "Capitalismo y Conocimiento. Materialismo Cognitivo, Propiedad Intelectual y Capitalismo Informacional”. Argentina. Disponible en:: https:/etcs.org/wp-content/uploads/2011/11/Zukerfeld-Capitalismo-y-Conocimiento-Volumen-IEl-Materialismo-Cognitivo-y-la-Tipolog\%C3\%ADa-del-Conocimiento.pdf

\section{B) Documentos oficiales}

Comisión Europea (2016) Agenda de habilidades para Europa. Recuperado de: https://eurlex.europa.eu/legal-content/ES/TXT/PDF/?uri=CELEX:52016DC0381\&from=EN

Comunidades Europeas (2007) Competencias clave para el aprendizaje permanente. Recuperado de: https://www.educacionyfp.gob.es/dctm/ministerio/educacion/mecu/movilidadeuropa/competenciasclave.pdf?documentId $=0901 \mathrm{e} 72 \mathrm{~b} 80685 \mathrm{fb} 1$

Comision Europea (2019)_European Education and Training Expert Panel Summary of findings and of the discussions at the 2019 Forum on the Future of Learning. Disponible en: https://ec.europa.eu/transparency/regexpert/index.cfm?do=groupDetail.groupMeetingDoc\& $\underline{\text { docid }=36318}$

Comisión Europea (2007) Informe Final del Proyecto Tuning América Latina: Reflexiones y perspectivas de la Educación Superior en América Latina. Recuperado de: http://tuning.unideusto.org/tuningal/index.php?option=com docman\&ltemid=191\&task=view ca tegory \& catid $=22 \&$ order $=$ dmdate published $\&$ ascdesc $=D E S C$ 
Departamento de educación de Reino Unido (2013) Currículum nacional para primaria y secundaria en el Reino Unido: Recuperado de: https://www.gov.uk/government/collections/national-curriculum

Estrategia para el Mercado Único Digital. Recuperado de: https://www.europarl.europa.eu/factsheets/es/sheet/64/una-agenda-digital-para-europa

Ley Orgánica 8/1985, de 3 de julio, reguladora del Derecho a la Educación. Tomado de: https://www.britishsummer.com/blog-aprender-ingles-extranjero/2014/09/12/lo-que-hayque-saber-del-sistema-educativo-ingles-antes-de-cursar-un-ano-escolar-en-reinounido/sistema-educativo-espanol-vs-ingles/

Marco europeo de competencias digitales para docentes. Recuperado de: https://ec.europa.eu/jrc/sites/jrcsh/files/digcompedu leaflet es-nov2017pdf.pdf

Marcos normativos de la Unión Europea. Recuperado de: https://europa.eu/europeanunion/index es

Marco para organizaciones educativas digitalmente competentes (DigCompOrg) Tomado de: $\quad$ https://ec.europa.eu/education/education-in-the-eu/european-education-area/digitaleducation-action-plan-action-1-connectivity-in-schools_es

Ministerio de Educación, Cultura y Deporte de España (2014) Currículo Básico de la Educación Primaria (España). Recuperado de: https://www.boe.es/buscar/pdf/2014/BOEA-2014-2222-consolidado.pdf

Ministerio de Educación y Ciencia de España (2006) Real Decreto 1513/2006. Recuperado de: https://www.boe.es/buscar/pdf/2006/BOE-A-2006-21409-consolidado.pdf

Ministerio de Educación y Ciencia de España (2006) Real Decreto 1630/2006. Recuperado de: https://www.boe.es/buscar/pdf/2007/BOE-A-2007-185-consolidado.pdf

Ministerio de Educación, Cultura y Deporte de España (2014) Real Decreto 126/2014. Recuperado de: https://www.boe.es/buscar/pdf/2014/BOE-A-2014-2222-consolidado.pdf

Ministerio de Educación, Cultura y Deporte de España (2014) Real Decreto 1105/2014 (versión resumen). Recuperado de: https://www.boe.es/buscar/pdf/2015/BOE-A-2015-37consolidado.pdf

Ministerio de Educación, Cultura y Deporte de España (2014) Real Decreto 1105/2014 (versión boletín oficial). Recuperado de: https://www.boe.es/boe/dias/2015/01/03/pdfs/BOE-A-2015-37.pdf

Recomendación del Parlamento Europeo y del Consejo, de 18 de junio de 2009, sobre el establecimiento de un marco de referencia europeo de garantía de calidad para la educación y formación profesionales. DO C 155 de 8.7.2009, p. 1-10

Recuperado de: https://eur-lex.europa.eu/legalcontent/EN/TXT/?qid=1523646815609\&uri=CELEX:32009H0708(01) 
Plan de Acción de Educación Digital. Tomado de: https://ec.europa.eu/education/educationin-the-eu/european-education-area/digital-education-action-plan-action-7-cybersecurity-ineducation_es

Plan de educación secundaria: Tomado de: https://www.educacionyfp.gob.es/dam/jcr:85b47b4b-81cc-41ce-bd6aa2608c9a5b6b/organizaci-n-eso-nuevo.pdf

Recomendación del Consejo sobre un Marco Europeo para la Calidad y el Aprendizaje Eficaz. Tomado de: https://ec.europa.eu/education/policies/eu-policy-in-the-field-ofvocational-education-and-training-vet_en

Recomendación del Consejo, de 22 de mayo de 2018, sobre las competencias clave para el aprendizaje. Recuperado de: https://ec.europa.eu/education/education-in-the-eu/councilrecommendation-on-key-competences-for-lifelong-learning en 